\title{
WestVirginiaUniversity
}

THE RESEARCH REPOSITORY @ WVU

Graduate Theses, Dissertations, and Problem Reports

2006

\section{Identifying *assessment practices in undergraduate accounting programs}

Anna L. Lusher

West Virginia University

Follow this and additional works at: https://researchrepository.wvu.edu/etd

\section{Recommended Citation}

Lusher, Anna L., "Identifying *assessment practices in undergraduate accounting programs" (2006). Graduate Theses, Dissertations, and Problem Reports. 2753.

https://researchrepository.wvu.edu/etd/2753

This Dissertation is protected by copyright and/or related rights. It has been brought to you by the The Research Repository @ WVU with permission from the rights-holder(s). You are free to use this Dissertation in any way that is permitted by the copyright and related rights legislation that applies to your use. For other uses you must obtain permission from the rights-holder(s) directly, unless additional rights are indicated by a Creative Commons license in the record and/ or on the work itself. This Dissertation has been accepted for inclusion in WVU Graduate Theses, Dissertations, and Problem Reports collection by an authorized administrator of The Research Repository @ WVU.

For more information, please contact researchrepository@mail.wvu.edu. 
Identifying Assessment Practices in Undergraduate Accounting Programs

\author{
Anna L. Lusher \\ Dissertation Submitted to the \\ College of Human Resources and Education \\ at West Virginia University \\ In Partial fulfillment of the requirements \\ for the Degree of \\ Doctor of Education \\ in \\ Educational Leadership Studies \\ Elizabeth Jones, Ph.D., Chair \\ Neil Bucklew, Ph.D. \\ Ernest Goeres, Ph.D. \\ Richard Hartnett, Ed.D. \\ Marsha Krotseng, Ed.D. \\ Department of Advanced Educational Studies \\ Morgantown, West Virginia \\ 2006
}




\begin{abstract}
Identifying Assessment Practices in Undergraduate Accounting Programs
\end{abstract}

Anna L. Lusher

The researcher conducted a survey of 786 baccalaureate accounting programs in the United States to determine the content and structure of their assessment plans. The study focused on five essential workplace skills: critical thinking, information literacy, oral communication, problem solving, and written communication. It examined the accounting programs and related assessment plans to determine whether the identified skills were integrated into the curriculum and were identified as learning outcomes in the assessment process. The study evaluated how faculty assess students' skills and how assessment results are used to make changes in programs and to improve student learning. The research also identified assessment related changes that have occurred. Responses were analyzed by three independent variables (Carnegie Classifications, (enrollment size, and region) to determine whether any significant differences existed.

Significant differences were found in 13 of the 82 dependent variables in the study. Significant differences were reported in the direct and indirect assessment instruments used to measure student learning, in the use of assessment data to make changes and improvements, and in the nature of those assessment related changes and improvements reported by the participants. Assessment audiences and methods used for dissemination of assessment results were also significantly different.

A greater number of significant differences were found for the dependent variables between size categories (eight) than between Carnegie Classifications (four) or region (one). More significant differences (four) were found in the indirect assessment instruments dependent variable (four) than in any other variable in the analysis.

All responding institutions reported that the five essential skills under study were addressed and identified as learning outcomes often or extensively in the accounting programs. In responses to questions about specific traditionally required courses, participants reported that the skills were mostly introduced or emphasized and occasionally not addressed. Albeit a low response rate (13\%), the major findings of this study indicate that accounting educators are making changes in accounting education in the areas that were identified as crucially in need of change in the four major accounting education studies over the past 25 years. 


\section{Acknowledgements}

I want to thank my family, friends, and colleagues for their understanding and patience throughout this once-in-a-lifetime experience. I especially want to acknowledge my doctoral committee members for their support and guidance as I completed my program of study and prepared my dissertation. Each of the following committee members contributed a unique perspective to my educational experience and to my research study.

Dr. Elizabeth A. Jones, Committee Chair

Dr. Marsha Krotseng

Dr. Ernest Goeres

Dr. Richard Hartnett

Dr. Neil Bucklew

Thank You 


\section{In Memory}

This work is dedicated to six members of my family who left us much too soon over the past three years: my brother, Raymond, age 52, his son, Chris, age 27, his daughter, Tiffany, age 22, their mother, Debbie, age 51, and two of my sister Dottie’s sons-my nephews, Joey, age 38, and Greg, age 31. Each of you left us at different times and under different circumstances, and all of you are greatly missed by those you left behind. 
Table of Contents

Page

$\begin{array}{lll}\text { Abstract } & \text { ii }\end{array}$

Acknowledgements $\quad$ iii

Dedication $\quad$ iv

Table of Contents $\quad$ V

Figures $\quad$ ix

Tables $\quad$ ix

Appendices $\quad$ xi

Chapter 1: Problem Statement 1

$\begin{array}{ll}\text { Essential Skills } & 5\end{array}$

$\begin{array}{ll}\text { Significance of Study } & 8\end{array}$

$\begin{array}{ll}\text { Purpose of Study } & 8\end{array}$

Research Questions $\quad 9$

$\begin{array}{ll}\text { Chapter 2: } \text { Literature Review } & 11\end{array}$

$\begin{array}{ll}\text { Accounting Organizations’ Recommendations } & 12\end{array}$

Four Major Accounting Education Studies $\quad 12$

Accounting Professionals’ Responses 16

Governmental Agencies Involvement 17

$\begin{array}{ll}\text { Connecting Education and Workplace Skills } & 18\end{array}$

Essential Workplace Skills $\quad 19$

Integrating Essential Skills into Undergraduate Business Programs 21

$\begin{array}{ll}\text { Assessment } & 24\end{array}$ 
$\begin{array}{ll}\text { Effective Learning Outcomes } & 26\end{array}$

$\begin{array}{ll}\text { Skills Assessed } & 26\end{array}$

$\begin{array}{lr}\text { Demonstrating Key Alignments } & 28\end{array}$

$\begin{array}{ll}\text { Formative and Summative Assessment Activities } & 30\end{array}$

$\begin{array}{ll}\text { Cumulative Assessment Data } & 31\end{array}$

$\begin{array}{ll}\text { Assessment Plan Criteria } & 36\end{array}$

Using Assessment Results to Make Improvements 42

Assessing the Assessment Process 42

Sharing Assessment Results 43

$\begin{array}{ll}\text { Reliability } & 44\end{array}$

$\begin{array}{ll}\text { Validity } & 45\end{array}$

Definition of Key Terms and Concepts $\quad 45$

Chapter 3: Research Design $\quad 52$

$\begin{array}{ll}\text { Population } & 52\end{array}$

$\begin{array}{ll}\text { Pilot Study } & 54\end{array}$

$\begin{array}{ll}\text { Participants } & 54\end{array}$

$\begin{array}{ll}\text { Carnegie Classification } & 55\end{array}$

Accrediting Organization Region 56

$\begin{array}{ll}\text { Student Enrollment } & 56\end{array}$

$\begin{array}{ll}\text { Pilot Study Demographics } & 57\end{array}$

Pilot Study Evaluation Form Analysis $\quad 59$

$\begin{array}{ll}\text { Questionnaire } & 61\end{array}$

$\begin{array}{ll}\text { Demographics } & 61\end{array}$ 
Data Collection and Analysis

Carnegie Classifications

Accrediting Organization Regions

Student Enrollment

Formal Study Demographics

Assessment Process

Research Question 1:

Differences in Essential Skills Addressed in Accounting Programs

Research Question 2:

Essential Skills Identified as Learning Outcomes in Accounting Programs

Research Question 3:

Essential Skills Addressed in Required Accounting Courses

Research Question 4:

Assessment Methods Used to Measure Skills and Competencies

Research Question 5:

Use of Assessment Results and Related Changes

Research Question 6:

Sharing Assessment Results

Reliability

Validity 
$\begin{array}{ll}\text { Background of Researcher } & 80\end{array}$

Chapter 4: Results $\quad 83$

Stage of Development of Assessment Plan 83

Frequency of Assessment Activity $\quad 86$

Assessment Activity at Academic Level $\quad 89$

$\begin{array}{lr}\text { Accounting Programs and Assessment Plans } & 90\end{array}$

Research Question 1:

Differences in Essential Skills Addressed in Accounting Programs 93

Research Question 2:

Essential Skills Identified as Learning Outcomes in Accounting Programs 97

Research Question 3:

Essential Skills Addressed in Required Accounting Courses 100

Research Question 4:

Assessment Methods Used to Measure Skills and Competencies

Research Question 5:

Use of Assessment Results and Related Changes 118

Research Question 6:

$\begin{array}{ll}\text { Sharing Assessment Results } & 129\end{array}$

$\begin{array}{ll}\text { Summary } & 139\end{array}$

Chapter 5: Conclusion and Recommendations 144

$\begin{array}{ll}\text { Assessment Process } & 144\end{array}$

Essential Skills and Competencies Addressed in Accounting Programs 146

Essential Skills and Competencies Identified as Learning Outcomes 147

Essential Skills and Competencies Addressed in Required Accounting Courses 148

$\begin{array}{ll}\text { Assessment Methods } & 150\end{array}$

$\begin{array}{ll}\text { Uses of Assessment Data } & 151\end{array}$ 
Assessment Related Changes and Improvements

Assessment Audiences

Dissemination of Assessment Results

Implications for Practice

Implications for Future Studies

References

Figure 1: Concept Map

Tables:

Table 1: Bloom's Taxonomy of Cognitive Skills

Table 2: Pilot Study Responses by Carnegie Classification

Table 3: Pilot Study Responses by Region

Table 4. Student Enrollment

Table 5. Pilot Study Responses by Size

Table 6. Pilot Study Respondents’ Title and Rank

Table 7. Required Degree Hours and Accounting Hours

Table 8. Program Graduates 2003-2004 Academic Year

Table 9. Number of Full-time and Part-time Faculty

Table 10. Pilot Study Evaluation Form Results

Table 11. Relationship between Data Collection Instrument and Research Questions 66

Table 12. Survey Responses by Carnegie Classification 67

Table 13. Survey Responses by Region 68

$\begin{array}{ll}\text { Table 14. Survey Responses by Size } & 70\end{array}$

Table 15. Formal Study Respondents’ Title and Rank 
Table 16. Degree Hours and Accounting Hours 72

Table 17. Program Graduates 2004 - 2005 Academic Year 72

$\begin{array}{ll}\text { Table 18. Full-time and Part-time Faculty } & 72\end{array}$

Table 19. Assessment Plan Development by Carnegie Classification 84

Table 20. Assessment Plan Development by Region 85

Table 21. Assessment Plan Development by Size 86

Table 22. Frequency of Assessment Activity by Carnegie Classification 87

Table 23. Frequency of Assessment Activity by Region 87

Table 24. Frequency of Assessment Activity by Size 88

Table 25. Assessment Activity at Academic Level 89

Table 26. Accounting Program and Assessment Plan by Carnegie Classification 91

Table 27. Accounting Program and Assessment Plan by Region 92

Table 28. Accounting Program and Assessment Plan by Size 93

Table 29. Essential Skills Addressed by Carnegie Classification 94

Table 30. Essential Skills Addressed by Region 95

Table 31. Essential Skills Addressed by Size 96

Table 32. Essential Skills Identified as Learning Outcomes by Carnegie Classification 97

Table 33. Essential Skills Identified as Learning Outcomes by Region 98

Table 34. Essential Skills Identified as Learning Outcomes by Size 99

Table 35. Critical Thinking Addressed in Required Accounting Courses 101

Table 36. Information Literacy Addressed in Required Accounting Courses 102

Table 37. Oral Communication Addressed in Required Accounting Courses 103

Table 38. Problem Solving Addressed in Required Accounting Courses 104 
Table 39. Written Communication Addressed in Required Accounting Courses 106

Table 40. Direct Assessment Methods by Carnegie Classification 108

Table 41. Direct Assessment Methods by Region 110

Table 42. Direct Assessment Methods by Size 111

Table 43. Indirect Assessment Methods by Carnegie Classification 113

Table 44. Indirect Assessment Methods by Region 115

Table 45. Indirect Assessment Methods by Size 117

Table 46. Use of Assessment Results by Carnegie Classification 119

Table 47. Use of Assessment Results by Region 121

Table 48. Use of Assessment Results by Size 123

Table 49. Assessment Related Changes and Improvements by Carnegie Classification 124

Table 50. Assessment Related Changes and Improvements by Region 126

Table 51. Assessment Related Changes and Improvements by Size 128

Table 52. Assessment Audiences by Carnegie Classification 130

Table 53. Assessment Audiences by Region 131

Table 54. Assessment Audiences by Size 133

Table 55. Dissemination of Assessment Results by Carnegie Classification 135

Table 56. Dissemination of Assessment Results by Region 137

Table 57. Dissemination of Assessment Results by Size 138

Appendices:

Appendix A: AICPA Core Competency Framework 172

Appendix B: Accrediting Organization Regions 182

Appendix C1: Dissertation Study Research Questions 184 


\section{Chapter 1: Problem Statement}

A movement calling for excellence in today's education system began in the 1980’s in an effort to improve public education at the middle and high school levels. The movement quickly expanded into a critique of the purpose and quality of higher education and a call for reform (Farmer, 1988). Proponents for reform expect higher education to assume multiple responsibilities. They believe that colleges and universities are obligated to create learning experiences that help students to become "good neighbors and involved citizens who are tolerant, free-thinking” individuals (Carnevale \& Porro, 1994, p. 9). These advocates for change also insist that education should prepare college graduates for gainful employment and successful careers.

Business leaders, professional organizations, and governmental agencies alike contend that college graduates lack the essential skills employers and other constituents expect of students upon completion of an undergraduate degree program. Employers assert that institutions of higher education are not providing the "necessary knowledge, skills, and abilities for the new world at work” (Van Horn, 1995, p. 1). “There appears to exist a large gap between the types of jobs available and the skills possessed by prospective employees” (Paulson, 2001, p. 42). A common complaint from employers is that new hires lack effective communication, critical thinking, and problem solving abilities.

The 1993 National Adult Literacy Survey (NALS) revealed alarming evidence that many two- and four-year college graduates cannot use basic reading, writing, and problem solving skills in everyday situations (The Conference Board, 1994). Another voice joined the call for reform when The National Goals Panel Report (2002) charged, “A disturbing and dangerous mismatch exists between what American society needs of higher education and 
what it is receiving. Nowhere is the mismatch more dangerous than in the quality of undergraduate preparation provided on many campuses” (p. 1).

Employers and other constituents are demanding that educators teach essential critical thinking, problem solving, oral and written communication skills, and the abilities to use computers and electronic databases. However, programs of study are designed to enable students to acquire career-specific knowledge. For example, business and professional fields such as law, accounting, engineering, and teaching require students to meet specific competency standards for entry-level positions. Therefore, educators must design curriculum and programs of study that will enhance the development of essential workplace skills while providing a sound foundation in the major field of study. Consequently, to successfully prepare students for careers, academic programs must integrate critical thinking, communication, and other essential skills into the coursework (Curry \& Wergin, 1993). The Association of American Colleges and Universities (AAC\&U) (2002) echoes these concerns stating that many students graduate from college "only to find themselves underprepared for professional, personal, and community life” (p. 1).

Increasingly, business reports a growing disparity between the skills college graduates possess and the skills the workplace requires. At a minimum, prospective employers expect new employees to have developed critical thinking, oral and written communication skills, and the ability to use computers and electronic databases (Goldberg \&Traiman, 2001). Business leaders maintain that today’s jobs require “increased use of communication and basic computation skills. . . and generally, use of well-developed intellectual capacities” (Rao \& Sylvester, April 2000, p. 11). According to Raymond and 
McNabb (1993) "poor communication skills are perceived by employers as a weakness of many business school graduates” (p. 202).

Business leaders are concerned about the quality of education students receive in higher education institutions. They contend that a quality education "helps students gain skills needed for a fulfilling life, much of which rests on being gainfully employed” (Michlitsch, 2002, p. 125). However, a survey of New Jersey employers revealed, "that no more than a third of recent college graduates were highly prepared for work” (Van Horn, 1995, p. 6). Respondents stressed that the demands of the workplace have increased substantially in recent years whereas the quality of graduates has remained virtually unchanged during this time. They remarked that institutions of higher education "have been too slow to respond to changing workplace conditions.... There has been a fundamental change in the workplace. Higher education institutions don’t understand this” (p. 11). In addition, recent college graduates complain of inadequacies in the skills and knowledge acquired in their undergraduate education (Oblinger \& Verville, 1998).

The accounting profession embarked on its quest for change in higher education in 1986. The profession's call for reform of accounting education began when the American Accounting Association's (AAA) Committee on the Future Structure, Content, and Scope of Accounting Education, known as the Bedford Committee, issued a report on the state of accounting education in America's colleges and universities. The Committee warned, “A growing gap exists between what accountants do and what accounting educators teach” (p. 172).

The authors asserted, “There is little doubt that the current content of professional accounting education, which has remained substantially the same over the past 50 years, is 
generally inadequate for the future accounting professional” (AAA, 1986, p. 172). Citing the major developments in the accounting profession and the expected changes for the future, the Committee recommended a serious restructuring of accounting education. A successful education program for the future will require a "revised, expanded curriculum” wherein the “scope and content. . . extends well beyond technical skills” (p. 179). An effective accounting education will help students develop intellectual capacities such as critical thinking, communication, and problem solving skills and will equip students with the necessary technical knowledge required of an entry level accounting professional.

Engineering, medical, and law professional organizations also maintain that the traditional learning experience should be expanded to encourage students to develop critical thinking, problem solving, written and oral communication skills (Curry \& Wergin, 1993). These professionals agree that change is necessary to prepare students with the skills needed for successful careers. Traditional professional education programs focus on specific knowledge unique to that profession. Practitioners must understand the technical and theoretical facets of the field; however, technical knowledge alone is not sufficient to successfully practice in today’s professional environments. Enhancing, communication, and analytical skills through practical application of acquired skills and knowledge enables students to develop professional expertise vital for career success (Curry \& Wergin, 1993).

Employers, professional organizations, and other constituents of higher education are demanding that educators design programs of study that focus on development of these essential skills (Curry \& Wergin, 1993; Carnevale \& Porro, 1994; Murnane \& Levy, 1996; Rao \& Sylvester, 2000; Goldberg \& Traiman, 2001; AAC\&U, 2002). Integrating essential skills and knowledge into the major fields of study allow students to hone the basic skills 
introduced in general education courses (Education Commission of the States, 1996). These essential skills are common course components that form the foundation for study in the major (Banta, 1999). Focusing on essential skills in the major field emphasizes how important these skills are in developing professional competencies (Palomba \& Banta, 1999).

\section{Essential Skills}

This research study focuses on five of the essential skills referred to most often by higher education constituents as necessary workplace skills. These five essential skills, also major dimensions of potential student learning outcomes, include:

1. Critical Thinking: The intellectually disciplined process of actively and skillfully conceptualizing, applying, analyzing, synthesizing, and/or evaluating information gathered from, or generated by, observation, experience, reflection, reasoning, or communication, as a guide to belief and action. Critical thinking can be seen as having two components: 1) a set of skills to process and generate information and beliefs, and 2) the habit, based on intellectual commitment, of using those skills to guide behavior (National Council for Excellence in Critical Thinking, p. 1, 2004). Critical thinking encompasses the ability to link data, knowledge, and insight together from various disciplines to provide information for decision-making. Being in tune with the "big picture” perspective is a necessary component for success (http://www.aicpaeca.org/library/ecc/ecc_learning/ecc_learning_exhibits.asp).

2. Information Literacy: An intellectual framework for identifying, finding, understanding, evaluating, and using information. It includes determining the nature and extent of needed information; accessing information effectively and efficiently; evaluating critically information and its sources; incorporating selected information in the learner's 
knowledge base and value system; using information effectively to accomplish a specific purpose; understanding the economic, legal, and social issues surrounding the use of information and information technology; and observing laws, regulations, and institutional policies related to the access and use of information (Middle States Commission on Higher Education, 2002, p. 2). Many accounting functions depend on obtaining information from within and outside of an entity. Accordingly, the individual preparing to enter the accounting profession needs to have strong research skills to access relevant guidance or other information, understand it, and apply it. Individuals entering the accounting profession must have the ability to access appropriate electronic databases to obtain decision-supporting information, appropriately use electronic software to build models and simulations, use technology assisted tools to assess and control risk and document work performed, and adopt new technology over time (http://www.aicpaeca.org/library/ecc/ecc_learning/ecc_learning_exhibits.asp).

3. Oral Communication: (Speaking) Organizes ideas and communicates oral messages appropriate to listeners and situations; participates in conversation, discussion, and group presentations; selects an appropriate medium for conveying a message; uses verbal language and other cues such as body language appropriate in style, tone, and level of complexity to the audience and occasion; speaks clearly and communicates a message; understands and responds to listener feedback; and asks questions as necessary (U. S. Department of Labor, Employment, and Training Administration \& U. S. Department of Education, 2000, p. 167). Accounting professionals are called upon to communicate financial and non-financial information to diverse individuals. Individuals entering the accounting profession should have the skills necessary to give and exchange information 
within a meaningful context and with appropriate delivery. They should have the ability to listen and deliver powerful presentations (http://www.aicpa-eca.org/library/ecc/ecc_ learning/ecc_learning_exhibits.asp).

4. Problem Solving: Recognizes that a problem exists, identifies possible reasons for the discrepancy, devises and implements a plan of action to resolve it, evaluates and monitors progress, and revises plans as revealed by findings. Other skills to include in the definition: Recognizing and defining the problem; trouble shooting; forming and testing hypotheses; analyzing problems; and identifying key causes and potential solutions (U. S. Department of Labor, Employment, and Training Administration \& U. S. Department of Education, 2000, p. 192). Accounting professionals are often asked to discern the true nature of a situation and then determine the principles and techniques needed to solve problems or make judgments. Thus, individuals entering the accounting profession should display effective problem-solving and decision-making skills, good insight and judgment, as well as innovative and creative thinking abilities (http://www.aicpaeca.org/library/ecc/ecc_learning/ecc_learning_exhibits.asp).

5. Written communication: Communicates thoughts, ideas, information, and messages in writing; records information completely and accurately; composes and creates documents such as letters, directions, manuals, reports, proposals, graphs, flow-charts, uses language style, organization, and format appropriate to the subject matter, purpose, and audience; includes supporting documentation and attends to level of detail; and checks, edits, and revises for correct information, appropriate emphasis, form, grammar, spelling, and punctuation (U. S. Department of Labor, Employment, and Training Administration \& U. S. Department of Education, 2000, p. 143). An accounting professional in public 
practice will be required to communicate the scope of work and findings or recommendations through effective business writing. Communicating clearly and objectively the completed work and the resulting findings is critical to the value of the professional service (http://www.aicpa-eca.org/library/ecc/ecc_learning/ecc_ learning_exhibits.asp).

As employers, government agencies, and professional organizations call for reform and increased accountability, higher education institutions are trying to document substantial changes in educational programs and record significant improvements in student learning.

\section{Significance of Study}

This study can be used to establish a database for accounting educators interested in assessment of baccalaureate accounting programs. It will provide useful information about the development and implementation of assessment plans and will offer strategies for reporting assessment results. For educators already engaged in assessment of accounting programs, the study can be useful in enhancing or modifying current assessment plans based on the practices identified in this study.

\section{Purpose of Study}

The main purpose of this study was to determine the current assessment practices utilized by faculty to assess undergraduate student learning in baccalaureate accounting programs. In addition, this study examines the extent that essential workplace skills (critical thinking, information literacy, oral communication, problem solving, and written communication) are integrated into the accounting curriculum. The accounting programs are grouped by Carnegie type, geographic location, and student enrollment to conduct the analysis and address the research questions. 


\section{Research Questions}

1. Is there a significant difference in how extensively these essential skills and competencies (critical thinking, information literacy, oral communication, problem solving, and written communication) are addressed in accounting programs by:
a. Carnegie classification?
b. Geographic region?
c. Enrollment numbers?

2. Is there a significant difference in how extensively these skills and competencies are articulated as student learning outcomes by:
a. Carnegie classification?
b. Geographic region?
c. Enrollment numbers?

3. How extensively are certain skills and competencies addressed within the individual required accounting courses?

4. Is there a significant difference in how extensively assessment methods are used to measure these skills and competencies by:
a. Carnegie classification?
b. Geographic region?
c. Enrollment numbers? 
5. Is there a significant difference in how extensively the assessment data are used to enhance the program and improve student learning by:
a. Carnegie classification?
b. Geographic region?
c. Enrollment numbers?

6. Is there a significant difference in how extensively faculty share the assessment results with multiple audiences by:
a. Carnegie classification?
b. Geographic region?
c. Enrollment numbers? 


\section{Chapter 2: Literature Review}

Many students, nationwide, graduate from college with a good and sometimes exceptional understanding of their fields of study, but they lack crucial communication, reasoning, decision making, and problem solving skills. Although mastery of domain knowledge often opens the door for new employees, successful careers are predicated upon a combination of skills.

According to Ewell (2003), "Business leaders say that although college graduates know the details of their disciplines, they lack good communication skills, they're not good at teamwork, and they lack appropriate leadership skills required for businesses today” (p. 33). Gardner \& Van der Veer (1998) report, “Employers identified specific competencies that included teamwork, effective written and oral expression, interpersonal communication” as desirable workplace skills (p. 65). Many employers report that most new job applicants are deficient in these skills (Jones, 1996).

Disenchanted with reports that many graduates lack the basic competencies required in the workplace, employers and policymakers are demanding that educators reform programs of study to help students develop the intellectual skills that enable them to succeed in the workplace (Carnevale, 1990). Critics are not requesting more detailed domain knowledge and skills. On the contrary, they are asking for more exposure to fundamental skills, the ability to think and communicate effectively. Stakeholders want documented improvements in students' communication, critical thinking, and problem solving abilities. These improvements are necessary to enhance workplace skills and to prepare students to be educated citizens in a democratic society (Jones, 1996). 


\section{Accounting Organizations’ Recommendations}

For nearly twenty years, the accounting profession has urged accounting educators to revise accounting education to keep pace with the changes in the accounting field and properly prepare students for careers in accounting. The accounting organizations contend that these requests have gone unheeded by the majority of educational institutions. Colleges and universities have experienced dramatic decreases in accounting enrollment during this same period; most witnessed a shift in student enrollment in its major areas of study from accounting majors to other business majors. The number of accounting faculty declined as well. A survey conducted by the American Institute of Certified Public Accountants (AICPA) (1997) noted that the number of bachelor's, master's, and doctoral degrees awarded in accounting from 1996 to 1999 declined more than 20\%.

Accounting professionals attribute the dilemma in accounting education primarily to “fundamental weaknesses in accounting education” [These] weaknesses in curricula and pedagogy are the more direct threats to our survival” (Albrecht \& Sack, 2000, p. 2). They cautioned that accounting programs would not survive unless immediate and drastic changes are implemented. In the past twenty years, the accounting profession has commissioned four major studies that confirm a drastic and immediate change in the delivery and content of accounting education is necessary if accounting programs are to survive as demonstrated in the study by Albrecht and Sack in 2000.

\section{Four Major Accounting Education Studies}

The first major study, the American Accounting Association's Committee on the Future Structure, Content, and Scope of Accounting Education, known as the Bedford Committee Report in 1986, warned that major changes in the accounting profession and 
expected future developments in the field “dictate expanded and updated education programs and serious rethinking of the optimal education for an accountant” (p. 179). The authors pointed out that an effective professional accounting program will “develop in students an understanding of the nature and skills of logical reasoning; a capacity for creative thinking and problem solving; ... and a facility with the methods of effective communication” (p. 180). They stressed that accounting education should include the general skills of analysis and synthesis of information, communication, problem solving, and computer systems.

In 1989, the existing Big 8 Accounting Firms advanced the call for change in the “Perspectives on Education: Capabilities for Success in the Accounting Profession” known as the "White Paper." The purpose of this second in a series of major studies was to identify the skills and knowledge that accounting graduates must possess to be successful as accounting professionals. In addition to the domain skills and knowledge of accounting, entry-level professionals must also be proficient in the basic general skills as well. Information literacy, critical thinking skills, problem solving skills, and communication skills, both oral and written, were identified among the principal general skills that "to be successful, individuals must bring to the practice” (p. 5). The accounting firms acknowledged that accounting graduates must have a vast range of interdependent skills. Furthermore, they cautioned that an effective curriculum supports both the domain specific and general skills.

The White Paper authors stated, "Post-secondary education should provide a strong fundamental understanding of accounting and auditing. . . A companion area includes the methods for gathering, summarizing and analyzing financial data” (p. 8). These graduates “need the ability to locate, obtain, and organize information from both human and electronic 
sources" (p. 6). They also state that the focus of accounting education "should be on developing analytical and conceptual thinking” (p. 8). "Individuals seeking to be successful in the diverse world of public accounting must be able to use creative problem solving skills. .. They must be able to solve diverse and unstructured problems. . Inductive thought processes and capabilities for judgment must be developed” (p. 6). The Paper also reveals that accounting professionals must be able to communicate effectively. Practitioners must "be able to transfer and receive information with ease.... Practitioners must be able to present and defend their views through formal and informal, written and oral presentation” (p. 5). The (then) Big 8 Firms also offered recommendations for changes in curriculum and new teaching methods to help "students to learn by doing” (p. 11). To demonstrate their support for this effort, they "committed up to $\$ 4$ million. . . for grants to colleges and universities to support the development of curricula that are responsive to the needs of the profession” (p. 2).

Due to the absence of response from educators to the previous reports, the American Accounting Association and the nation's Big 8 Accounting Firms commissioned the Accounting Education Change Commission (AECC) to conduct yet another major study of accounting education in 1996. The AECC determined that academic programs are not meeting the educational needs of accounting students and issued Position and Issue Statements that provided broad guidelines for restructuring accounting programs.

The intent of the AECC Position and Issue Statements was to improve the academic preparation of students by equipping them with the skills and knowledge to become successful accounting professionals. The AECC recognized that graduates of accounting programs are expected to possess competent intellectual, interpersonal, and communication 
skills and encouraged a greater emphasis on critical thinking, analytical, written and oral communication skills in accounting education to promote a better understanding of the demands of the accounting profession (Gainen \& Locatelli, 1995).

The most recent of the four major studies of accounting education commissioned by the accounting profession was conducted in 2000 by two accounting professors, Steve Albrecht and Robert Sack. Accounting organizations believed that the warnings of the previous reports had gone unheeded by the majority of educational institutions and requested the study due to the perceived lack of response. The study confirmed that, except for a few schools, accounting education had remained virtually unchanged and the methods of delivery were the same as those used 20 to 30 years ago.

This study again warned of the need for change in accounting education. In fact, the authors stated, "We cannot emphasize strongly enough that it is now survival we are talking about, not merely changing to be better. There can be no further delays without serious consequences” (p. 3). The urgency of the need for change in accounting education was reemphasized when the authors declared, "Business and technology have passed us by and we must change now quickly just to survive” (p. 2).

The report also focused on the changes in the business world and the inability of accounting education to keep pace. "Accounting education is perceived as being too narrow and backward looking and too costly for the benefits received” (p. 35). Historically, accounting education has prepared students to analyze business transactions, to record those transactions in journals and ledgers to complete the accounting process, and to prepare financial statements in Principles of Accounting. Intermediate and advanced accounting courses continue to focus on details that are rule-based and require rote memorization. 
However, technological advancements have "replaced the needs and minimized the rewards" (p. 37) of performing these tasks and have eliminated the need to focus on this type of work, especially in the beginning accounting courses (Albrecht \& Sack, 2000).

\section{Accounting Professionals’ Responses}

Doney and Lephardt (1993) affirm that accounting students need critical thinking and reasoning skills to meet the demands of the accounting profession and asserted that accounting education should help students develop intellectual skills and master basic principles. A survey of corporate America by the Gary Siegel Organization in 1994 disclosed that accounting graduates are still ill prepared for accounting careers. The study recommended restructuring accounting programs to better prepare students as accounting professionals. Business leaders, the accounting profession, and accounting educators are urged to work together to develop a curriculum that will equip students with the skills to meet the needs of corporate America.

In 2000, the AICPA Core Competency Framework (See Appendix A) was created by the AICPA’s Pre-Professional Competency Task Force as a source of guidance on the competencies that are expected of students entering into the accounting profession. This Framework provides an extensive list of competencies that are grouped as: (1) functional competencies (technical competencies); (2) personal competencies (individual attributes and values); and (3) broad business perspective competencies (understanding of internal and external business contexts).

The focus of the Framework is on essential workplace skills rather than on the traditional content areas of accounting because a skills-based curriculum supports a variety of career choices for future accounting professionals. The accounting profession urges 
educators to reform accounting curricula and programs to integrate the development of these competencies into the traditional content and knowledge areas. Bob Elliott, former member of the AECC, considers the Framework "a logical and valuable extension of the work of the AECC” (AICPA, 2002).

Woven throughout the AICPA’s Core Competency Framework are the five essential skills that are the focus of this study. Although the Framework's competencies may be described as strategic thinking, research skills, report presentation, decision modeling, or report preparation, each category includes critical thinking, information technology, oral communication, problem solving, and written communication as vital requisite core competencies of entry-level accounting professionals.

In 2001, the AICPA committed more than \$5 million to the Careers in Accounting Project dedicated to working with educators at all levels from elementary school to graduate school to inform students about the changes in the accounting profession and assist in setting higher standards for accounting education. The program furnishes lesson plans for various disciplines that integrate accounting principles and concepts into the field of study (AICPA, 2001).

Governmental Agencies’ Involvement

State governments are delegated the legal responsibility for providing higher education to the public through the United States Constitution. The states entrust the higher education institutions to oversee the quality and adequacy of the education provided by those institutions. However, the state governments retain jurisdiction over the educational institutions and have the authority to review and evaluate academic programs. Many states have assigned the institutions’ programmatic reviews to accrediting organizations that require 
the institutions to develop assessment plans to measure student learning (Ewell, Lutz, \& Ratcliff, 1997).

Political leaders and governmental agencies have issued directives in an attempt to compel institutions of higher education to determine the source of the education crisis and make the necessary changes to rectify it (Burke, 2002). In 1981, then Secretary of Education, T. H. Bell, created the National Commission on Excellence in Education. The Commission's charge was to study the quality of education in the United States and report its findings to the Nation. Secretary Bell created the Commission in response to the “widespread public perception that something is seriously remiss in our educational system" (National Commission on Excellence in Education, 1983, p. 1). In response to the concerns and demand of constituents, the Secretary of Education, William Bennet, in 1988, instructed accrediting organizations that receive federal funding include documentation of student learning outcomes in the assessment of higher education institutions in the United States (Palomba \& Banta, 1999).

\section{Connecting Education and Workplace Skills}

In August 2000, the U. S. Department of Labor and the Department of Education issued a report that identified essential skills required in the workplace. These skills include the foundation basic skills of reading, writing, arithmetic, listening, and speaking. The report also identified creative thinking, problem solving, and reasoning skills as foundation thinking skills. In addition, the ability to select and apply appropriate technology was identified as a crucial workplace competency.

The 1994 National Goals Panel Report recognized that much work must be done to improve the connection between higher education and the workplace. The Committee stated, 
"We need a clearer understanding of the knowledge and skills these graduates attain and how they relate to the demands of a world marketplace” (Conference Board, 1994, p. 1). Accordingly, Jones (2002) reports “A significant gap exists between the ideal professional education outcomes that are deemed necessary for effective performance in the workplace and the actual abilities and skill levels perceived by employers, supervisors, and recent college graduates” (p. 11).

Furthermore, employers and educators in graduate programs report, “an enormous chasm exists between what higher education claims it is doing and what is actually achieved” (Langenberg, 1997, p. A64). While some academics contend the current system is sufficient, many educators acknowledge that the current education requirements of completing a predetermined course of study do not guarantee that graduates acquire the desired workplace skills and knowledge required for successful careers (Oblinger \& Verville, 1998).

\section{Essential Workplace Skills}

In 1994, the U. S. Department of Education sponsored a study to determine the basic skills that faculty at higher education institutions, legislators, and business leaders identify as most important for college students to acquire (Jones, 1994). The participants were asked to assess the skills they considered most important from an extensive inventory of writing, speech, and critical thinking skills. The interviewees agreed that in addition to the basic writing, speech, and listening skills needed to communicate, students should also develop advanced higher-order skills to enable them to critically analyze information, solve problems, and draw valid conclusions (Jones \& Associates, 1994). The study concluded that critical 
thinking, reasoning, and advanced skills in writing and speech are crucial in the workplace today.

The ability to apply the transferable skills of general education (critical thinking, problem solving, written and oral communication, and reasoning skills) is recognized as one of the four levels of development in attaining the educational goals of business majors (Jones, 1995). Jones states that students should understand basic business tools used in management, recognize economic and environmental issues, be familiar with the functional areas of business, and integrate general education skills to enhance their abilities to use financial data and business skills to make sound business decisions (1995).

In 1991, the Secretary’s Commission on Achieving Necessary Skills (SCANS) program identified the following skills among the essential foundation skills and workplace competencies that American workers need for job success.

Foundation skills:

* Basic skills (reading, writing, speaking, and listening, etc.)

* Thinking skills (creative thinking, decision making, problem solving, etc.) Workplace competencies:

* Information (acquires, evaluates, interprets information, and uses computers to process information, etc.)

* Technology (select, apply, maintain, and troubleshoot technology)

Technical skills in computers and telecommunications are essential workplace tools in today’s business environment (SCANS, 1991). Businesses can purchase or design computer systems that process information much more effectively and efficiently than in years past. Knowledge of career specific software applications and the ability to adapt to 
various versions is a strong marketable skill. Technology has revolutionized business communication as well. Employees will be expected to demonstrate effective oral and written communication skills and to determine the most appropriate channel of communication through the use of these tools (Brantley \& Davis, 1997).

Sternberg (1996) asserts that businesses value employees who are successfully intelligent. Employers seek successfully intelligent recruits who are capable of analyzing and solving problems and are creative in formulating and applying good ideas. Many academic programs prepare students with domain knowledge but fail to equip students with the valuable workplace skills that employers demand (Oblinger \& Verville, 1998).

Murnane and Levy (1996) speculate that there are two types of basic skills necessary to get a job today: hard and soft skills. Hard skills consist of "basic mathematics, problem solving, and reading abilities at levels much higher than many high school graduates now attain”, and soft skills include “the ability to make effective oral and written presentations" (p. 9). Employees who do not possess adequate workplace skills "will fall further and further behind those who have the skills, creating a dangerous schism in society” and the "gap widens between the earning power of people with a high school education or less and those with education beyond high school” (Carnevale \& Porro, 1994, p. 9).

\section{Integrating Essential Skills into Undergraduate Business Programs}

An Association of American Colleges (AAC) report asserts that connection with other disciplines is a crucial goal of major fields of study. "Ultimately, the goal of the major should be the development of students' capacities for making connections and for generating their own translations and syntheses” (1991, p. 5). In fact, the report criticizes the traditional design of curriculum and program structure that stresses discipline specific information and 
neglects to encourage integrating general education skills and synthesizing knowledge from other areas to add value to the learning process.

In an AAC report published in 1992, the association stated that integrating general education curriculum with programs of study curriculum and providing opportunities for students to apply knowledge and skills acquired in general education courses in the major fields of study are key elements of strong programs. The report strongly encourages assessment policy to include program reviews that "incorporate findings from assessment of student learning” and examine “direct examples of students’ learning across the major as part of their overall review of program quality” (p. 2).

The American Association of Colleges and Universities’' (AAC\&U) National Panel Report (2002) envisions changes in higher education that will deliver an education of lasting value, a learning experience that will equip students with the "analytical, integrative, and practical skills graduates need" (p. ix). The association urges educators to provide a "twentyfirst century liberal education-liberal not in any political sense, but in terms of liberating and opening the mind, and of preparing students for responsible action” (p. xii). These students will become "empowered through the mastery of intellectual and practical skills, informed by knowledge about the natural and social worlds, and responsible for their personal actions and for civic values" (p. 24). This approach will provide a "practical education because it develops just those capacities needed by every thinking adult: analytical skills, effective communication, practical intelligence, ethical judgment, and social responsibility” (p. 26). To obtain these ambitious goals, the National Panel Report stresses that professional programs of study, such as business, law, and engineering must integrate the traditionally separate general education component of the curriculum into the major fields of study (2002). 
Integrating general education skills into the major fields of study provides the opportunity to develop and strengthen these essential competencies.

General education programs provide the vital skills and knowledge that employers are seeking. Integrating general education into the majors "provides a curricular anchor at the end of the undergraduate experience” (Gardner \& Van der Veer, 1998, p. 23). This practice permits general education skills to be applied and developed across the curriculum. A National Institute for Higher Education report issued in 1984 recommended that course and curriculum requirements should not only contain career specific subject matter, but should also provide an opportunity for students to develop “capacities of analysis, problem solving, communication, and synthesis of knowledge” (p. 43). Professional programs of study should integrate knowledge and skills from a variety of disciplines to prepare students for a successful career.

Students develop higher-order skills (critical thinking, written and oral communication, and problem solving) best when the skills are reinforced throughout the program of study. Undergraduates learn best when required to synthesize knowledge and skills acquired in different disciplines. Ongoing reinforcement of acquired skills and knowledge through application lessens the risk of atrophy due to non-use. Integration of general education skills and knowledge into the major fields of study provides the opportunity to exercise and hone the basic skills introduced in general education courses (Education Commission of the States, 1996).

Essential workplace skills are the result of the "general education component of the curriculum” enhanced by career domain knowledge and skills acquired in the degree programs (Voorhees, 2001, p. 51). A comprehensive and effective general education 
program and assessment plan can play a crucial role in the development and improvement of essential workplace skills.

Van Horn (1995) posits that to strengthen the connection between higher education and workplace skills, three conditions must be met:

1. Employers must precisely define the knowledge, skills, and abilities (KSAs) that are important for improved work performance;

2. Colleges and universities must be able to redesign programs and teaching methods to transmit those KSAs; and

3. Higher education institutions must assess student performance on those KSAs and report to prospective employers (pp. 3-4).

Faculty and administrators of degree programs have moved away from the view that they should emphasize only discipline-specific content knowledge, concepts, and theories. Essential skills, such as communication and problem solving, are now addressed within the major fields of study (Jones, 1996).

\section{Assessment}

Accrediting organizations responded to pressures for reform by requiring colleges and universities (that received federal funds) to create and implement formal assessment plans to measure student learning. This movement called upon higher education institutions to assess student development of skills and values in programs of study that faculty members and other stakeholders identify as critical for the institution’s graduates to possess (Palomba \& Banta, 1999).

Joining the crusade for educational reform at the Charlottesville Education Summit in 1989, the nation's governors recommended developing a performance-based assessment of 
graduating college seniors' abilities “to think critically, communicate effectively, and solve problems" (Ewell, 1991, p. 12). These governors realized that "without a comprehensive strategy to improve the knowledge and skills of their young people, their states' long-term economic prospects would be bleak” (Schwartz \& Robinson, 2000, p. 173). This action expanded the assessment movement to include assessment of student development of essential core competencies acquired in general education programs as part of the departmental review of degree programs.

The federal government supported the drive for accountability in its Goals 2000 report. One of the educational goals for the nation to have accomplished by the year 2000, goal six, objective five, states that an increasing number of students will possess effective critical thinking, problem solving, and communication skills (Jones, 1996). In response to the first Annual Report Card on the nations' six educational goals and the governors’ summit, Marchese (1991) commented that reformers assume that "education should be a goal-driven enterprise, its quality measured by learning outcomes. . . the reformers want new external demonstrations of what students know and are able to do” (p. 4).

Accrediting bodies have been the driving force behind assessment at most institutions. Although these organizations require some form of assessment, none prescribe a particular type or model. An institution must design an assessment plan tailored to fit its needs. Assessment plans should be "designed to measure what graduates know, what they can do, and what they value” (Palomba \& Banta, 1999, p. 4). How programs of study contribute to students' knowledge and skills, and how the learning experience can be enhanced are concerns also examined in the assessment process. 


\section{Effective Learning Outcomes}

In 2001, the Association of American Colleges and Universities (AAC\&U) published its project Partners with Accreditors on Assessment (PAA) that provided "Criteria of Good Practice for assessing the performance of seniors in a way that integrates general education and field-specific outcomes” (p. 2). The PAA report identified specific knowledge, abilities, and performances expected of graduating students. Speaking, writing, reasoning, and the ability to access, evaluate, and use information appropriately are among the desired skills acknowledged as learning outcomes.

These outcomes include core proficiencies and inquiry capacities such as oral and written communication skills, qualitative and quantitative reasoning, critical thinking, and information literacy. These proficiencies are cultivated through consistent practice across the curriculum and should be agreed upon by the entire faculty. Students develop these capacities through expertise gained in a major, engagement in various types of disciplinary inquiry, and integrative work in connecting courses and fields (AAC\&U, 2001).

Huba and Freed (2000) state that learning outcomes should be student-focused. They should center on what students will be able to do with their knowledge upon completion of the course or program and provide direction for students to achieve those aims. The outcomes should also focus on "learning resulting from an activity rather than the activity itself” (p. 98). Skills and knowledge gained from the activity should be assessed, not the curricular activities experienced in the program.

\section{Skills Assessed}

The core proficiencies and inquiry capacities identified in the AAC\&U report (2001) include the "higher order thinking skills" described in Bloom's Taxonomy of Cognitive 
Objectives (1956) in Table 1. Many educators use Bloom’s taxonomy as a basis for assessment of student learning (Palomba \& Banta, 1999). The taxonomy presents six levels of the cognitive domain that begins with the simplest levels of cognitive skill involving recall and recognition of knowledge, comprehension, and application of information to work problems and progresses to the highest levels requiring more complex skills to analyze, synthesize, and evaluate information.

Table 1. Bloom's Taxonomy of Cognitive Objectives

Level

Definition

Knowledge Students recall or recognize information, ideas, and principles in the approximate form in which they were learned.

Comprehension Students translate, comprehend, or interpret information based on prior learning.

Application Students select, transfer, and use data and principles to complete a problem or task with a minimum of direction.

Analysis Students distinguish, classify, and relate the assumptions, hypotheses, evidence, or structure of a statement or question.

Synthesis Students originate, integrate, and combine ideas into a product, plan or proposal that is new to them.

Evaluation Students appraise, assess, or critique on a basis of specific standards and criteria.

Most academic programs include the first three levels (knowledge, comprehension, and application) as learning objectives; however, employers are seeking graduates who can do more than passively follow directions and do as they are told to do. They need employees who possess the higher-level skills and demonstrate the ability to analyze information to make sound decisions, to integrate knowledge into new creative ideas, and to evaluate 
information based on established standards and criteria (Goldberg \& Traiman, 2001).

Faculty should agree on the skills and knowledge expected of students upon completion of the program and create learning outcomes that indicate whether students have realized those expectations. Student learning outcomes should explain the desired student skills and behaviors stating what students will be able to do with the skills and knowledge acquired (Huba \& Freed, 2000).

Additionally, affective and psychomotor skills are major categories assessed in the learning process. Values and attitudes reflect a person’s convictions about issues and opinions and influence an individual's behavior; these traits depict an individual's character. Affective qualities consist of sensitivity to others' values and beliefs, ethics, leadership skills, and lifelong learning. Psychomotor skills such as agility, acuity, and coordination are also important dimensions of education. These types of skills are often assessed through direct observation of behavior and performance (Palomba \& Banta, 1999).

\section{Demonstrating Key Alignments}

Goals and learning outcomes of degree programs and courses must be compatible with those presented in the institution's mission statement (Huba \& Freed, 2000). Mission statements define institutional values, goals, and vision and describe the qualities the institutions’ graduates should possess (Palomba \& Banta, 1999). The mission statement’s learning goals “define the common curricular ground that unites the university” (Huba \& Freed, 2000, p. 104). These goals are intentionally broad to permit the academic units to develop individualized mission statements, goals, and outcomes that correspond with the institution's mission. As a rule of thumb when developing outcomes, Huba and Freed inform, "Institution-wide outcomes will be more general than academic program outcomes. 
Academic program outcomes will be more general than individual course outcomes” (2000, p. 116).

The student qualities and characteristics defined in the institution's mission statement form a basis for what students should know when they complete a degree program. Student learning outcomes at the program and course level should focus on professional standards of excellence for the field of study and skills and abilities central to the discipline as well as those general skills that cut across disciplines. The focus should be on aspects of learning that will develop and endure (Huba \& Freed, 2000).

The AAC\&U (2001) PAA project promotes structuring courses and fine-tuning teaching styles to enhance student learning and improve performance results as students progress through an academic program. The PAA report provided guidelines for effective assessment plans. These guidelines include:

* Assessments are designed to demonstrate successful integration of the major and the general education components of the degree program.

* There is both formative and summative assessment of student learning.

* Learning outcomes addressed in assessment are consistent and cumulative building throughout the educational program in tune with a longitudinal view of student development.

* Assessments are created, implemented, sustained, and rated collaboratively by faculty responsible for general education and the majors.

There are integrative courses and assignments embedded in the curriculum in which (a) students not only master knowledge and skills but practice integration; (b) faculty coach 
students to make connections between the major and general education; and (c) students are engaged in some culminating activity or product

Formative And Summative Assessment Activities

Effective assessment programs focus on enhancing the student learning experience. To meet this objective, assessment data should be collected, analyzed, and used by faculty to make improvements for students as they complete their programs of study (Jones, 2002). Terenzini (1989) defines assessment activities carried out during a program of study as formative activities that provide feedback to be used to modify and shape the program. The author also identifies assessment activities performed at the end of the program of study as summative assessment that is used to make judgments about the program or performance. Erwin asserts that assessment activities conducted during a program of study generate data intended for improvement; whereas, data collected at the end of a program are often used to demonstrate accountability (1991).

Formative assessment activities are increasing on college campuses as faculty and administrators continually strive to improve student learning. "The strongly held view that students should learn from assessment has increased the use of formative assessment approaches focused on individual students” (Palomba \& Banta, 1999, p. 8). Summative assessment of student learning usually obtained during the senior year provides a snapshot of student learning at a point in time, but offers little evidence of students' gains over time. The authors note that formative assessment activities allow students direct feedback about their performance and provides occasion for enhancing their skills through self-assessment and self-improvement. 


\section{Cumulative Assessment Data}

To determine improvement in student learning, documentation of students' entering abilities is needed. The educational achievements of students during previous formal education years must be known to ascertain skills and knowledge acquired in the current curriculum. Such information would permit faculty to establish baseline evidence of students’ skill development as beginning undergraduates (Ratcliff, Jones, \& Hoffman, 1993). Assessment activities should provide comparative data to determine the degree of skill development achieved during the program of study at the institution. Assessment data should contribute "feedback that can be used to modify, shape, and improve” students' skills (Palomba and Banta, 1999, p. 7).

Assessment of seniors provides valuable data about students’ skills and knowledge at graduation. However, these students receive little direct feedback and do not have the opportunity to improve their skills before leaving the institution. Ewell indicates that students who receive direct feedback about their performances tend to better understand the assessment process and the expectations placed upon them. Feedback can "pay immediate dividends because students can use their mistakes to identify ways to improve” (1997, p. 5).

Ideally, students develop the ability to critically analyze and effectively communicate information and master career-specific technology early in their academic pursuits to enhance learning and skill development in later courses. Therefore, sophomore-, junior-, and senior-level courses present the appropriate setting to measure the development and application of these essential workplace skills. Assessment data collected in the formative stages would provide evidence of students' skill development as they progress through the academic program (Huba \& Freed, 2000). Focusing on measuring students’ abilities at 
various stages of progression through the program lessens the probability of disappointment in the level of skill held by students at graduation.

Current literature demonstrates that employers, policy makers, and faculty agree upon the broad areas of knowledge, skills, and abilities that should be attained by undergraduates (Jones, 1994). Students should possess intellectual skills that enable them to gather, organize, and process information to solve unstructured problems. They should have the ability to make informed decisions and exercise good judgment based upon comprehension of the information (Ratcliff, 1995).

Advocates of change in higher education stress the importance of building upon these skills in the major fields so students can develop and hone these competencies. Linking essential skills, assessment, and accounting education supports change in accounting programs and curriculum that will improve student learning and equip students with the essential skills that enable them to succeed in the workplace. This study examines accounting programs and the related assessment plans to determine the actions that have been taken by educators and the changes that have been made in accounting programs to meet the expectations of all constituents of improved student learning at higher education institutions.

The Concept map in Figure 1 summarizes the purpose and content of this research paper. The assessment process begins with recommendations for changes and improvements by constituents of education. Recommendations surface because employers, governmental agencies, professional organizations, and other constituents recognize that college graduates are under-prepared for their careers. Numerous studies have revealed that potential employees are lacking in essential workplace skills and knowledge. This research study 
focuses on five essential workplace skills: critical thinking, information technology, oral communication, problem solving, and written communication.

To adequately prepare students, the development of these essential skills must be identified as objectives of the programs and integrated into the major field of study along with the career-specific knowledge. For public institutions, state governance recommends that graduating students demonstrate proficiency in these identified skills. In fact, most states, including West Virginia, mandate assessment of graduating seniors to determine the level of development of these essential skills. Courses and programs of study should be designed to enable students to develop these essential skills as they acquire the domainspecific skills in their program of study.

The assessment process enables educators to establish goals and objectives regarding essential skills and to determine how well their courses and programs are meeting that end. Various assessment techniques are used to measure a student's progress. Direct methods of observation of student performance and indirect methods of student opinions and attitudes are collected in the freshman, sophomore, junior, and senior years to ascertain student development and attainment of essential skills. The assessment data are collected and analyzed, and the results are used to make changes in programs and courses that will improve student learning.

Successful assessment plans provide a means of disseminating assessment information freely to constituents and welcome constructive feedback that can lead to improvements in the learning experience. Feedback influences all stages of this process. It is vital that institutions obtain sufficient, competent feedback to permit participants to form knowledgeable opinions and make practical decisions to transform accounting programs into 
vehicles that equip students with the necessary skills and knowledge required in the workplace. 
Figure 1. Conceptual Framework

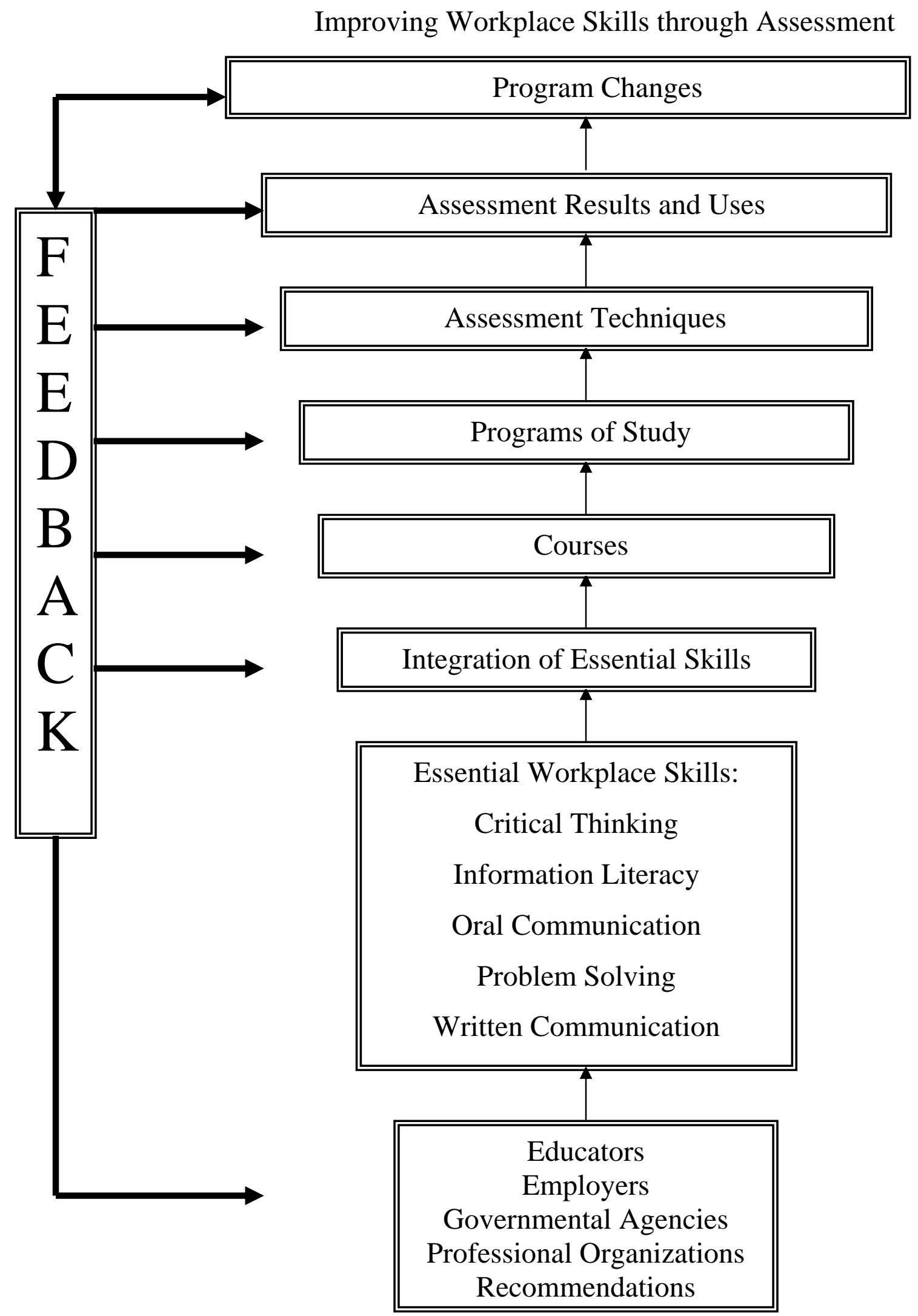




\section{Assessment Plan Criteria}

The Handbook of Accreditation of the Commission on Institutions of Higher Education of the North Central Association (NCA) developed the "Hallmarks of Successful Programs to Assess Student Academic Achievement” (1994). The NCA principles advise that a successful assessment plan:

* Flows from the institution’s mission,

* Has a conceptual framework,

* Has faculty ownership/responsibility,

* Has institutional-wide support,

* Uses multiple measures,

* Provides feedback to students and the institution,

* Leads to improvement, and

* Includes a process for evaluating the assessment program (Huba \& Freed, 67).

\section{Mission Statement}

Student learning outcomes should be based upon an institution’s mission and educational values as described in its mission statement. The mission statement should guide teaching and shape learning. It should provide "the framework that characterizes what is unique and special about graduates of the institution’s programs” (Huba \& Freed, 2000, p. 72). An assessment plan should clearly identify the skills that students should possess upon completion of the degree program to satisfy the stated mission. Therefore, a clearly defined mission statement is a necessary component of the assessment process.

A successful assessment plan is based upon a foundation that includes the faculty’s shared perspective of learning and agreed-upon educational goals. An effective plan 
integrates teaching, curriculum, learning, and assessment into a continuous system in a manner that enables faculty to remain focused on those shared goals (Huba \& Freed, 2000). A major reason for assessment is to ascertain how academic programs contribute to student learning and development. Through assessment, educators can determine whether students are developing desired competencies and values, whether the curriculum imparts the vital knowledge and skills of the discipline, and whether students can integrate learning from individual courses into a complete educational experience that prepares them for their careers (Palomba \& Banta, 1999).

\section{Faculty Ownership and Commitment}

Faculty involvement is crucial to the success of any assessment program. Typically, faculty in one department or major work together to create and administer assessment activities that measure the student learning outcomes for that discipline or major (Huba \& Freed, 2000). Every faculty member should be assigned some role in the assessment process. They should be responsible for developing assessment plans, selecting assessment instruments, carrying out the assessment, interpreting the results, and making recommendations for change based upon the data (Huba \& Freed, 2000).

Faculty should articulate what they expect students to know and what graduates should be able to do after completing a program of study. They must identify the desired traits and competencies to measure and determine which tools will effectively gauge the level of proficiency attained (Maki, 2002). These identified skills and competencies should then be targeted as learning outcomes and measured in the assessment process (Huba \& Freed, 2000). 


\section{Institutional Support}

Administrators must advocate assessment and demonstrate a commitment to the process. Although assessment should be faculty-owned and faculty-driven, administrators can provide leadership in the development of an assessment plan and aid in coordinating an effective comprehensive campus-wide process (Palomba \& Banta, 1999). The administration can provide evidence of support by providing faculty training through workshops and seminars. Institutions can establish faculty development funds and designate assessment as a line item in the annual budget to convey dedication to the assessment process (Huba \& Freed, 2000).

\section{Assessment Measures}

Peggy Maki (2002), former Director of Assessment at the American Association for Higher Education, encourages institutions to utilize assessment results to confirm that its goals are attained and to determine how it can improve the quality of education to improve student learning outcomes. Assessment instruments must provide information about students' competencies in selected areas and be predictive, that is, be an indicator of the students’ future performance (Huba \& Freed, 2000).

Maki (2002) recommends using a combination of direct methods of assessment such as portfolio collections of students work over time or capstone projects and indirect methods such as employer surveys or student focus groups to analyze learning outcomes. Indirect methods of assessment support evidence of student learning obtained through direct methods and provide another lens to analyze how students learn and develop (2002).

Course-embedded assessment is an efficient and cost-effective assessment technique that serves a dual purpose. Selected coursework generates assessment data that allow faculty 
to evaluate the course and student learning and provides a basis for assigning student grades for the course (Palomba \& Banta, 1999). “Course-embedded assessment strategies” are “diagnostic and supportive of the development of students as learners” (Farmer, 1999, p. 199). Huba and Freed (2000) advise that course-embedded assessment is an effective means of addressing program outcomes as well as specific course outcomes.

The capstone course is often used in academic programs to assess graduating students’ skills and knowledge. These courses are designed to incorporate concepts and principles learned in earlier classes and to encourage students to connect those experiences to demonstrate comprehensive learning (Palomba \& Banta, 1999). Capstone course activities may involve individual or team activities in the form of a senior project, case study, research paper, or completion of a portfolio.

Carey \& Gregory (2003) suggest creating a framework for course evaluation and revision that includes categories for learner characteristics, the learning environment, course content, and essentials for learning as indicators of a quality teaching and learning experience. Instructors establish indicators for each category in the framework and use assessment data to determine whether the indicators are being addressed in the courses. Learner characteristics such as the student’s intellectual aptitude, prerequisites, motivation, and maturity are evaluated in terms of student learning. The framework also includes elements of the learning environment, instructional facilities, delivery methods, times, and locations as attributes of the learning experience.

Review of the skills and knowledge and their relevance to the students' needs and learning outcomes is part of the process. The assessment data is also used to determine the appropriateness of the course content. The essentials for learning characteristics focus on 
student attributes such as attention, confidence, and satisfaction. Other characteristics in that category relate to the relevance of the course content in guiding students, opportunities for skill development, and the linking of new content with existing knowledge Carey \& Gregory (2003).

Assessment data are collected throughout the course using various assessment instruments including quizzes, surveys, projects, case studies, etc. After analyzing the assessment data, instructors make the determination whether an indicator is addressed in the course. If it is determined that an indicator is not met, instructors should review the indicators to determine whether they are realistic and attainable. If it is determined that the expectations are not unreasonably high, the instructor would then conclude that students are lacking in the identified areas. The solution could require adjusting standards if the indicators are unrealistic and unattainable or providing interventions to meet students' needs if students indeed demonstrate deficiencies (Carey \& Gregory, 2003).

Most institutions use a combination of commercially- and locally-developed assessment instruments. Commercially developed assessment instruments provide national norms for comparison purposes, and the vendor already addresses the issues of validity and reliability. They also provide a database of information for comparison to allow the institution to compare its students with students nationwide (Maki, 2001).

As an alternative, locally developed assessment instruments can provide the desired information for the institution. Faculty should analyze the current methods of examination. Many of the assessed competencies are already tested on a regular basis in the course work. Adapting or expanding current evaluation tools can provide competent data in the assessment process (Cottell, Jr. \& Harwood, 1998). Local assessment instruments can be very effective 
if developed and interpreted properly. However, locally developed instruments can only provide information about local students and subgroups (Walvoord, Bardes, Denton, 1998). Feedback

Chickering and Gamson (1987) state, "No feedback can occur without assessment. But assessment without timely feedback contributes little to learning” (p. 3). The aim of assessment in higher education is to measure student learning to enable the institution to determine whether students have acquired particular competencies desired of graduates in a field of study. However, students should receive information about the skills being assessed and the instruments used in the assessment process to enable them to improve their skills (Huba \& Freed, 2000).

Students can redirect their efforts when feedback about performance is made available to them. They should be given opportunities to perform. Additionally, suggestions for improvement should be a central component of the feedback. They need to reflect on what they have accomplished and what they have not mastered. “Assessment best serves as a strategy for improving student learning when it becomes an integral part of the teachinglearning equation by providing continual feedback on academic performance to students” (Farmer, 1999, p. 199).

Assessment results reflect upon course material, program goals, methods of instruction, and other factors that shape the educational experience (Banta, 2002). Feedback can play a central role in decisions that lead to program changes as well as influence curriculum development and revisions. Administrators can also utilize assessment results in evaluating academic programs during scheduled program reviews (Huba \& Freed, 2000). 


\section{Using Assessment Results to Make Improvements}

The assessment process is only successful if it results in enhancement of the educational experience. Assessment data should lead to improvements in student learning; it should be used to make changes in the learning experiences and to strengthen the curriculum. Decisions concerning funding, budgets, planning, academic programs, courses, student activities, and much more hinge on the data collected in the assessment process (Maki, 2002). Faculty and department administrators rely on assessment results to make changes in courses and programs. "Results determine program effectiveness, thereby indicating whether changes are needed to achieve intended outcomes and better conformance with mission vision, and goals” (p. 91).

Instructors should receive feedback from students about the structure and format of individual courses for consideration in planning future classes. Assessment information can reveal a need to add, delete, or change curriculum to meet the needs of students or the changing environment (Huba \& Freed, 2000). A recent study of postsecondary institutions’ use of assessment results in decision making revealed that assessment data influenced the modification of student assessment plans, teaching methods, academic programs, and general education (Peterson \& Augustine, 2000a). Black and Duhon (2003) suggest that assessment results can be the conduit for curriculum, program, and pedagogy changes.

\section{Assessing the Assessment Process}

It takes time to develop a practical assessment plan. Just as with any other process, it requires development, implementation, feedback, evaluation, and adjustments. Refining and improving the assessment plan is crucial (Maki, 2002). In 1994, the Joint Committee on 
Standards for Educational Evaluation established standards for assessment program

evaluation. Assessment programs should meet these four criteria:

1. Utility, including identification of stakeholders, credibility of evaluators, pertinence of information, and clarity and timeliness of reporting

2. Feasibility, including practicality of procedures, political viability, and cost effectiveness

3. Propriety, including service to participants, community, and society, respect for the rights of those involved, and provisions for complete and fair assessment

4. Accuracy, including program documentation, use of valid and reliable procedures, appropriate analysis, impartial reporting, and justified conclusions (Palomba \& Banta, 1999, p. 15).

Assessment is a long-term, dynamic process focused on the fundamental purpose of the institution. It is imperative that the process be evaluated to determine how well the assessment data reflect the institution's ability to meet these standards. The assessment process should be reviewed periodically to determine whether the principles of assessment are being followed and how well the course and program assessment activities complement each other (Huba \& Freed, 2000).

\section{Sharing Assessment Results}

After assessment data has been gathered, measured, and evaluated, it must be organized into useful reports and communicated to internal and external audiences alike. A well-designed and executed assessment plan provides assessment data about the learning experience to many constituents. Faculty, students, other college personnel use assessment data to make improvements in the learning experience; various offices, departments, and 
individuals receive data for different purposes. The underlying theme, however, is to improve the college's programs, courses, and services. State government leaders and accrediting organizations require periodic assessment reports as well (Banta \& Associates, 1993).

The data reported to each recipient should be determined by the needs of the group receiving the data. Assessment information can be reported to the general public in brochures and flyers and posted on websites. It may also be published in formal reports to accrediting organizations and state legislative bodies (Palomba \& Banta, 1999).

Reports should describe the process, the subjects, the purpose of the study, and the methods used to collect and measure the data. The results should be quantified so that specific findings are interpreted appropriately and reported in a manner that can be understood by the readers. The information should also be reported honestly and without bias. Recommendations and conclusions should be clearly stated and indicate the actions that are to be taken as a result of the project. The assessment process is only successful if it results in improvement of the educational experience. Assessment is a continuous process. Once the reports have been disseminated and recommended changes have been implemented, the process begins again (Huba \& Freed, 2000).

\section{Reliability}

To be effective, measurement instruments must be reliable and consistently produce similar results when applied independently over time. For example, a scale that registers a person's weight as 100 pounds in the morning and 125 pounds in the afternoon would be considered unreliable. The person’s weight should remain relatively constant within the timeframe indicated; fluctuations of 25 pounds in weight are not realistic. Fraenkel and 
Wallen define reliability as "the degree to which scores obtained with an instrument are consistent measures of whatever the instrument measures” (2003, p. G-7).

\section{Validity}

Information gathered by the instrument must have a direct correlation to the area being assessed. The instrument must measure what it purports to measure. Validity is defined as "the degree to which evidence supports any inferences a researcher makes based on the data he or she collects using a particular instrument” (Fraenkel and Wallen, 2003, p. 158). For example, a computerized exam comprised of mathematical computations would provide valuable information about the mathematical aptitude of the student, but would produce very little information about a student's oral communication skills. Effective measurement instruments would enhance the reliability and validity of the assessment data by consistently providing sound, dependable information (Bryman \& Cramer, 2001).

\section{Definition of Key Terms and Concepts}

For the purposes of this study, the following definitions will be used.

Assessment: The process of gathering and discussing information from multiple and diverse sources to develop a deep understanding of what students know, understand, and can do with their knowledge as a result of their educational experiences; the process culminates when assessment results are used to improve subsequent learning (Huba and Freed, 2000). A systematic collection, review, and use of information about educational programs undertaken for the purpose of improving student learning and development (Palomba and Banta, 1999).

Commercial assessment instruments: Standardized assessment tools available nationally 
designed to measure a wide array of skills. Commercial instruments provide national norms for comparison purposes. Issues of validity and reliability are already addressed by the vendor. Commercial instruments provide a database of information for comparison to allow the institution to compare its students with students nationwide (Maki, 2001).

Direct Assessment Methods: Assessment methods that provide direct evidence of student learning such as portfolios that collect student work over time, course-embedded assignments that provide evidence of how well students transfer learning into a new context, and capstone projects that provide evidence of how well students integrate and apply principles, concepts, and abilities into a culminating project (National Association of Student Personnel Administrators, 2002).

Domain Knowledge: Knowledge and skills specific to a discipline or career (Oblinger \& Verville, 1998).

\section{Essential Skills:}

Critical Thinking: The intellectually disciplined process of actively and skillfully conceptualizing, applying, analyzing, synthesizing, and/or evaluating information gathered from, or generated by, observation, experience, reflection, reasoning, or communication, as a guide to belief and action. Critical thinking can be seen as having two components: 1) a set of skills to process and generate information and beliefs, and 2) the habit, based on intellectual commitment, of using those skills to guide behavior (National Council for Excellence in Critical Thinking, p. 1, 2004). Critical thinking encompasses the ability to link data, knowledge, and insight together from various disciplines to provide information for decision-making. Being in tune 
with the "big picture" perspective is a necessary component for success (http://www.aicpa-eca.org/library/ecc/ecc_learning/ecc_learning_exhibits.asp). Information Literacy: An intellectual framework for identifying, finding, understanding, evaluating, and using information. It includes determining the nature and extent of needed information; accessing information effectively and efficiently; evaluating critically information and its sources; incorporating selected information in the learner's knowledge base and value system; using information effectively to accomplish a specific purpose; understanding the economic, legal, and social issues surrounding the use of information and information technology; and observing laws, regulations, and institutional policies related to the access and use of information (Middle States Commission on Higher Education, 2002, p. 2). Many accounting functions depend on obtaining information from within and outside of an entity. Accordingly, the individual preparing to enter the accounting profession needs to have strong research skills to access relevant guidance or other information, understand it, and apply it. Individuals entering the accounting profession must have the ability to access appropriate electronic databases to obtain decision-supporting information, appropriately use electronic software to build models and simulations, use technology assisted tools to assess and control risk and document work performed, and adopt new technology over time (http://www.aicpaeca.org/library/ecc/ecc_learning/ecc__learning_exhibits.asp).

Oral Communication: (Speaking) Organizes ideas and communicates oral messages appropriate to listeners and situations; participates in conversation, discussion, and group presentations; selects an appropriate medium for conveying a message; uses 
verbal language and other cues such as body language appropriate in style, tone, and level of complexity to the audience and occasion; speaks clearly and communicates a message; understands and responds to listener feedback; and asks questions as necessary (U. S. Department of Labor, Employment, and Training Administration \& U. S. Department of Education, 2000, p. 167). Accounting professionals are called upon to communicate financial and non-financial information to diverse individuals. Individuals entering the accounting profession should have the skills necessary to give and exchange information within a meaningful context and with appropriate delivery. They should have the ability to listen and deliver powerful presentations (http://www.aicpa-eca.org/library/ecc/ecc_learning/ecc_learning_exhibits.asp). Problem Solving: Recognizes that a problem exists, identifies possible reasons for the discrepancy, devises and implements a plan of action to resolve it, evaluates and monitors progress, and revises plans as revealed by findings. Other skills to include in the definition: Recognizing and defining the problem; trouble shooting; forming and testing hypotheses; analyzing problems; and identifying key causes and potential solutions (U. S. Department of Labor, Employment, and Training Administration \& U. S. Department of Education, 2000, p. 192). Accounting professionals are often asked to discern the true nature of a situation and then determine the principles and techniques needed to solve problems or make judgments. Thus, individuals entering the accounting profession should display effective problem-solving and decisionmaking skills, good insight and judgment, as well as innovative and creative thinking abilities (http://www.aicpa-eca.org/library/ecc/ecc_learning/ecc_ learning_exhibits.asp). 
Written communication: Communicates thoughts, ideas, information, and messages in writing; records information completely and accurately; composes and creates documents such as letters, directions, manuals, reports, proposals, graphs, flowcharts, uses language style, organization, and format appropriate to the subject matter, purpose, and audience; includes supporting documentation and attends to level of detail; and checks, edits, and revises for correct information, appropriate emphasis, form, grammar, spelling, and punctuation (U. S. Department of Labor, Employment, and Training Administration \& U. S. Department of Education, 2000, p. 143). An accounting professional in public practice will be required to communicate the scope of work and findings or recommendations through effective business writing. Communicating clearly and objectively the completed work and the resulting findings is critical to the value of the professional service (http://www.aicpaeca.org/library/ecc/ecc_learning/ecc_learning_exhibits.asp).

Essential Workplace Skills: “Foundation Skills” and “Competencies.”

Foundation Skills: the academic and behavioral characteristics that competencies are built on.

Foundation Skills:

1. Basic skills_-reading, writing, speaking, listening, and knowing arithmetic and mathematical concepts;

2. Thinking skills_-reasoning, making decisions, thinking creatively, solving problems;

Competencies: relate to what people actually do at work. 
1. Information skills — using computers to process information and acquiring and evaluating, organizing and maintaining, and interpreting and communicating information;

2. Systems skills-understanding systems, monitoring and correcting system performance, and improving and designing systems;

3. Technology utilization skills—selecting technology, applying technology to a task, and maintaining and troubleshooting technology (Whetzel, 2000).

Feedback: Assessment results used to redirect students’ efforts in order to improve student learning and to redirect faculty's efforts that lead to advancements in teaching practices. Helpful feedback permits students the opportunity to reflect on their own learning and development and encourages self-adjustment that will enhance their future learning and performance (Palomba \& Banta, 1999).

Formative assessment: Assessment activities that provide comparative data to determine the degree of skill development achieved. Formative assessment data provides feedback that can be used to modify, shape, and improve students' skills as they progress through their academic programs (Palomba and Banta, 1999).

General education: Typically a two-year program of study identified as the core curriculum at most colleges. The program is designed to encompass all the basic education courses deemed necessary as a foundation for the required courses in the major area of study and considered essential in transforming students into wellrounded individuals (American Association of Colleges, 1985).

Indirect Assessment Methods: Assessment methods that provide indirect evidence of 
student learning and development such as alumni, student, or employer surveys that provide self-reports or reports from those who observe students' work, student focus groups that provide interpretations or perceptions of student learning, and graduate follow-up studies that provide evidence of how well an institution prepared students for advanced work (National Association of Student Personnel Administrators, 2002).

Locally developed assessment instruments: Assessment tools created from current methods of examination used by faculty to test many of the competencies on a regular basis in the course work. These instruments only provide information about local students and subgroups (Maki, 2001).

Reliability: The degree to which scores obtained with an instrument are consistent measures of whatever the instrument measures (Fraenkel \& Wallen, 2003, p. G-7).

Summative Assessment: A one-time assessment of student learning usually obtained at the end of the educational process to ascertain mastery level of achievement (Maki, 2002).

Student Learning Outcomes: Student learning and development as reflected in the results of assessment activities (Palomba and Banta, 1999). Statements describing faculty intentions about what students should know, understand, and be able to do with their knowledge when they graduate (Huba \& Fried, 2000).

Validity: A valid instrument measures what it is supposed to measure (Fraenkel and Wallen, 2003, p. 119). The degree to which evidence supports any inferences a researcher makes based on the data she/he collects using a particular instrument (Fraenkel and Wallen, 2003, p. 158). 


\section{Chapter 3: Research Design}

This research study examined accounting program assessments at selected colleges and universities in the United States. The study focused on identifying the current assessment practices utilized in baccalaureate accounting programs by examining the skills and competencies assessed and determining the methods of assessment used. This research also investigated what course and/or program changes were made as a result of the assessment findings. An overview of the research design and the pilot study results are presented in this chapter. In addition, specific data collected and the methods used are identified. The pilot study questionnaire (See Appendix D1), formal study questionnaire (See Appendix D2), pilot study evaluation forms (See Appendices F1, F2) pilot study cover

letter (See Appendix E), and the formal study cover letter (See Appendix G) are presented in the appendices.

A quantitative research design was used in this study. A major strength of quantitative research is that a substantial amount of information can be collected from a representative sample of the population. For example, a survey poses the same questions to all participants, and the data gathered can be subjected to extensive quantitative analysis and interpretation to fully address the research questions. However, there are some limitations. The instrument's format limits responses to predetermined choices that can prevent participants from expanding and clarifying responses. A low response rate of about $9 \%$ to 10\% can also be a major limitation (Fraenkel, \& Wallen, 2003).

\section{Population}

The population of undergraduate degree accounting programs was identified initially from the Hasselback Accounting Faculty Directory 2004-2005 (2004). The $30^{\text {th }}$ Annual 
Accounting Faculty Directory compiled a list of United States and international institutions offering four-year accounting programs from information provided by the institutions. Researchers sometimes question how different factors affect the population under study (Howell, 2002). This study examined the effect of the following three factors: Carnegie Classification, accrediting organization regions (See Appendix B), and student enrollment in the accounting program on the assessment process of baccalaureate accounting programs.

The researcher identified the institutional classification of these colleges and universities by using the Carnegie Classification system (Carnegie Classification of Institutions of Higher Education, 2000, Electronic data file, fourth revision, 2003). The Carnegie Classifications were further revised in 2004 and in 2006. The Carnegie Foundation identifies doctorate granting institutions as those that offer baccalaureate programs but are committed to graduate education through the doctorate. Master's colleges and universities are institutions that offer baccalaureate programs, but they are committed to graduate education through the master's. Baccalaureate colleges are primarily undergraduate institutions with a major emphasis on baccalaureate programs (Carnegie Classification of Institutions of Higher Education, 2000, Electronic data file, fourth revision, 2003).

The six traditional Carnegie Classifications were condensed into three classifications for this study. The classifications are: (1) doctoral (Doctoral/Research UniversitiesExtensive and Doctoral/Research Universities-Intensive), (2) master’s (Master’s Colleges and Universities-I and Master’s Colleges and Universities-II), and (3) baccalaureate (Baccalaureate Colleges-Liberal Arts and Baccalaureate Colleges-General). A coding system was developed for the questionnaire to permit anonymity. 
The codes for the Carnegie Classifications were: (1) doctoral, (2) master’s, and (3) baccalaureate. The codes for types of institutions were: (a) public and (b) private, and the codes for geographic regions as established by the Associations of Schools and Colleges (See Appendix B) were: (A) Middle States, (B) New England, (C) North Central, (D) North West, (E) Southern, and (F) Western. In addition, the accounting programs in the study were grouped by student enrollment to further analyze responses and address the research questions (See Appendix C2).

\section{Pilot Study}

An initial pilot study was conducted March 18, 2005 to establish reliability and discover any unforeseen problems. Twenty deans, chairs, or directors of accounting education programs at institutions in the United States listed in the Hasselback Accounting Faculty Directory (2004) were purposively selected as participants. A proportionate number from each Carnegie Classification and accrediting organization region identified in the study were included in the pilot study.

\section{Participants}

A cover letter (See Appendix E), the survey instrument (See Appendix D1), and pilot study evaluation form (See Appendix F1) were sent to the selected faculty leaders of the undergraduate accounting degree programs. The letter asked the participants to complete the questionnaire and the pilot study evaluation form and return them in the enclosed selfaddressed, stamped envelope. Only two of the twenty recipients, ten percent of the pilot study, returned them. Because the two responses did not provide ample information to make a determination about the readability, user-friendliness, and validity of the instruments, another mailing was prepared. 
The recipients of the second mailing on June 6, 2005 were also selected from the deans, chairs, or directors of accounting education programs listed in the Hasselback Accounting Faculty Directory (2004). For this mailing, however, deans, chairs, or directors of accounting programs designated as having accounting accreditation in the Directory were purposively selected. The response rate was $20 \%$ for the second mailing. An additional question was added to the evaluation form in the second mailing. Respondents were asked to indicate the most convenient month and when during the month (early, mid, or late) in the fall 2005 semester to mail the formal survey. Four participants returned the questionnaires and revised pilot study evaluation forms (See Appendix F2). A total of six accounting program chairs responded from the 40 individuals who were invited for the pilot study that yielded a 15\% overall response rate.

The researcher interviewed each participant on the telephone or corresponded by email asking them questions about the structure and format of the instrument, the ease of response selection, the clarity of the cover letter and survey questions, and the purpose of the study. The respondents were asked to offer any constructive comments or suggestions. The pilot study data were analyzed to determine if it yielded consistent results and to detect possible flaws in the design of the instrument or the research plan that would need to be corrected before the study proceeded (Fraenkel \& Wallen, 2003).

\section{Carnegie classification.}

The questionnaires were mailed to accounting program administrators at higher education institutions in the three Carnegie Classifications designed for this study. The six respondents in the pilot study were equally divided between two of the Carnegie Classifications (See Table 2). Three participants were from the doctoral classification and 
three from the master's. Five responses were from public institutions, and one was from a private institution.

Table 2

Pilot Study Responses by Carnegie Classification

\begin{tabular}{lcrrrrrr}
\hline \multirow{2}{*}{ Carnegie } & \multicolumn{2}{c}{ Public } & \multicolumn{2}{c}{ Private } & \multicolumn{2}{c}{ Total } \\
Classification & $\mathrm{N}$ & $\%$ & $\mathrm{~N}$ & $\%$ & $\mathrm{~N}$ & $\%$ \\
\hline Doctoral & 3 & 50 & 0 & 0 & 3 & 50 \\
Master's & 2 & 33 & 1 & 17 & 3 & 50 \\
Baccalaureate & 0 & 0 & 0 & 0 & 0 & 0 \\
\hline Total & 5 & 83 & 1 & 17 & 6 & 100 \\
\hline
\end{tabular}

Accrediting organization region.

The accounting programs in the pilot study were located in four of the six identified regions (See Table 3). Two respondents were from the Southern region, two from North Central, and one from the Middle States.

Table 3

Pilot Study Responses by Region

\begin{tabular}{llrlrrrr}
\hline \multicolumn{1}{c}{ Region } & \multicolumn{2}{c}{ Public } & \multicolumn{2}{c}{ Private } & \multicolumn{2}{c}{ Total } \\
\cline { 2 - 5 } & $\mathrm{N}$ & $\%$ & $\mathrm{~N}$ & $\%$ & $\mathrm{~N}$ & $\%$ \\
\hline Middle States & 1 & 17 & 0 & 0 & 1 & 17 \\
New England & 0 & 0 & 1 & 17 & 1 & 17 \\
North Central & 2 & 33 & 0 & 0 & 2 & 33 \\
North West & 0 & 0 & 0 & 0 & 0 & 0 \\
Southern & 2 & 33 & 0 & 0 & 2 & 33 \\
Western & 0 & 0 & 0 & 0 & 0 & 0 \\
\hline Total & 5 & 83 & 1 & 17 & 6 & 100 \\
\hline
\end{tabular}

Other than the response from a private institution in the New England region, the remaining respondents were from public institutions.

\section{Student enrollment.}

Enrollment by headcount (See Table 4) ranged from 176 to 500 students with a mean of 277. Enrollment by full-time equivalent (FTE) ranged from 180 to 480 students with a mean of 348 for the accounting programs in the pilot study. 
Table 4

Student Enrollment

\begin{tabular}{lcccccccr}
\hline Enrollment & N & Missing & Min & Max & R & M & Mdn & Mode \\
Headcount & 5 & 1 & 176 & 500 & 324 & 277 & 250 & 176 \\
FTE & 4 & 2 & 180 & 480 & 300 & 348 & 365 & 180 \\
\hline
\end{tabular}

Further analysis of the range of reported student enrollment numbers determined the distribution of accounting programs within small, mid-size, and large categories (See Table 5). For the pilot study, a program was considered small if enrollment headcount was less than 200 students, mid-size if enrollment was between 200 and 400 students, and large if enrollment was greater than 400 students.

\section{Table 5}

Pilot Study Response by Size

\begin{tabular}{|c|c|c|c|c|c|c|}
\hline \multirow[t]{2}{*}{ Size } & \multicolumn{2}{|c|}{$\underline{\text { Public }}$} & \multicolumn{2}{|c|}{ Private } & \multicolumn{2}{|c|}{ Total } \\
\hline & $\mathrm{N}$ & $\%$ & $\mathrm{~N}$ & $\%$ & $\mathrm{~N}$ & $\%$ \\
\hline Small & 2 & 33 & 0 & 0 & 2 & 33 \\
\hline Mid-size & 2 & 33 & 0 & 0 & 2 & 33 \\
\hline Large & 1 & 17 & 0 & 0 & 1 & 17 \\
\hline Missing & 0 & 0 & 1 & 17 & 1 & 17 \\
\hline Total & 5 & 83 & 1 & 17 & 6 & 100 \\
\hline
\end{tabular}

The same process was used to determine the small, mid-size, and large enrollment categories for the formal study. Two of the pilot study programs were small in enrollment, two were mid-size, and one was large. One respondent did not answer the question.

\section{Pilot Study Demographics}

The first section of the questionnaire elicited seven responses that garnered demographic information about the participants and the institutions’ accounting programs. The first two responses revealed the title and faculty rank of the respondents (See Table 6) ensuring that each respondent was in the position to have knowledge of the assessment process and access to the desired assessment data. One of the six respondents in this pilot 
study was a director of the accounting program and five were chairs, three were associate professors and three were full professors.

Table 6

Pilot Study Respondents’ Title and Rank

\begin{tabular}{llr} 
Title & $\mathrm{N}$ & $\%$ \\
\hline Director/Coordinator & 1 & 17 \\
Chair & 5 & 83 \\
Dean & 0 & 0 \\
\hline Total & 6 & 100 \\
\hline
\end{tabular}

Rank

\begin{tabular}{rr}
$\mathrm{N}$ & $\%$ \\
\hline 3 & 50 \\
3 & 50 \\
0 & 0 \\
\hline 6 & 100 \\
\hline
\end{tabular}

The required degree hours for the accounting programs in the pilot study ranged from 122 to 130 hours with a mean, median, and mode of 126 hours (See Table 7). The number of required hours in accounting courses ranged from 24 to 36 with a mean of 31, median of 32, and a mode of 36 hours.

Table 7

Required Degree Hours and Accounting Hours

\begin{tabular}{llrrrrrr} 
Required Hours & N & Min & Max & R & M & Mdn & Mode \\
\hline Degree & 6 & 122 & 130 & 8 & 126 & 126 & 126 \\
Accounting & 6 & 24 & 36 & 12 & 31 & 32 & 36 \\
\hline
\end{tabular}

Five of the six respondents reported the number of accounting graduates for the 20032004 academic year (See Table 8). The size of the graduating class at the participating institutions ranged from 69 to 102 with a mean of 84 and median of 80.

Table 8

Program Graduates 2003-2004 Academic Year

\begin{tabular}{lcccccccr}
\hline Graduates & $\mathrm{N}$ & Missing & Min & Max & R & M & Mdn & Mode \\
& 5 & 1 & 69 & 102 & 33 & 84 & 80 & 69 \\
\hline
\end{tabular}


The number of full-time faculty ranged from 13 to 18 (See Table 9), and the number of adjunct (part-time) faculty members ranged from none to four.

Table 9

Number of Full-time and Adjunct Faculty

\begin{tabular}{llcrrrrrr} 
Faculty & N & Missing & Min & Max & R & M & Mdn & Mode \\
Full-time & 6 & 0 & 13 & 18 & 5 & 15 & 15 & 14 \\
Adjunct & 5 & 1 & 0 & 4 & 4 & 2 & 2 & 0 \\
\hline
\end{tabular}

Pilot Study Evaluation Form Analysis

The pilot study evaluation form elicited participant responses about the format and content of the cover letter and survey instrument, the ease of response selection, the clarity of the questions, and the purpose of the study.

Participants' responses to the questions on the evaluation form were summarized (See Table 10). All respondents indicated that the cover letter clearly stated the intent and content of the survey and adequately described the purpose of the study. There was also unanimous agreement that the cover letter was easy to understand, and the instructions for completing and returning the survey and evaluation forms were clear.

Four of the respondents indicated that the cover letter conveyed the benefits of the study to accounting educators; one participant did not agree, while another did not respond to the question. Five of the participants agreed that the cover letter encouraged participation in the study; only one respondent was not in agreement.

The participants all indicated that the format of the questionnaire was easy to follow. Five of the six respondents agreed that the questions were easy to read and answer, while only one indicated the questions were not. All but one respondent reported that they understood all of the questions. 
Table 10

Pilot Study Evaluation Form Results

\begin{tabular}{lll}
\hline Questions & Yes No $\begin{array}{c}\text { No } \\
\text { Response }\end{array}$ \\
\hline
\end{tabular}

\section{Cover Letter}

1. Is the intent and content of the survey clearly stated? 6

2. Does the letter adequately describe the purpose of the study? 6

3. Is the letter easy to understand?

4. Are the instructions for completing and returning the survey and evaluation form clear?

5. Does the letter convey the benefits of this study to accounting educators?

6. Does the letter encourage you to participate in the study?

6

$5 \quad 1$

\section{Questionnaire}

1. Is the format of the questionnaire easy to follow?

2. Are the questions easy to read and answer?

3. Is there any question you did not understand?

5. Are there any questions that you believe should be added?

One participant suggested that questions about accreditation should be added to the survey instrument; four participants responded that they did not believe any questions should be added; and one did not respond to the question. In addition to the questions presented in Table 10, the pilot study evaluation form asked respondents to indicate how long it took them to complete the questionnaire. The six respondents indicated that the completion time ranged from six to twenty-five minutes with an average time of sixteen minutes.

The second pilot study evaluation form was revised to include a question about the most convenient month and time during the month to mail the formal study to participants in the 2005 fall semester. Three of the four responses indicated September was the optimum month, and two of the four also stated that early September was the most opportune time. 


\section{Questionnaire}

The pilot study questionnaire (See Appendix D1) contained ten sections that addressed different facets of accounting programs’ assessment plans. The first section contained seven questions to which the recipients were asked to respond.

\section{Demographics.}

The first two statements revealed the title and faculty rank of the respondents. These two statements were not numbered in the pilot study questionnaire, but they were numbered in the formal study survey instrument. The remaining five questions collected data about the accounting programs. Questions one and two indicated the total number of hours required for the baccalaureate degree and the required number of accounting hours included in the degree.

Question three requested the number of students enrolled by FTE and by head count. Respondents reported that some institutions did not count FTE, and they were not sure how to respond to the term head count. The question was revised to ask for the number of students enrolled in the accounting programs. Question four of section one asked for the number of accounting graduates in the academic year $2003-2004$. The academic year was changed to 2004 - 2005 to reflect the accurate time period for the formal study. Also, the terms full-time and adjunct used to describe faculty caused some confusion in question five that asked for the number of accounting faculty. It was reported that part-time and full-time adjuncts were employed at some institutions. The term adjunct was deleted from the formal study questionnaire to alleviate the uncertainty.

The pilot study questionnaire did not ask for the accounting programs’ accreditation information. The participants indicated that this information could be a determinant in the 
development of assessment plans and occurrence of assessment activities. A question was inserted in section one that asked whether the baccalaureate accounting programs were accredited, and another question requesting the names of the accrediting organizations was also added to the formal study questionnaire.

Assessment process.

Section two of the questionnaire contained eight questions that obtained information about the stated purpose of the accounting program, collection of assessment data, the focus of the assessment process, and the student learning outcomes. Question six asked about the level of development of an assessment plan.

The answer choices included (1) has not created an assessment plan, (2) in the beginning stages of developing an assessment plan, (3) has developed an assessment plan, and (4) has implemented an assessment plan. One participant reported that the accounting faculty had not created an assessment plan, but they were planning to develop one. However, an answer choice for that situation was not available. The second section of the formal study’s questionnaire was changed to offer another answer choice. Will develop an assessment plan in the near future was inserted as answer choice 2 for the stages of development of assessment plans in question six.

Frequency of assessment.

Question seven inquired about the frequency of assessment activity. The answer choices were (1) episodic, it occurs during program review, for accreditation purposes, or as needed and (2) on-going, it is a routine activity in the program. One response indicated that assessment occurred more often than episodic at that institution, but it was not yet an ongoing activity. This comment yielded a change to the responses for this particular question in 
the formal study's survey instrument. It was expanded to include the choice of "periodic, but not an integral part of the program” to describe more accurately how often assessment occurred.

The Likert Scale was used to record responses for the remaining questions in this section and most of the questions in the survey. Originally, the Likert Scale answer choices were (1) extensively, (2) somewhat, (3) very little, or (4) not at all. One participant indicated that responses to some of the questions fell somewhere between extensively and somewhat due to time constraints and level of development. In response, an additional level of measurement, “often” was added between extensively and somewhat on the Likert scale to provide more definitive responses.

The participants did not make suggestions or report any difficulty with questions 14 through 23 in the Essential Skills and Student Outcomes sections of the survey instrument that asked if the essential skills under study were addressed in the accounting courses and identified as student learning outcomes in the assessment process.

Essential skills addressed in courses.

The pilot study questionnaire included a matrix for question 24 that asked about the extent to which the essential skills under study were addressed in each accounting course offered in the program. The rows of the matrix contained seven courses that were offered in most accounting programs and spaces for five other courses to be identified by the respondents. The five essential skills were identified in the columns of the matrix. The answer choices I (Introduced), NA (Not at All), and E (Emphasized) were typed in each space on the matrix. The participants were asked to circle the choice in each cell that best described the extent to which the skills were addressed in the accounting courses. 
The question was described as too confusing and difficult to answer by the participants. The answer choices were removed from the matrix cells to minimize confusion, and the participants of the formal study were asked to write I (to indicate Introduced), NA (to indicate Not at All), or E (to indicate Emphasized) in each of the cells to indicate the extent to which the skills were addressed in each of the accounting courses. Respondents also reported that many accounting programs have two separate courses for Principles of Accounting; therefore, the Accounting Principles course selection in question 24 was separated into Principles of Financial Accounting (I) and Principles of Managerial Accounting (II) for clarity.

Assessment activity and methods.

The Assessment Activities section of the questionnaire contained questions 25 to 44 that inquired about the school years in which the students were engaged in assessment and the methods of assessment used to measure student learning. To determine the methods of assessment used, participants were given a list of direct methods and a list of indirect methods of assessment. In the direct methods part of the section, Question 27, the course embedded selection was removed. Respondents indicated that many of the direct methods listed could also be course embedded. The participants did not offer any comments or suggestions for questions 45 through 79 in the remaining four sections of the questionnaire, Assessment Results, Assessment Related Changes and Improvements, Assessment Audiences, and Methods of Dissemination of Assessment Results.

At the end of the questionnaire, respondents were asked if they wanted to receive results of the study. If so, they were asked to select between an email attachment and the postal service as the method of delivery. This section was expanded in the formal study 
questionnaire to provide adequate space for names and mailing addresses if they wanted to receive a copy of the study.

The pilot study data generated several practical suggestions that initiated important changes to the cover letter and questionnaire. The subsequent changes improved the readability and functionality of the survey instrument and served to enhance its validity and reliability.

\section{Formal Study}

In the formal study, 786 faculty members in charge of undergraduate accounting degree programs within the defined population of colleges and universities were invited to participate in the survey process. The titles of such individuals included coordinators of undergraduate accounting programs or directors. The specific names of these individuals were not identified. One hundred two participants returned questionnaires; the response rate was $13 \%$. Five questionnaires were returned marked not deliverable or unable to forward, and two participants sent email messages stating that their institutions did not have baccalaureate accounting programs. Of the 102 questionnaires returned, 96 were usable responses.

\section{Data Collection and Analysis}

This study used a descriptive survey to obtain information that was further analyzed to discover the similarities and differences in accounting program assessment procedures. “A descriptive survey involves asking the same set of questions . . of a large number of individuals either by mail, by telephone, or in person” (Fraenkel \& Wallen, 2003, p. 13). The researcher developed a questionnaire (See Appendix D2) to obtain information about 
assessment of student learning outcomes for accounting programs at higher education institutions.

The questionnaire was designed to elicit responses that indicated whether the undergraduate accounting program integrated and assessed these five essential skills (critical thinking, information literacy, oral communication, problem solving, and written communication). The survey also contained questions that inquired about the methods used to measure these five essential skills, who received the assessment data, and how the assessment data were used to improve student learning. The respondents were also asked how the assessment process influenced curriculum and program changes.

The survey instrument contained 10 sections. The relationship between the survey instrument and the research questions is presented in Table 11. The first section included nine questions that collected demographic information about the institutions' accounting programs. Data from questions one through nine were analyzed by calculating percentages, means, and ranges.

Table 11 Relationship between Data Collection Instrument and Research Questions Sections Research Questions Survey Questions

1. Undergraduate Accounting Program Information

Demographic Information Assessment Plan Information

2. Assessment Process

3. Essential Skills

4. Student Learning Outcomes

5. Essential Skills Addressed in Accounting Programs

6. Assessment Activities

7. Assessment Results

8. Changes and Improvements

9. Assessment Audiences

10. Dissemination of Results
1 through 9

10 through 17

RQ 1

RQ 2

RQ 3

RQ 4

RQ 5

RQ 6
18 through 22

23 through 27

28

29 through 47

48 through 55

56 through 64

75 through 82

65 through 74 
The questionnaires were disseminated by the U. S. Postal Service with return postage paid. One follow-up mailing was conducted for non-respondents.

\section{Carnegie Classification}

The questionnaires were mailed to accounting program administrators at higher education institutions in the three condensed Carnegie Classifications for this study: doctoral, master's, and baccalaureate. The original sample consisted of 786 institutions surveyed, 26\% were doctoral universities, 18\% were public institutions, and $8 \%$ were private (See Table 12). The master's colleges and universities comprised 52\% of the institutions in the study. Of these, $30 \%$ were public and $22 \%$ were private institutions. The remaining $22 \%$ of the institutions were baccalaureate colleges; $5 \%$ were public and $17 \%$ were private institutions.

Table 12

Survey Response by Carnegie Classification

\begin{tabular}{|c|c|c|c|c|c|c|c|c|c|c|c|c|}
\hline \multirow{3}{*}{$\begin{array}{l}\text { Carnegie } \\
\text { Classification }\end{array}$} & \multicolumn{5}{|c|}{ Surveys Mailed } & \multicolumn{5}{|c|}{ Responses } & \multicolumn{2}{|c|}{$\begin{array}{c}\text { Response } \\
\text { Rate }\end{array}$} \\
\hline & \multicolumn{2}{|c|}{$\underline{\text { Public }}$} & \multicolumn{2}{|c|}{ Private } & Total & \multicolumn{2}{|c|}{ Public } & \multicolumn{2}{|c|}{ Private } & \multirow{2}{*}{$\frac{\text { Total }}{\mathrm{N}}$} & \multirow{2}{*}{\multicolumn{2}{|c|}{$\begin{array}{cr}\text { By } & \text { Total } \\
\text { Group } & \text { Mailed } \\
\% & \% \\
\end{array}$}} \\
\hline & $\overline{\mathrm{N}}$ & $\%$ & $\mathrm{~N}$ & $\%$ & $\overline{\mathrm{N}} \%$ & $\mathrm{~N}$ & $\%$ & $\mathrm{~N}$ & $\%$ & & & \\
\hline Doctoral & 142 & 18 & 65 & 8 & 207 & 15 & 11 & 5 & 8 & 20 & 10 & 2 \\
\hline Master’s & 235 & 30 & 171 & 22 & 406 & 36 & 15 & 17 & 10 & 53 & 13 & 7 \\
\hline Baccalaureate & 36 & 5 & 137 & 17 & $173 \quad 22$ & 11 & 31 & 18 & 13 & 29 & 17 & 4 \\
\hline Total & 413 & 53 & 373 & 47 & 786100 & 62 & 57 & 40 & 31 & 102 & $\mathrm{XX}$ & 13 \\
\hline
\end{tabular}

Of the 786 questionnaires mailed, 102 responses were received, with an overall response rate of $13 \%$. Of the total response rate, doctoral universities returned $2 \%(n=20)$, 15 were public institutions and five were private; master's institutions returned $7 \%(n=53)$, 36 from public institutions and 17 from private ones; and baccalaureate colleges returned 4\% $(n=29)$ with 11 public and 18 private institutions represented. 
The response rate ranged from $10 \%$ to $17 \%$ of the survey instruments mailed within each classification. Doctoral institutions returned 10\% $(n=20)$ of the 207 questionnaires mailed to them. Master's institutions returned 13\% $(n=53)$ of the 406 questionnaires mailed to that classification. With the greatest response rate, baccalaureate institutions returned 17\% $(n=29)$ of the 173 questionnaires mailed to them.

\section{Accrediting Organization Regions}

The established regions of the institutions’ accrediting organizations (Middle States, New England, North Central, North West, Southern, and Western) constitute the region categories for this survey (See Appendix B). Institutions were separated into one of six categories according to the accrediting organization region of each institution.

Of the original sample of 786 accounting programs, 149 or $19 \%$ were located in the Middle States region, 57 in public institutions and 92 in private ones (See Table 13). The New England region included 55, 7\% of the total programs surveyed, with 25 in public and 30 in private institutions. The North Central region’s 251 institutions comprised 32\% of the accounting programs included in the survey, 133 public institutions and 118 private.

Table 13

Survey Response by Region

\begin{tabular}{|c|c|c|c|c|c|c|c|c|c|c|c|c|c|}
\hline \multirow{3}{*}{ Region } & \multicolumn{6}{|c|}{ Surveys Mailed } & \multicolumn{5}{|c|}{ Responses } & \multicolumn{2}{|c|}{$\begin{array}{c}\text { Response } \\
\text { Rate }\end{array}$} \\
\hline & \multicolumn{2}{|c|}{ Public } & \multicolumn{2}{|c|}{ Private } & \multicolumn{2}{|c|}{ Total } & \multicolumn{2}{|c|}{ Public } & \multicolumn{3}{|c|}{ Private Total } & $\begin{array}{c}\text { By } \\
\text { Group }\end{array}$ & $\begin{array}{r}\text { Total } \\
\text { Mailec }\end{array}$ \\
\hline & $\mathrm{N}$ & $\%$ & $\mathrm{~N}$ & $\%$ & $\mathrm{~N}$ & $\%$ & $\mathrm{~N}$ & $\%$ & $\mathrm{~N}$ & $\%$ & $\mathrm{~N}$ & $\%$ & $\%$ \\
\hline Middle States & 57 & 7 & 92 & 12 & 149 & 19 & 7 & 7 & 11 & 11 & 18 & 12 & 2.0 \\
\hline New England & 25 & 3 & 30 & 4 & 55 & 7 & 0 & 0 & 1 & 1 & 1 & 2 & 0.1 \\
\hline North Central & 133 & 17 & 118 & 15 & 251 & 32 & 26 & 25 & 19 & 19 & 45 & 18 & 6.0 \\
\hline North West & 25 & 3 & 12 & 1 & 37 & 5 & 5 & 5 & 1 & 1 & 6 & 16 & 0.8 \\
\hline Southern & 142 & 18 & 98 & 13 & 240 & 30 & 20 & 19 & 7 & 7 & 27 & 11 & 3.0 \\
\hline Western & 32 & 4 & 22 & 3 & 54 & 7 & 4 & 4 & 1 & 1 & 5 & 9 & 0.6 \\
\hline Total & 414 & 52 & 372 & 48 & 786 & 100 & 62 & 60 & 40 & 40 & 10 & $X X$ & 13.0 \\
\hline
\end{tabular}


The North West region contained 37 institutions, 5\% of the total, 25 were public and 12 were private. The Southern region included 240 programs, 30\% of the total, with 142 public and 98 private. The remaining 54 institutions, $7 \%$ of the total mailed were in the Western region and included 32 public and 22 private institutions. Of the 786 questionnaires mailed, $13 \%$ were returned $(n=102)$. The Middle States region returned $2 \%(n=18)$, the New England area returned .1\% $(n=1)$, and the North Central region returned 6\% $(n=45)$. Responses from the North West region represented .8\% $(n=6)$ of the total mailed, the Southern area returned 3\% $(n=27)$, and the Western institutions accounted for .6\% $(n=5)$ of the questionnaires returned.

The response rate ranged from $2 \%$ to $18 \%$ within each classification. Responses from the Middle States region totaled 18 (12\% of the questionnaires mailed to that region), with 7 public and 11 private institutions represented as seen in Table 13. The New England region had only one response (2\%) from a private institution. Accounting program administrators in the North Central region returned 45 questionnaires (18\%) from 26 public and 19 private institutions. Only six responses were returned from the North West region representing 16\% of the number mailed to the region, five from public institutions with one private institution responding. The Southern region accounted for 27 responses (11\%) with 20 public institutions and 7 private ones represented. Institutions in the Western region returned five responses (9\%), four from public institutions and one from a private one.

\section{Student Enrollment}

Student enrollment ranges were determined and the table (See Table 14) completed after analyzing the responses to survey question 5 of the Undergraduate Accounting Program Assessment Questionnaire (See Appendix D2). Reported enrollment at the 
participating programs ranged from as few as ten students to as many as 1200 . With nearly one-half of the accounting programs reporting enrollment of less than 200 students, it was not possible to establish ranges with even distribution in the size categories. The small category cutoff was set at 199; the range for the mid-size category was established between 200 and 400; and the range for the large group was set at greater than 400 encompassing programs with enrollment of 400 to 1200 students. Grouping the programs in these categories permitted a faithful representation of enrollment at the participating accounting programs.

\section{Table 14}

Survey Response by Size

\begin{tabular}{lrrrrrr}
\hline Size & \multicolumn{3}{c}{ Public } & \multicolumn{2}{c}{ Private } & \multicolumn{2}{c}{ Total } \\
\cline { 2 - 6 } & \multicolumn{1}{c}{ N } & $\%$ & $\mathrm{~N}$ & $\%$ & $\mathrm{~N}$ & $\%$ \\
\hline Small & 18 & 18 & 25 & 24 & 43 & 42 \\
Mid-size & 29 & 28 & 9 & 9 & 38 & 37 \\
Large & 10 & 10 & 1 & 1 & 11 & 11 \\
Missing & 6 & 6 & 4 & 4 & 10 & 10 \\
\hline Total & 63 & 62 & 39 & 38 & 102 & 100 \\
\hline
\end{tabular}

Note. Small < 200; Mid-size $=200-400$; Large $>400$.

The small enrollment category included 43 of the responses (42\%), with 18 public and 25 private institutions represented. The mid-size category represented 38 (37\%) of the responses; public institutions accounted for 29 and private institutions accounted for nine of the questionnaires returned in this category. The large accounting program category encompassed 11 (11\%) of the accounting programs; public institutions represented 10, and private institutions represented one of the responses. Of the $10(10 \%)$ programs that did not indicate enrollment size, there were six public institutions and four private institutions.

Upon review of results for questions 8 and 9 pertaining to the accreditation status of the accounting programs and the accrediting organizations, it was clear respondents did not understand the questions; therefore, no analysis was conducted. Descriptive statistics 
including sample means and percentages were used to profile the demographics of the accounting faculty participants and accounting programs. Descriptive statistics permitted the researcher to readily collect and closely examine the data before invoking more technically involved procedures of research and analysis (Howell, 2002).

Formal Study Demographics

The first section of the questionnaire gathered demographic information about the participants, the institutions’ accounting programs, required hours, and faculty.

Participants' title and faculty rank.

Of the 102 administrators responding, 51\% were director/coordinators (See Table 15). Chairs comprised $41 \%$ of the respondents; deans accounted for $2 \%$; and $6 \%$ did not indicate a formal title. Results also indicated that 41 respondents were full professors, 47 were associate professors, 8 were assistant professors, and 6 did not indicate faculty rank.

\section{Table 15}

Formal Study Respondents’ Title and Rank

\begin{tabular}{lrr} 
Title & $\mathrm{N}$ & $\%$ \\
\hline & & \\
Director/Coordinator & 52 & 51 \\
Chair & 42 & 41 \\
Dean & 2 & 2 \\
Missing & 6 & 6 \\
\hline Total & 102 & 100 \\
\hline & & \\
Rank & $\mathrm{N}$ & $\%$ \\
\hline & & \\
Full Professor & 41 & 40 \\
Associate Professor & 47 & 46 \\
Assistant Professor & 8 & 8 \\
Missing & 6 & 6 \\
\hline Total & 102 & 100 \\
\hline
\end{tabular}




\section{Program hours.}

The responses revealed that most programs required 128 hours for the undergraduate accounting degree (the mode) with a mean of 126 and a median of 125 hours. Hours ranged from 120 to 140 for the Baccalaureate degree. Ninety-two of the participants revealed that required accounting hours ranged from 15 to 58 for the accounting degrees, with a mean of 31 hours and a median and mode of 30.

Table 16

Required Degree Hours and Accounting Hours

\begin{tabular}{lccrrrrrr} 
Required Hours & N & Missing & Min & Max & R & M & Mdn & Mode \\
Degree & 96 & 6 & 120 & 140 & 20 & 126 & 125 & 128 \\
Accounting & 92 & 10 & 15 & 58 & 28 & 31 & 30 & 30 \\
\hline
\end{tabular}

Program graduates and faculty.

The number of graduates (See Table 17) ranged from 0 to 275 students with a mean of 57, a median of 40, and a mode of 30 graduates as reported by 93 of the 102 accounting programs.

Table 17

Program Graduates 2004-2005 Academic Year

\begin{tabular}{cccccccrr}
\hline & N & Missing & Min & Max & R & M & Mdn & Mode \\
\hline Graduates & 93 & 57 & 0 & 275 & 275 & 57 & 40 & 30 \\
\hline
\end{tabular}

Table 18 shows that 95 of the 102 participants reported that the number of full-time faculty ranged from one to 25 . The number of part-time faculty members reported by 94 respondents ranged from none to 40.

Table 18 Full-time and Part-time Faculty

\begin{tabular}{lcccccccc}
\hline Faculty & $\mathrm{N}$ & Missing & Min & Max & $\mathrm{R}$ & $\mathrm{M}$ & Mdn & Mode \\
Full-time & 95 & 7 & 1 & 25 & 24 & 7 & 5 & 3 \\
Part-time & 94 & 8 & 0 & 40 & 40 & 3 & 2 & 1 \\
\hline
\end{tabular}




\section{Assessment Process}

The second section of the survey contained eight questions (items 10 through 17) about the level of development of the assessment plan and the overall purpose. Question 10 indicated the institution's stage of involvement in assessment. Question 11 revealed whether the assessment process was on-going, periodic, or episodic. Public institutions of higher education are required to undergo a self-evaluation process to provide evidence of student learning and improve the quality of education (Palomba \& Banta, 1999).

States assign institutional programmatic reviews to accrediting organizations that require the institutions to develop assessment plans to measure student learning (Ewell, Lutz, \& Ratcliff, 1997). This data were analyzed and means and standard deviations were calculated to ascertain the percentage of programs in the various stages of development and implementation of an assessment plan.

Additional information about the assessment process was gleaned from questions 11 through 17. Participants selected a response regarding how extensively certain activities occurred by using a Likert scale. A Likert Scale is a method of measurement used to record a response to a survey question giving participants a choice of degrees of agreement with the posed question or statement. Typically, the answer-choices are presented in a range from strongly agree to strongly disagree. The Likert Scale responses in this survey were (1) extensively, (2) often, (3) somewhat, (4) very little, and (5) not at all.

Research Question 1: Differences in How Extensively Essential Skills are Addressed in Accounting Programs

The third section consisted of five questions (items 18 through 22) that addressed research question one pertaining to how extensively the essential skills under study (critical 
thinking, information literacy, oral communication, problem solving, and written communication) were addressed in the accounting programs by Carnegie Classification, region, and size. Responses to questions in the third section were also gathered by using a Likert Scale. Means were calculated and significant differences were determined by using an analysis of variance (ANOVA).

A study sponsored by the U. S. Department of Education asked faculty, legislators, and business leaders to identify skills and knowledge they considered crucial in the workplace. The study concluded that critical thinking, reasoning, advanced writing, and oral communication skills were important skills for college students to acquire (Jones, 1994). Another U. S. Department of Education report identified the ability to integrate these essential skills with business skills to analyze financial data and make sound business decisions as a primary goal of business majors (Jones, 1995).

Research Question 2: Essential Skills Identified as Learning Outcomes in Accounting Programs

The fourth section (questions 23 through 27) indicated to what degree the essential skills under study were articulated as student learning outcomes in the assessment process. The data gathered from these questions addressed research question two. Again, an ANOVA determined if there were significant differences by Carnegie type, region, and size.

State governors recommend that state institutions of higher education develop a performance based assessment of graduating seniors' critical thinking, oral and written communication, and problem solving skills (Ewell, 1991; Schwartz \& Robinson, 2000). Development of these essential workplace skills is a critical component of the program of study (Marchese, 1991). Assessing these skills in the program of study measures the skills 
and knowledge educators, employers, governmental agencies, and other stakeholders deem critical for students to possess for successful careers (Banta, 2002).

\section{Research Question 3: Essential Skills Addressed in Required Accounting Courses}

In the fifth section (questions 28a through 28m), the respondents were asked to indicate the extent to which the essential skills were addressed in specific required accounting courses that were part of the students' programs of study or core courses offered by the institution by entering in the appropriate cells in the matrix a letter I if the skill was introduced, the letter $\mathrm{E}$ if the skill was emphasized, or the letters NA if the skill was not addressed.

Question 29 in section six indicated at what level student assessment occurs throughout a student's academic program. These survey items addressed research question three regarding how extensively certain skills and competencies were addressed within the individual required accounting courses by Carnegie Classification, region, and size. The responses were analyzed and percentages were reported.

A National Institute for Higher Education report (1984) recommended that course requirements should provide the opportunity for students to develop capacities for critical thinking, problem solving, communication, and synthesis of knowledge. Likewise, accounting organizations and professionals have called for reform in accounting education.

These calls for reform do not ask for more domain specific skills; they ask that accounting education help students develop intellectual capacities such as critical thinking, communication, and problem solving skills (American Accounting Association, 1986; Big 8 Accounting Firms, 1989; Dooney \& Lephardt, 1993; Gainen \& Locatelli, 1995; AECC, 1996; AICPA, 1997; Albrecht \& Sack, 2000; AICPA, 2000; AICPA, 2001). 


\section{Research Question 4: Assessment Methods Used to Measure Skills and Competencies}

The remaining questions in section six (questions 30 through 47) addressed research question 4 regarding whether there were significant differences in how extensively assessment methods were used to measure essential skills and competencies. The questions gathered data about how frequently indirect and direct assessment methods were used at the institutions. Participants responded using a Likert scale. Direct methods included student portfolios, course embedded assessments, capstone projects, juried reviews of student projects or performances, internships, case studies, locally designed tests, and standardized national tests. Indirect methods included alumni, student, and employer surveys, focus groups, graduate follow-up studies, retention and transfer studies, exit interviews, and reflective papers. The survey also provided space for the respondents to add other direct and indirect assessment instrument(s) that were not listed. Successful assessment plans use multiple measures (NCA, 1994).

Assessment instruments collect information about students’ competencies. Interpretation of the data collected permits institutions to determine how well they are achieving their goals (Huba \& Freed, 2000). Maki (2002) recommends using a combination of direct and indirect methods of assessment to analyze student learning. The author maintains that indirect methods support evidence of student learning obtained through direct methods. An ANOVA was used to analyze to what extent the institutions used direct and indirect methods of assessment.

Research Question 5: Use of Assessment Results and Related Changes

The seventh section of the survey (questions 48 through 55) addressed research question five to determine if there were significant differences by Carnegie Classification, region, and enrollment in how extensively assessment results were used to enhance 
accounting programs and improve student learning. Institutional planning, resource allocation, curricular changes, program review, student recruitment, improving student learning, and evaluation of the assessment process were among the items listed.

The survey instrument also provided space for the respondents to add any other way(s) assessment results were used. Deans, chairs, or program directors were asked to select on the Likert scale the degree to which each institution used its assessment results. An ANOVA was used to determine whether there were significant differences.

Assessment results provide information about course materials, program goals, methods of instruction, student learning, and other factors that shape the educational experience (Banta, 2002). Decisions about funding, budgets, planning, academic programs, courses, student activities, and much more hinge on assessment data collected (Maki, 2002; Black \& Duhon, 2003).

Assessment data should be used in academic program and curriculum reviews (Huba \& Freed, 2000). Students should receive timely feedback about their performance in assessment activities to enable them to improve their skills (Huba \& Freed, 2000). Refining and improving the assessment process is an important component of a successful assessment plan. Assessment results should be used to evaluate and revise the assessment process (Maki, 2002; Palomba \& Banta, 1999).

The eighth section (questions 56 through 64) also addressed research question five. It investigated the specific nature of improvements that have occurred based on assessment results (institutional planning, resource allocation, curricular changes, program review, student recruitment, improving student learning, evaluation of the assessment process, and faculty self-evaluation of teaching techniques). 
The respondents were asked to indicate to what degree changes have occurred in these areas due to assessment. The survey instrument also provided space for the respondents to add other change(s) that have occurred due to assessment. A recent study revealed that assessment results influence the modification of student assessment plans, teaching methods, academic programs, and general education (Peterson \& Augustine, 2000a). Successful assessment plans lead to improvement in student learning (NCA, 1994). An ANOVA was used to analyze the data collected.

\section{Research Question 6: Sharing Assessment Results}

Section nine provided answers to research question 6 that asked if there was a significant difference in how extensively the faculty share assessment results. In this section, the participants were asked to indicate to what degree groups or individuals received assessment reports from the institution. An ANOVA was once again used to determine significant differences. Questions 65 through 74 listed students, parents, faculty, administrators, governance board, general public, alumni organizations, business leaders, and professional organizations. The survey instrument also provided space for the respondents to add any other recipient(s) of the institutions’ assessment reports. An ANOVA was used to analyze the responses.

Questions 75 through 82 also addressed research question six by asking how extensively specific methods were used to disseminate assessment results. The respondents were asked to indicate to what degree the institution used the identified methods of making assessment results available. Questions 75 through 82 listed the institution’s newspaper, required reports to accrediting organization and governance board, marketing campaigns, institution's website, catalog, brochures, conference presentations and workshops as means 
of distributing assessment results to constituents. The survey instrument also provided space for the respondents to add other method(s) the institution used to make assessment results available to its audiences. An ANOVA was used to analyze to what extent the institutions used the identified methods to disseminate assessment results.

Assessment reports should be tailored to the needs of the recipient. Reports should describe the assessment process, the subjects assessed, the purpose of assessment, the methods used to collect and measure assessments, the main findings, and how the results have been used to make specific improvements (Maki, 2002). A well-designed assessment plan provides assessment results to internal and external audiences. Faculty, students, parents, administrators, and other constituents need assessment data to make sound decisions that affect student learning (Palomba \& Banta, 1999). Government leaders and accrediting organizations require periodic assessment reports from institutions of higher education (Banta \& Associates, 2003).

Official assessment reports are presented to state government leaders, governing bodies, and accrediting organizations (Banta \& Associates, 1993). Brochures, flyers, and websites are useful means of communicating assessment data to prospective students, parents, and the general public (Palomba \& Banta, 1999).

\section{Reliability}

Reliability refers to the consistency of the scores obtained for each individual from one instrument to another and from one item to another within an instrument (Fraenkel \& Wallen, 2003). A standardized survey where participants answer the same questions in the same order can enhance reliability. Internal reliability refers to consistency within the questionnaire. Similar questions in different parts of the survey that yield similar responses 
establish reliability (Suskie, 1996). For example, Question 14 in the survey instrument (See Appendix D2) inquired about how extensively the assessment process focused on improving student learning. Question 53 referred to how extensively the assessment results were used to improve student learning, and question 61 inquired about the changes in student learning that have occurred due to assessment. To establish reliability, these three questions should elicit similar responses.

\section{Validity}

Investigators are also concerned with content validity. Content validity refers to the content and format of the instrument. The content of the instrument must adequately represent the domain content; the instrument questions must pertain to the topic under study. The entire survey was developed based upon the review of literature and the work of numerous scholars in the field of assessment.

The format of the instrument refers to the appearance of the instrument including clarity of directions, size of type, and appropriate language (Fraenkel \& Wallen, 2003). Conducting a pilot study that requested the participants to complete the Pilot Study Evaluation Form enhanced the content validity of this study.

\section{Institutional and Individual Subject Approval}

Copies of the pilot study letter to participants, pilot study evaluation form, questionnaire, and formal study letter to participants were submitted to the West Virginia University Institutional Review Board for the Protection of Human Subjects (IRB) for approval before the study was conducted. The researcher received formal IRB approval (See Appendix H) before proceeding with the pilot study and the survey. The researcher has completed the HIPAA registration (See Appendix I) requirement. 


\section{Background of Researcher}

The researcher is a doctoral student in the Educational Leadership program at West Virginia University. Her credentials include a Master's of Business Administration degree, a Bachelors of Business Administration degree with a concentration in accounting, and a Certified Public Accountant. She is an Associate Professor of Accounting and Assessment Coordinator for the School of Business at a state university. She is also a member of the American Institute of Certified Public Accountants, the American Accounting Association, and a charter member of the recently created West Virginia Council of Accounting Educators serving as the 2006 President-elect and Steering Committee Chair.

The researcher is a member of the West Virginia Society of Certified Public Accountants (WVCPAs) previously serving on the Careers in Accounting Committee and the West Virginia Educator's Seminar Roundtable. On behalf of the WVCPAs, she presented the accounting profession's views on changes in accounting and discussed the profession's concerns about accounting education at high-school business education teachers’ workshops throughout the state for the West Virginia Department of Education.

In addition, the researcher was involved in assessment activities at a state college where she was formerly employed. She was co-chair of the General Studies Program Committee that was charged with oversight of the general education program and the development and implementation of the Program's assessment plan. She also conducted an extensive audit of the general education program and evaluated the assessment plan for the program. The researcher prepared the general education section of the self-evaluation report for the college's accrediting organization. 
She has also penned two articles on general education and assessment that were published in the Summer 2004 issue of the Journal of General Education. She wrote the article, Assessing General Education Skills in an Undergraduate Business Degree Program, and co-authored A Framework for Assessing General Education Outcomes within the Majors. The researcher was also guest editor of that special issue.

The researcher's interest in accounting education began as an accounting student and grew even stronger as an accounting educator. Her first appointment as an accounting educator in the late 1990's presented challenges that added another dimension to her career. The accounting program at the institution had experienced a dramatic decline in enrollment, and administrators asked the researcher to conduct a study to determine the needs and demands of the community and the viability of the accounting program.

Surveys of community and business leaders and research on recommendations offered by the accounting profession revealed the growing concerns and impending crisis in accounting education. As a result, the researcher recognized the role of assessment in accounting education. Realizing that educators have made changes to improve accounting education and equip students with the skills and knowledge to become successful accounting professionals, the researcher decided to examine the assessment process at colleges and universities offering baccalaureate accounting programs in the United States to document assessment procedures and related changes that have occurred and to make this data available to professional organizations and other constituents interested in assessment of accounting education. 


\section{Chapter 4: Results}

In this chapter, the major findings for each of the research questions and the corresponding items on the revised survey instrument (See Appendix D2) are presented. First, demographic data obtained from the survey is discussed because it provides useful background information to better understand the accounting programs including their current stage of assessment plans.

The first part of the survey consisted of a series of demographic questions. Six participants answered the demographic information in the first section of the questionnaire, but they did not complete the remaining sections. They stated that their institutions did not have accounting programs so these six survey responses were removed from the entire study.

Four of the participants who completed the questionnaire did not report accounting program enrollment; therefore, size could not be determined for these programs. Enrollment numbers were used to determine the categories for size; therefore, these four responses were excluded from all of the analyses that were conducted by size of program, but they were included in the analyses by Carnegie Classification and region in this study.

\section{Stage of Development of Assessment Plan}

Participants were asked to indicate the level of development for their accounting program assessment plans. The answer choices were: not created, will develop soon, in the development stage, plan has been developed, and plan implemented. Percentages were calculated and summarized by the three treatment groups, Carnegie Classifications, region, and size. 
Stage of Development of Assessment Plan by Carnegie Classification

Results indicated that approximately $24 \%$ of doctoral institutions would be developing an assessment plan soon, 24\% were developing a plan, $11 \%$ had developed an assessment plan, and $41 \%$ had already implemented one (See Table 19). About $11 \%$ of the master's classification programs had not created an assessment plan, 8\% would develop a plan soon, 33\% were in the process of developing one, $15 \%$ had developed a plan, and another 33\% had already implemented an assessment plan.

Table 19

Assessment Plan Development by Carnegie Classification

\begin{tabular}{|c|c|c|c|c|c|c|c|c|c|c|c|c|}
\hline \multirow{3}{*}{$\begin{array}{l}\text { Carnegie } \\
\text { Classification }\end{array}$} & \multirow{2}{*}{\multicolumn{2}{|c|}{$\begin{array}{c}\text { Not } \\
\text { Created }\end{array}$}} & \multirow{2}{*}{\multicolumn{2}{|c|}{$\begin{array}{l}\text { Will } \\
\text { develop d } \\
\text { soon }\end{array}$}} & \multicolumn{2}{|c|}{$\begin{array}{l}\text { In the } \\
\text { evelopment }\end{array}$} & \multirow{2}{*}{\multicolumn{2}{|c|}{$\begin{array}{c}\text { Plan } \\
\text { has been } \\
\text { developed }\end{array}$}} & \multirow{2}{*}{\multicolumn{3}{|c|}{$\begin{array}{l}\text { Plan } \\
\text { Implemented }\end{array}$}} & \\
\hline & & & & & & ge & & & & & & \\
\hline & $\mathrm{N}$ & $\%$ & $\mathrm{~N}$ & $\%$ & $\mathrm{~N}$ & $\%$ & $\mathrm{~N}$ & $\%$ & $\mathrm{~N}$ & $\%$ & & \\
\hline Doctoral & 0 & 0 & 4 & 24 & 4 & 24 & & 11 & 7 & & 17 & 100 \\
\hline Master's & 6 & 11 & 4 & 8 & 17 & 33 & 8 & 15 & 17 & 33 & 52 & 10 \\
\hline Baccalaureate & & 15 & 2 & 7 & 9 & 33 & 5 & 19 & 7 & 26 & 27 & 10 \\
\hline
\end{tabular}

The baccalaureate program administrators reported that $15 \%$ had not created an assessment plan, $7 \%$ would soon develop one, $33 \%$ of the programs were developing an assessment plan, $19 \%$ of them had already developed one, and $26 \%$ of them had implemented a plan.

Stage of Development of Assessment Plan by Region

A coding system developed for this survey identified the regional accrediting area. Of the accounting programs in the Middle States region, $12 \%$ had not created a plan, another $12 \%$ would develop a plan soon, $47 \%$ were developing an assessment plan, $23 \%$ had already developed one, and 6\% had already implemented an assessment plan (See Table 20). Only one response was received from the New England region, and it indicated an assessment plan was being developed. The North Central region reported that 7\% had not created an 
assessment plan, 11\% of them would develop a plan soon, 29\% were developing an assessment plan, 13\% had developed an assessment plan, and 40\% were already engaged in assessment activity. In the North West, $40 \%$ would develop a plan soon, $40 \%$ of the programs were developing an assessment plan, and 20\% had already developed a plan.

Table 20

Assessment Plan Development by Region

\begin{tabular}{|c|c|c|c|c|c|c|c|c|c|c|c|c|}
\hline \multirow[b]{2}{*}{ Region } & \multicolumn{2}{|c|}{$\begin{array}{c}\text { Not } \\
\text { Created }\end{array}$} & \multicolumn{2}{|c|}{$\begin{array}{c}\text { Will } \\
\text { develop } \\
\text { soon } \\
\end{array}$} & \multicolumn{2}{|c|}{$\begin{array}{c}\text { In the } \\
\text { development } \\
\text { stage }\end{array}$} & \multicolumn{2}{|c|}{$\begin{array}{c}\text { Plan } \\
\text { has been } \\
\text { developed } \\
\end{array}$} & \multicolumn{2}{|c|}{$\begin{array}{c}\text { Plan } \\
\text { Implemented }\end{array}$} & \multicolumn{2}{|c|}{ Total } \\
\hline & $\mathrm{N}$ & $\%$ & $\mathrm{~N}$ & $\%$ & $\mathrm{~N}$ & $\%$ & $\mathrm{~N}$ & $\%$ & $\mathrm{~N}$ & $\%$ & $\mathrm{~N}$ & $\%$ \\
\hline Middle States & 2 & 12 & 2 & 12 & 8 & 47 & 4 & 23 & 1 & 6 & 17 & 100 \\
\hline New England & 0 & 0 & 0 & 0 & 1 & 100 & 0 & 0 & 0 & 0 & 1 & 100 \\
\hline North Central & 3 & 7 & 5 & 11 & 13 & 29 & 6 & 13 & 18 & 40 & 45 & 100 \\
\hline North West & 0 & 0 & 2 & 40 & 2 & 40 & 1 & 20 & 0 & 0 & 5 & 100 \\
\hline Southern & 5 & 22 & 1 & 4 & 5 & 22 & 3 & 13 & 9 & 39 & 23 & 100 \\
\hline Western & 0 & 0 & 0 & 0 & 1 & 20 & 1 & 20 & 3 & 60 & 5 & 100 \\
\hline
\end{tabular}

Of the Southern region responses, 22\% had not created an assessment plan, 4\% would develop one soon, 22\% were developing an assessment plan, 13\% had already developed one, and 39\% had implemented an assessment plan. In the Western region, all of the programs were engaged in assessment activity, 20\% were in the development stage, another 20\% had already developed a plan, and 60\% had implemented an assessment plan.

Stage of Development of Assessment Plan by Size

Accounting program chairs identified the size of their student enrollment within their accounting programs. Of the reporting accounting programs with small (less than 200) student enrollment, 16\% had not created an assessment plan, 9\% stated they would develop a plan soon, 37\% of the accounting programs reported assessment plans in the development stage, $12 \%$ indicated they had developed an assessment plan, and $26 \%$ reported they had implemented an assessment plan (See Table 21). 
The accounting programs with mid-size student enrollment (between 200 to 400) indicated that $8 \%$ had not created an assessment plan, another $8 \%$ would soon develop one soon, $21 \%$ were developing one, another $21 \%$ had developed a plan, and $42 \%$ of the accounting programs had implemented an assessment plan.

Table 21

Assessment Plan Development by Size

\begin{tabular}{|c|c|c|c|c|c|c|c|c|c|c|c|c|}
\hline \multirow[b]{2}{*}{ Size } & \multicolumn{2}{|c|}{$\begin{array}{c}\text { Not } \\
\text { Created }\end{array}$} & \multicolumn{2}{|c|}{$\begin{array}{c}\text { Will } \\
\text { develop } \\
\text { soon }\end{array}$} & \multicolumn{2}{|c|}{$\begin{array}{c}\text { In the } \\
\text { development } \\
\text { stage }\end{array}$} & \multicolumn{2}{|c|}{$\begin{array}{r}\text { Plan } \\
\text { has been } \\
\text { developed } \\
\end{array}$} & \multicolumn{2}{|c|}{$\begin{array}{c}\text { Plan } \\
\text { Implemented }\end{array}$} & \multicolumn{2}{|c|}{ Total } \\
\hline & $\mathrm{N}$ & $\%$ & $\mathrm{~N}$ & $\%$ & $\mathrm{~N}$ & $\%$ & $\mathrm{~N}$ & $\%$ & $\mathrm{~N}$ & $\%$ & $\mathrm{~N}$ & $\%$ \\
\hline Small & 7 & 16 & 4 & 9 & 16 & 37 & 5 & 12 & 11 & 26 & 43 & $\overline{100}$ \\
\hline Mid-size & 3 & 8 & 3 & 8 & 8 & 21 & 8 & 21 & 16 & 42 & 38 & 100 \\
\hline Large & 0 & 0 & 3 & 28 & 4 & 36 & 0 & 0 & 4 & 36 & 11 & 100 \\
\hline
\end{tabular}

Note. Small $<200$; Mid-size $=200-400$; Large $>400$.

The accounting programs in the large group (more than 400 students in each program) reported that $28 \%$ would develop an assessment plan soon, $36 \%$ were in the developmental stages, and 36\% had implemented one.

\section{Frequency of Assessment Activity}

The accounting program chairs were asked to indicate how often assessment occurred at their institutions by selecting one of the following answer choices: 1) episodic, 2) periodic, or 3) on-going. Episodic assessment is defined as assessment activity that occurs during program review, for accreditation purposes, or as needed. Periodic assessment is defined as occurring periodically, but it is not an integral part of the accounting program, and on-going assessment is a routine activity in the program.

Frequency of Assessment by Carnegie Classification

Survey results (See Table 22) for the doctoral institutions revealed that $23 \%$ of the doctoral programs reported episodic assessment activity, $12 \%$ reported periodic, and 65\% of them reported on-going assessment activity. 
Table 22

Frequency of Assessment Activity by Carnegie Classification

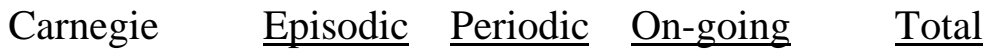

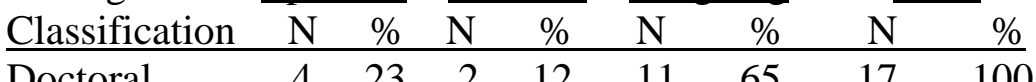

$\begin{array}{lllllllll}\text { Master's } & 10 & 21 & 16 & 33 & 22 & 46 & 48 & 100\end{array}$

\begin{tabular}{lllllllll} 
Baccalaureate & 6 & 25 & 4 & 17 & 14 & 58 & 24 & 100 \\
\hline
\end{tabular}

The findings also showed that $21 \%$ of the master's programs reported episodic assessment activity, 33\% reported periodic, and 46\% reported on-going assessment activity. The baccalaureate programs reported that $25 \%$ were engaged in episodic assessment activity, 17\% were involved in periodic, and 58\% reported on-going assessment activity.

Frequency of Assessment by Region

An analysis of the frequency of assessment activity by region revealed that $35 \%$ of the accounting programs in the Middle States region were engaged in episodic assessment activity, 30\% were involved in periodic assessment, and 35\% were engaged in on-going assessment activity (See Table 23).

Table 23

Frequency of Assessment Activity by Region

\begin{tabular}{|c|c|c|c|c|c|c|c|c|}
\hline \multirow[b]{2}{*}{ Region } & \multicolumn{2}{|c|}{ Episodic } & \multicolumn{2}{|c|}{ Periodic } & \multicolumn{2}{|c|}{ On-going } & \multicolumn{2}{|c|}{ Total } \\
\hline & $\mathrm{N}$ & $\%$ & $\mathrm{~N}$ & $\%$ & $\mathrm{~N}$ & $\%$ & $\mathrm{~N}$ & $\%$ \\
\hline Middle States & 6 & 35 & 5 & 30 & 6 & 35 & 17 & 100 \\
\hline New England & 1 & 100 & 0 & 0 & 0 & 0 & 1 & 100 \\
\hline North Central & 8 & 19 & 10 & 23 & 25 & 58 & 43 & 100 \\
\hline North West & 0 & 0 & 0 & 0 & 5 & 100 & 5 & 100 \\
\hline Southern & 5 & 28 & 5 & 28 & 8 & 44 & 18 & 100 \\
\hline Western & 0 & 0 & 2 & 40 & 3 & 60 & 5 & 100 \\
\hline
\end{tabular}

In the New England category, only one program responded, and that program reported episodic assessment activity. In the North Central region, 19\% of the respondents reported episodic activity, 23\% indicated they were involved in periodic assessment, and 58\% reported on-going assessment activity. 
The North West reported $100 \%$ of the programs were engaged in on-going assessment activity. In the Southern region, $28 \%$ of the programs reported episodic assessment, another $28 \%$ reported periodic, and $44 \%$ reported on-going assessment activity. In the Western area, 40\% reporting periodic activity, and 60\% reported on-going assessment activity.

Frequency of Assessment by Size

The frequency of assessment activities was examined by the size of the student enrollment in the accounting program. Assessment activity responses indicated that $24 \%$ of the programs in the small category reported episodic assessment activity, 29\% reported periodic assessment, and 47\% reported on-going assessment activity (See Table 24). Of the programs in the mid-size category, 19\% reported episodic activity, another 19\% reported periodic, and $62 \%$ of the programs reported on-going assessment activity.

Responses from colleges and universities in the large category indicated that $27 \%$ were engaged in episodic assessment activity, another $27 \%$ reported periodic activity, and $46 \%$ reported ongoing assessment activity.

Table 24

Frequency of Assessment Activity by Size

\begin{tabular}{|c|c|c|c|c|c|c|c|c|}
\hline \multirow[b]{2}{*}{ Size } & \multicolumn{2}{|c|}{ Episodic } & \multicolumn{2}{|c|}{$\underline{\text { Periodic }}$} & \multicolumn{2}{|c|}{ On-going } & \multicolumn{2}{|c|}{ Total } \\
\hline & $\mathrm{N}$ & $\%$ & $\mathrm{~N}$ & $\%$ & $\mathrm{~N}$ & $\%$ & $\mathrm{~N}$ & $\%$ \\
\hline Small & 9 & 24 & 11 & 29 & 18 & 47 & 38 & 100 \\
\hline Mid-size & 7 & 19 & 7 & 19 & 22 & 62 & 36 & 100 \\
\hline Large & 3 & 27 & 3 & 27 & 5 & 46 & 11 & 100 \\
\hline
\end{tabular}

Note. Small < 200; Mid-size $=200-400$; Large $>400$.

Assessment Activity at Academic Level

Participants were asked to indicate at what point(s) in the students' programs of study assessment activities were conducted (See Table 25). The choices were Freshman (F), Sophomore (SO), Junior (J), Senior (SR), and Post-graduate (P-G). Of the 102 returned 
questionnaires, 81 of the respondents indicated that their accounting programs conducted assessment activity at least once in a student's academic career. The responses were not analyzed by the three treatment conditions (Carnegie Classification, region, and size) due to the scope of the analysis.

Table 25. Assessment Activity at Academic Level

\section{Frequency of Assessment Activity}

\begin{tabular}{|c|c|c|c|c|c|c|c|c|c|c|c|}
\hline \multicolumn{2}{|c|}{ Once } & \multicolumn{2}{|c|}{ Twice } & \multicolumn{2}{|c|}{ Three Times } & \multicolumn{2}{|c|}{ Four Times } & \multicolumn{2}{|c|}{$\underline{\text { Five times }}$} & \multicolumn{2}{|c|}{$\underline{\text { Total }}$} \\
\hline $\mathrm{N}$ & $\%$ & $\mathrm{~N}$ & $\%$ & $\mathrm{~N}$ & $\%$ & $\mathrm{~N}$ & $\%$ & $\mathrm{~N}$ & $\%$ & $\mathrm{~N}$ & $\%$ \\
\hline 16 & 20 & 17 & 21 & 22 & $27 *$ & 20 & 25 & 6 & 7 & 81 & 100 \\
\hline
\end{tabular}

Twenty percent of the participants indicated that assessment occurred only once. Most likely, it was during the senior year, because $16 \%$ of the respondents reported that assessment activity that occurred once was conducted in the senior year. Three percent of the responses reported assessment activity during the junior year only, and one percent stated that assessment occurred during the sophomore year only.

Twenty-one percent of the respondents reported that students were assessed twice during their academic careers. Assessment occurred in the freshman and senior years in 3\% of the programs, in the junior year and post-graduate at $1 \%$, in the junior and senior years at $6 \%$, in the sophomore and senior years at $4 \%$, and in the senior year and post-graduate level at $7 \%$ of the accounting programs.

Responses from $27 \%$ of the programs revealed that assessment activity occurred three times during a student's program of study. Twelve percent of the respondents reported assessment occurred at the sophomore, junior, and senior levels; $10 \%$ indicated assessment occurred at the junior, senior, and post-graduate levels; and 1\% reported assessment at the freshman, senior, and post-graduate levels. One percent of the respondents reported 
assessment at the freshman, sophomore, and senior levels; another $1 \%$ indicated assessment occurred at the sophomore, senior, and post-graduate levels, and the remaining $1 \%$ stated that assessment occurred at the sophomore, junior, and post-graduate levels.

Assessment occurred four times during a student's academic career at $25 \%$ of the reporting programs. The participants reported assessment activity at $14 \%$ of the programs at the sophomore, junior, senior, and post-graduate levels. The administrators reported assessment activity occurred four times for students at another $11 \%$ of the programs as well, but these programs conducted assessment at the freshman level instead of post-graduate. Of the 81 reporting participants, 7\% reported assessment activity at all levels: the freshman, sophomore, junior, senior, and post-graduate levels.

\section{Accounting Programs and Assessment Plans}

Information about the stated purpose of the accounting program and its assessment plan, the collection of assessment data, the focus of the assessment process, and the student learning outcomes was obtained. The Likert scale responses were analyzed on a scale of 1-5 as follows: 1-Extensively, 2-Often, 3-Somewhat, 4-Very Little, and 5-Not At All. The responses from the New England $(n=1)$, North West $(n=5)$, and Western $(n=5)$, regions were excluded from all of the Analyses of Variance (ANOVA) by region conducted in this study due to insufficient response rates.

\section{Accounting Programs and Assessment Plans by Carnegie Classification}

Leaders of the accounting programs were asked if the accounting program had a clear explicitly stated purpose that guided assessment in the program (See Table 26). The doctoral programs had a clear explicitly stated purpose that guided assessment extensively, and the master's and baccalaureate accounting programs often had a clear explicitly stated purpose. 
Respondents also indicated that assessment data were collected and analyzed often and that assessment focused on student learning often at all three classifications.

Table 26

Accounting Programs and Assessment Plans by Carnegie Classification

Group 1 Group 2 Group 3

And Assessment Plans

$\mathrm{D}$

$\mathrm{M}$

B

Stated purpose ${ }^{\mathrm{a}}$

$\begin{array}{cccccc}\text { M } & \text { SD } & \text { M } & \text { SD } & \text { M } & \text { SD } \\ 1.50 & .73 & 2.35 & 1.18 & 2.37 & 1.28\end{array}$

Assessment data collected and analyzed ${ }^{\mathrm{a}}$

Improves student learning ${ }^{\mathrm{b}}$

$\begin{array}{llllll}2.06 & .77 & 2.45 & 1.10 & 2.50 & .93\end{array}$

Accountability

$\begin{array}{llllll}1.75 & .77 & 2.20 & 1.02 & 2.17 & .94\end{array}$

Reflects program goals, etc ${ }^{c}$

$\begin{array}{llllll}2.38 & .81 & 2.53 & 1.06 & 2.70 & .93\end{array}$

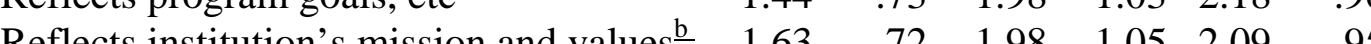

Note. $\mathrm{D}=$ Doctoral; $\mathrm{M}=$ Master's; $\mathrm{B}=$ Baccalaureate.

${ }^{a} n=96,{ }^{b} n=95,{ }^{c} n=94$.

Participants reported that assessment often focused on accountability at the doctoral institutions, and somewhat focused on accountability at the master's and baccalaureate ones. Respondents indicated that the student learning outcomes often reflected the accounting programs’ goals and objectives for learning at the master's and baccalaureate institutions, and extensively reflected the programs' goals and objectives at the doctoral programs. The responses also indicated that student learning outcomes often reflected the institution’s mission and its values at programs in all three classifications.

Accounting Programs and Assessment Plans by Region

The participants’ responses were also analyzed by region, and the means and standard deviations were calculated for comparison (See Table 27). The respondents indicated that the accounting programs often had a clear explicitly stated purpose that guided assessment in all of the regions. The responses indicated that assessment data were collected and analyzed somewhat in the Middle States region and often at the North Central and Southern regions. 
In addition, the results indicated that assessment focused on improving student learning often at these accounting programs.

Table 27

Accounting Programs and Assessment Plans by Region

Accounting Programs

$\frac{\text { Group 1 }}{\mathrm{MS}} \quad \frac{\text { Group 2 }}{\mathrm{NC}} \quad \frac{\text { Group 3 }}{\mathrm{S}}$

and Assessment Plans

M $\quad$ SD $\quad$ M $\quad$ SD $\quad M \quad$ SD

Stated purpose ${ }^{\mathrm{a}}$

$\begin{array}{llllll}2.24 & 1.39 & 2.30 & 1.23 & 2.16 & .90\end{array}$

Assessment data collected and analyzed ${ }^{\mathrm{a}}$

Improves student learning ${ }^{\mathrm{b}}$

Accountability

2.71

1.21

$.97 \quad 2.05$

1.03

Reflects program goals, etc ${ }^{c}$

2.25

1.13

$1.04 \quad 1.84$

2.50

$1.15 \quad 2.63$

$.95 \quad 2.26$

.76

Reflects institution's mission and values $\underline{\text { b }}$

1.69

$87 \quad 2.14$

$1.14 \quad 1.74$

.99

Note. $\mathrm{MS}=$ Middle States; $\mathrm{NC}=$ North Central; $\mathrm{S}=$ Southern.

${ }^{a} n=85,{ }^{b} n=84,{ }^{c} n=83$.

Assessment focused on accountability somewhat in the North Central region programs, and accountability was often the focus of assessment at the Middle States and Southern regions. The participants also indicated that student learning outcomes reflected the accounting program goals and the institutions' mission and values often at the accounting programs in all of the regions.

\section{Accounting Programs and Assessment Plans by Size}

The responses were also analyzed by size to determine the means and standard deviation for comparison (See Table 28). Responses indicated that the accounting programs in the small, mid-size, and large categories often had a clear explicitly stated purpose that guided assessment in the program.

Participants reported that assessment data were collected and analyzed somewhat at the accounting programs in the small group, and often at the mid-size and large programs. The respondents indicated that the accounting programs focused often on improving student learning at the programs in all of the categories by size. Accountability was often the focus 
of assessment at mid-size programs and somewhat at small and large ones. Student learning outcomes reflected the programs' goals and the institutions' mission and values often at the accounting programs in the size categories.

Table 28

Accounting Programs and Assessment Plans by Size

\begin{tabular}{|c|c|c|c|c|c|c|}
\hline \multirow{3}{*}{$\begin{array}{l}\text { Accounting Programs } \\
\text { and Assessment Plans }\end{array}$} & \multicolumn{2}{|c|}{ Group 1} & \multicolumn{2}{|c|}{ Group 2} & \multicolumn{2}{|c|}{ Group 3} \\
\hline & \multicolumn{2}{|c|}{$\mathrm{S}$} & \multicolumn{2}{|c|}{$\mathrm{M}$} & \multicolumn{2}{|c|}{$\mathrm{L}$} \\
\hline & $\mathrm{M}$ & SD & $\mathrm{M}$ & SD & $\mathrm{M}$ & SD \\
\hline Stated purpose $^{\mathrm{a}}$ & 2.42 & 1.31 & 1.97 & 1.07 & 2.00 & .94 \\
\hline Assessment data collected and analyzed ${ }^{\mathrm{a}}$ & 2.53 & 1.08 & 2.22 & .95 & 2.40 & .97 \\
\hline Improves student learning & 2.27 & 1.99 & 1.86 & .98 & 2.40 & .84 \\
\hline Accountability ${ }^{\mathrm{b}}$ & 2.62 & 1.01 & 2.35 & 1.03 & 2.90 & .74 \\
\hline Reflects program goals, etc ${ }^{c}$ & 2.17 & 1.06 & 1.76 & .98 & 1.80 & .79 \\
\hline Reflects institution's mission and values ${ }^{\mathrm{C}}$ & 2.16 & 1.09 & 1.81 & .94 & 1.80 & .63 \\
\hline
\end{tabular}

Note. $\mathrm{S}=$ Small $<200 ; \mathrm{M}=$ Mid-size $=200-400 ; \mathrm{L}=$ Large $>400$.

${ }^{a} \mathrm{n}=92^{\mathrm{b}} \mathrm{n}=91,{ }^{\mathrm{c}} \mathrm{n}=90$.

\section{Research Question 1: Differences in Essential Skills Addressed in Accounting Programs}

Research question one asked if there were significant differences in how extensively the essential skills under study (critical thinking, information literacy, oral communication, problem solving, and written communication) were addressed across the treatment conditions.

Research Question 1a: Differences in Essential Skills Addressed in Accounting Programs by Carnegie Classification

Participants’ responses were analyzed first by Carnegie Classification (See Table 29). An Analysis of Variance (ANOVA) was computed for each of the five dependent variables (critical thinking, information literacy, oral communication, problem solving, and written communication). The independent variable in each one-way, between subjects ANOVA was Carnegie Classification (doctoral versus master's versus baccalaureate). The ANOVA for critical thinking yielded $\mathrm{F}(2,93)=.133, \mathrm{p}<.05$ and was not significant. The ANOVA for 
information literacy yielded $(\mathrm{F}(2,92)=.611, \mathrm{p}<.05)$ and was not significant. The ANOVA for oral communication yielded $\mathrm{F}(2,92)=.579, \mathrm{p}<.05$ and was not significant. The ANOVA for problem solving yielded $\mathrm{F}(2,92)=.123, \mathrm{p}<.05$ and was not significant. The ANOVA for written communication yielded $\mathrm{F}(2,92)=.768, \mathrm{p}<.05$ and was not significant.

Table 29

Essential Skills Addressed by Carnegie Classification

\begin{tabular}{|c|c|c|c|c|c|c|c|}
\hline \multirow[b]{2}{*}{ Essential Skills Addressed } & \multicolumn{2}{|c|}{$\frac{\text { Group } 1}{\mathrm{D}}$} & \multicolumn{2}{|c|}{$\frac{\text { Group } 2}{\mathrm{M}}$} & \multicolumn{2}{|c|}{$\frac{\text { Group } 3}{\mathrm{~B}}$} & \multirow[b]{2}{*}{$\mathrm{F}$} \\
\hline & $\mathrm{M}$ & SD & M & SD & $\mathrm{M}$ & SD & \\
\hline Critical Thinking $^{\mathrm{a}}$ & 1.56 & .73 & 1.65 & .64 & 1.67 & .64 & .133 \\
\hline Information Literacy ${ }^{\mathrm{b}}$ & 1.69 & .79 & 1.90 & .65 & 1.92 & .78 & .611 \\
\hline Oral Communication $^{\mathrm{b}}$ & 2.00 & .63 & 2.08 & .89 & 2.25 & .61 & .579 \\
\hline Problem Solving & 1.38 & .50 & 1.45 & .61 & 1.46 & .51 & .123 \\
\hline Written Communication $^{\underline{b}}$ & 1.94 & .77 & 1.94 & .75 & 2.17 & .82 & .768 \\
\hline
\end{tabular}

Note. $\mathrm{D}$ = Doctoral; $\mathrm{M}$ = Master's; B = Baccalaureate.

${ }^{a} n=96,{ }^{b} n=95$.

Critical thinking, information literacy, oral communication, and written communication were addressed often, and problem solving was addressed extensively in the accounting programs in the Carnegie Classifications.

Research Question 1b: Essential Skills Addressed in Accounting Programs by Region

The responses were also analyzed by region to determine if significant differences existed in the responses (See Table 30). Due to the sparse response in three of the six geographic regions, New England $(n=1)$, North West $(n=5)$, and Western $(n=5)$, responses from these regions were excluded from all of the analyses by region.

An Analysis of Variance (ANOVA) was computed for each of the five dependent variables (critical thinking, information literacy, oral communication, problem solving, and written communication). The independent variable in each one-way, between subjects ANOVA was region (middle states versus north central versus southern). 
The ANOVA for critical thinking yielded $\mathrm{F}(2,82)=.302, \mathrm{p}<.05$ and was not significant. The ANOVA for information literacy yielded $F(2,81)=.482, \mathrm{p}<.05$ and was not significant. The ANOVA for oral communication yielded $F(2,81)=.936, \mathrm{p}<.05$ and was not significant. The ANOVA for problem solving yielded $F(2,81)=.723, \mathrm{p}<.05$ and was not significant. The ANOVA for written communication yielded $F(2,81)=1.117$, p < .05 and was not significant.

Table 30

Essential Skills Addressed by Region

\begin{tabular}{|c|c|c|c|c|c|c|c|}
\hline \multirow{2}{*}{ Essential Skills Addressed } & \multicolumn{2}{|c|}{$\frac{\text { Group } 1}{\mathrm{MS}}$} & \multicolumn{2}{|c|}{$\frac{\text { Group } 2}{\mathrm{NC}}$} & \multicolumn{2}{|c|}{ Group 3} & \multirow[b]{2}{*}{$\mathrm{F}$} \\
\hline & M & SD & $\mathrm{M}$ & SD & $\mathrm{M}$ & SD & \\
\hline $\begin{array}{l}\text { Critical Thinking } \\
\text { a }\end{array}$ & 1.69 & .70 & 1.60 & .58 & 1.74 & .73 & .302 \\
\hline Information Literacy ${ }^{b}$ & 1.75 & .77 & 1.95 & .71 & 1.89 & .66 & .482 \\
\hline Oral Communication $^{\mathrm{b}}$ & 1.87 & .81 & 2.18 & .81 & 2.16 & .69 & .936 \\
\hline Problem Solving & 1.38 & .62 & 1.41 & .54 & 1.58 & .61 & .723 \\
\hline Written Communication ${ }^{\underline{b}}$ & 1.69 & .70 & 2.02 & .82 & 2.21 & .63 & 1.117 \\
\hline
\end{tabular}

Note. MS = Middle States; $\mathrm{NC}=$ North Central; $\mathrm{S}=$ Southern.

${ }^{a} \mathrm{n}=85,{ }^{b} \mathrm{n}=84$.

Participants indicated that critical thinking, information literacy, oral communication, and written communication were addressed often in the accounting programs in the reporting regions. The responses revealed that problem solving, however, was addressed often at the programs in the Southern regions, and extensively in the Middle States and North Central. Research Question 1c: Essential Skills Addressed in Accounting Programs by Size The responses were also analyzed by size (See Table 31). An Analysis of Variance (ANOVA) was computed for each of the five dependent variables (critical thinking, information literacy, oral communication, problem solving, and written communication). The independent variable in each one-way, between subjects ANOVA was size (small versus mid-size versus large). 
Table 31

Essential Skills Addressed by Size

\begin{tabular}{|c|c|c|c|c|c|c|c|}
\hline \multirow[t]{2}{*}{ Essential Skills Addressed } & \multicolumn{2}{|c|}{$\frac{\text { Group } 1}{\mathrm{~S}}$} & \multicolumn{2}{|c|}{$\frac{\text { Group } 2}{M}$} & \multicolumn{2}{|c|}{$\frac{\text { Group 3 }}{L}$} & \multirow[b]{2}{*}{$\mathrm{F}$} \\
\hline & M & SD & M & SD & $\mathrm{M}$ & $\mathrm{SD}$ & \\
\hline Critical Thinking ${ }^{\mathrm{a}}$ & 1.59 & .64 & 1.62 & .64 & 1.80 & .79 & .389 \\
\hline Information Literacy ${ }^{b}$ & 1.92 & .78 & 1.81 & .62 & 1.70 & .82 & .456 \\
\hline Oral Communication ${ }^{\mathrm{b}}$ & 2.28 & .79 & 2.05 & .81 & 1.80 & .42 & 1.647 \\
\hline Problem Solving ${ }^{\mathrm{b}}$ & 1.37 & .49 & 1.49 & .61 & 1.50 & .71 & .476 \\
\hline Written Communication $^{\underline{b}}$ & 2.21 & .84 & 1.92 & .72 & 1.60 & .52 & 1.219 \\
\hline
\end{tabular}

Note. $\mathrm{S}=$ Small $<200 ; \mathrm{M}=$ Mid-size $=200-400 ; \mathrm{L}=$ Large $>400$.

${ }^{a} \mathrm{n}=92,{ }^{b} \mathrm{n}=91$.

The ANOVA for critical thinking yielded $\mathrm{F}(2,89)=.389, \mathrm{p}<.05$ and was not significant. The ANOVA for information literacy yielded $\mathrm{F}(2,88)=.456, \mathrm{p}<.05$ and was not significant. The ANOVA for oral communication yielded $\mathrm{F}(2,88)=1.647, \mathrm{p}<.05$ and was not significant. The ANOVA for problem solving yielded $F(2,88)=.476, p<.05$ and was not significant. The ANOVA for written communication yielded $F(2,88)=1.219, \mathrm{p}<$ .05 and was not significant. When the responses were analyzed by student enrollment, critical thinking, information literacy, oral communication, and written communication were addressed often as learning outcomes in the small, mid-size, and large accounting programs. Problem solving, however, was addressed extensively at the programs in the size categories.

Research Question 2: Essential Skills Identified as Learning Outcomes in Accounting Programs

The respondents were asked to indicate how extensively the essential skills were identified as student learning outcomes in the accounting programs' assessment plans. Survey results were analyzed to determine if significant differences existed among the responses. 
Research Question 2a: Essential Skills Identified as Learning Outcomes by Carnegie Classification

An Analysis of Variance (ANOVA) was computed (See Table 32) for each of the five dependent variables (critical thinking, information literacy, oral communication, problem solving, and written communication). The independent variable in each one-way, between subjects ANOVA was Carnegie Classification (doctoral versus master’s versus baccalaureate).

Table 32 Essential Skills Identified as Learning Outcomes by Carnegie Classification

\begin{tabular}{|c|c|c|c|c|c|c|c|}
\hline \multirow[b]{2}{*}{ Essential Skills Identified } & \multicolumn{2}{|c|}{$\frac{\text { Group } 1}{\mathrm{D}}$} & \multicolumn{2}{|c|}{$\frac{\text { Group } 2}{M}$} & \multicolumn{2}{|c|}{$\frac{\text { Group } 3}{\mathrm{~B}}$} & \multirow[b]{2}{*}{$\mathrm{F}$} \\
\hline & M & $\mathrm{SD}$ & $\mathrm{M}$ & SD & $\mathrm{M}$ & SD & \\
\hline Critical Thinking $^{\mathrm{a}}$ & 1.87 & .92 & 1.94 & 1.05 & 2.13 & 1.01 & .383 \\
\hline Information Literacy $^{\mathrm{a}}$ & 2.07 & .88 & 2.27 & 1.06 & 2.30 & 1.18 & .254 \\
\hline Oral Communication $^{a}$ & 1.93 & .80 & 2.43 & 1.24 & 2.35 & .93 & 1.167 \\
\hline Problem Solving ${ }^{\mathrm{a}}$ & 1.53 & .74 & 1.84 & 1.05 & 1.91 & 1.00 & .728 \\
\hline Written Communication $^{\underline{b}}$ & 2.07 & .96 & 2.29 & 1.20 & 2.17 & 1.07 & .253 \\
\hline
\end{tabular}

Note. $\mathrm{D}$ = Doctoral; $\mathrm{M}$ = Master's; B = Baccalaureate. ${ }^{\mathrm{a}} \mathrm{n}=96^{\mathrm{b}} \mathrm{n}=95$.

The ANOVA for critical thinking yielded $\mathrm{F}(2,93)=.383, \mathrm{p}<.05$ and was not significant. The ANOVA for information literacy yielded $F(2,93)=.254, p<.05$ and was not significant. The ANOVA for oral communication yielded $F(2,93)=1.167, \mathrm{p}<.05$ and was not significant. The ANOVA for problem solving yielded $F(2,93)=.728, p<.05$ and was not significant. The ANOVA for written communication yielded $F(2,92)=.253$, $p<$ .05 and was not significant.

When analyzed by classification, critical thinking, information literacy, problem solving, oral communication, and written communication all were identified as student learning outcomes often at the accounting programs in all of the Carnegie Classifications. 


\section{Research Question 2b: Essential Skills Identified as Learning Outcomes by Region}

The responses were analyzed by region to determine if significant differences existed in how extensively the essential skills were identified as learning outcomes (See Table 33). An Analysis of Variance (ANOVA) was computed for each of the five dependent variables (critical thinking, information literacy, oral communication, problem solving, and written communication). The independent variable in each one-way, between subjects ANOVA was region (middle states versus north central versus southern).

Table 33

Essential Skills Identified as Learning Outcomes by Region

\begin{tabular}{|c|c|c|c|c|c|c|c|}
\hline \multirow{3}{*}{ Essential Skills Identified } & \multicolumn{2}{|c|}{ Group 1} & \multicolumn{2}{|c|}{ Group 2} & \multicolumn{2}{|c|}{ Group 3} & \multirow[b]{3}{*}{$\mathrm{F}$} \\
\hline & \multicolumn{2}{|c|}{ MS } & \multicolumn{2}{|c|}{$\mathrm{NC}$} & \multicolumn{2}{|c|}{$\bar{S}$} & \\
\hline & M & $\mathrm{SD}$ & $\mathrm{M}$ & SD & $\mathrm{M}$ & SD & \\
\hline Critical Thinking $^{\mathrm{a}}$ & 1.82 & .81 & 2.02 & 1.09 & 2.06 & .87 & .305 \\
\hline Information Literacy $^{\mathrm{a}}$ & 1.88 & .86 & 2.52 & 1.11 & 2.06 & .80 & 2.078 \\
\hline Oral Communication $^{a}$ & 2.18 & 1.13 & 2.29 & 1.13 & 2.44 & .92 & .272 \\
\hline Problem Solving $^{\mathrm{a}}$ & 1.53 & .72 & 1.88 & 1.11 & 1.89 & .76 & .898 \\
\hline Written Communication $^{\mathrm{b}}$ & 1.94 & 1.09 & 2.20 & 1.12 & 2.50 & 1.04 & 1.143 \\
\hline
\end{tabular}

Note. $\mathrm{MS}=$ Middle States; NC = North Central; $\mathrm{S}=$ Southern.

${ }^{\mathrm{a}} \mathrm{n}=85,{ }^{\mathrm{b}} \mathrm{n}=83$.

The ANOVA for critical thinking yielded $\mathrm{F}(2,82)=.305, \mathrm{p}<.05$ and was not significant. The ANOVA for information literacy yielded $F(2,82)=2.078, \mathrm{p}<.05)$, and was not significant. The ANOVA for oral communication yielded $F(2,82)=.272$, $\mathrm{p}<.05$ and was not significant. The ANOVA for problem solving yielded $\mathrm{F}(2,82)=.898, \mathrm{p}<.05$ and was not significant. The ANOVA for written communication yielded $F(2,80)=1.143$, $\mathrm{p}<.05$ and was not significant.

Respondents indicated that critical thinking, oral communication, problem solving, and written communication often were identified as student learning outcomes in the accounting programs in all three of the regions analyzed. Information literacy somewhat was 
identified as a student learning outcome at the programs in the North Central region and often identified at the programs in the Middle States and Southern regions.

Research question 2c: Essential skills Identified as Learning Outcomes by Size

The assessment data were analyzed by student enrollment to determine if significant differences existed in how extensively essential skills were identified as student learning outcomes by size (See Table 34).

Table 34

Essential Skills Identified as Learning Outcomes by Size

\begin{tabular}{|c|c|c|c|c|c|c|c|}
\hline \multirow{2}{*}{ Essential Skills Identified } & \multicolumn{2}{|c|}{ Group 1} & \multicolumn{2}{|c|}{ Group 2} & \multicolumn{2}{|c|}{ Group 3} & \multirow{2}{*}{$\mathrm{F}$} \\
\hline & $\mathrm{M}$ & SD & $\mathrm{M}$ & $S D$ & $\mathrm{M}$ & SD & \\
\hline Critical Thinking $^{\mathrm{a}}$ & 2.00 & .94 & 1.92 & 1.06 & 2.33 & 1.22 & .587 \\
\hline Information Literacy $^{\mathrm{a}}$ & 2.30 & 1.08 & 2.19 & 1.02 & 2.11 & 1.36 & .151 \\
\hline Oral Communication $^{a}$ & 2.49 & 1.12 & 2.11 & 1.07 & 2.67 & 1.22 & 1.512 \\
\hline Problem Solving $^{\mathrm{a}}$ & 1.76 & .95 & 1.84 & 1.01 & 2.00 & 1.22 & .221 \\
\hline Written Communication $^{\text {a }}$ & 2.33 & 1.20 & 2.14 & 1.06 & 2.33 & 1.32 & .302 \\
\hline
\end{tabular}

Note. $\mathrm{S}=$ Small $<200 ; \mathrm{M}=$ Mid-size $200-400 ; \mathrm{L}=$ Large $>400$.

${ }^{\mathrm{a}} \mathrm{n}=92$.

An Analysis of Variance (ANOVA) was computed for each of the five dependent variables (critical thinking, information literacy, oral communication, problem solving, and written communication). The independent variable in each one-way, between subjects ANOVA was size (small versus mid-size versus large).

The ANOVA for critical thinking yielded $\mathrm{F}(2,89)=.587, \mathrm{p}<.05$ and was not significant. The ANOVA for information literacy yielded $F(2,89)=.151, \mathrm{p}<.05$ and was not significant. The ANOVA for oral communication yielded $F(2,89)=1.512$, $\mathrm{p}<.05$ and was not significant. The ANOVA for problem solving yielded $F(2,89)=.221, \mathrm{p}<.05$ and was not significant. The ANOVA for written communication yielded $\mathrm{F}(2,89)=.302$, $\mathrm{p}<$ .05 and was not significant. 
Critical thinking, information literacy, problem solving, and written communication were identified often as student learning outcomes in the small, mid-size, and large accounting programs. Oral communication was identified often as a student learning outcome at the small and mid-size programs, but it was identified somewhat as a learning outcome at the large accounting programs.

\section{Research Question 3: Essential Skills Addressed in Required Accounting Courses}

Respondents were asked to indicate the extent to which the essential skills under study were addressed in required accounting courses that constitute the core program of study in traditional accounting programs. Participants were asked to review a listing of courses presented in a matrix and circle, in the appropriate cell, (I) if the skill was introduced into the course, (E) if the skill was emphasized in the course, and (NA) if the skill was not addressed in the course.

The responses were analyzed on a scale from 1 to 3 as follows: (1) the skill was introduced into the course, (2) the skill was emphasized in the course, and (3) the skill was not addressed in the course. The responses were not analyzed by the three treatments due to the scope of the analysis.

Research Question 3a: Essential Skills Addressed in Required Accounting Courses: Critical Thinking

The results indicated that critical thinking was introduced in $65 \%$ of the Principles of Financial Accounting (I) courses, emphasized in 30\%, and not addressed in 5\% of them (See Table 35). Principles of Managerial Accounting (II) faculty reported that critical thinking was introduced in $54 \%$ of the courses, emphasized in $42 \%$ of the courses, and not addressed in $4 \%$ of them. Participants reported that critical thinking was introduced in $17 \%$ of the Intermediate Accounting courses, emphasized in $80 \%$, and not addressed in $3 \%$ of them. 
Table 35

Critical Thinking Addressed in Required Accounting Courses

Critical Thinking

\begin{tabular}{lrrrrrrrr}
\multicolumn{1}{c}{ Course } & \multicolumn{3}{c}{$\mathrm{I}$} & \multicolumn{3}{c}{$\mathrm{E}$} & \multicolumn{3}{c}{$\mathrm{NA}$} & \multicolumn{2}{c}{ Total } \\
& $\mathrm{N}$ & $\%$ & $\mathrm{~N}$ & $\%$ & $\mathrm{~N}$ & $\%$ & $\mathrm{~N}$ & $\%$ \\
\hline Principles of Financial Accounting (I) & 55 & 65 & 25 & 30 & 4 & 5 & 84 & 100 \\
Principles of Managerial Accounting (II) & 43 & 54 & 34 & 42 & 3 & 4 & 80 & 100 \\
Intermediate Accounting & 14 & 17 & 67 & 80 & 3 & 3 & 84 & 100 \\
Cost Accounting & 13 & 16 & 65 & 80 & 3 & 4 & 81 & 100 \\
Taxation & 15 & 18 & 63 & 77 & 4 & 5 & 82 & 100 \\
Advanced Accounting & 5 & 7 & 61 & 83 & 7 & 10 & 73 & 100 \\
Auditing & 3 & 4 & 73 & 90 & 5 & 6 & 81 & 100 \\
Accounting Information Systems & 12 & 17 & 51 & 74 & 6 & 9 & 69 & 100 \\
\hline
\end{tabular}

Note: I = Introduced; E= Emphasized; and NA = Not Addressed.

In Cost Accounting, results showed that critical thinking was introduced in $16 \%$ of the courses, emphasized in $80 \%$ of them, and not addressed in $4 \%$ of the courses. In Tax courses, the respondents indicated that critical thinking was introduced in $18 \%$ of the courses, emphasized in77\%, and not addressed in 5\% of the courses.

In Advanced Accounting, participants indicated that critical thinking was introduced, in $7 \%$ of the courses, emphasized in $83 \%$ of the course, and not addressed in $10 \%$. The respondents indicated that critical thinking was introduced in $4 \%$ of the Auditing courses, emphasized in $90 \%$, and not addressed in $6 \%$ of the courses. The participants reported that critical thinking was introduced in $17 \%$ of the Accounting Information Systems (AIS) courses, emphasized in another $74 \%$, and not addressed in $9 \%$ of the courses.

Research Question 3b: Essential Skills Addressed in Required Accounting Courses: Information Literacy

The responses indicated that Information literacy was introduced in 52\% of the Principles of Financial Accounting (I) courses, emphasized in 20\%, but not addressed in 28\% of them (See Table 36). Participants reported that information literacy was introduced in 
47\% of the Principles of Accounting (II) courses, emphasized in 23\% of the courses, and not addressed in $30 \%$ of them.

Additionally, respondents reported that information literacy was introduced in $32 \%$ of the Intermediate Accounting courses, emphasized in 55\%, and not addressed at all in 13\% of them. Information literacy was introduced in $28 \%$ of the Cost Accounting courses, emphasized in 52\%, and not addressed in $20 \%$ of the courses.

In the Taxation courses, respondents indicated that information literacy was introduced in $16 \%$ of the courses, emphasized in $75 \%$, and not introduced in $9 \%$ of the courses. Participants reported that information literacy was introduced in $26 \%$ of the Advanced Accounting courses, emphasized in 62\%, and not addressed in $12 \%$ of them. The responses indicated that information literacy was introduced in $12 \%$ of the Auditing courses, emphasized in $74 \%$, and not addressed in $14 \%$ of them.

Table 36

Information Literacy Addressed in Required Accounting Courses

\begin{tabular}{lrrrrrrrr}
\hline \multirow{2}{*}{ Course } & \multicolumn{9}{c}{ Information Literacy } \\
\cline { 2 - 10 } & \multicolumn{1}{c}{ I } & \multicolumn{1}{c}{ E } & \multicolumn{1}{c}{ NA } & \multicolumn{3}{c}{ Total } \\
& $\mathrm{N}$ & $\%$ & $\mathrm{~N}$ & $\%$ & $\mathrm{~N}$ & $\%$ & $\mathrm{~N}$ & $\%$ \\
\hline Principles of Financial Accounting (I) & 44 & 52 & 17 & 20 & 23 & 28 & 84 & 100 \\
Principles of Managerial Accounting (II) & 37 & 47 & 18 & 23 & 24 & 30 & 79 & 100 \\
Intermediate Accounting & 26 & 32 & 45 & 55 & 11 & 13 & 82 & 100 \\
Cost Accounting & 22 & 28 & 42 & 52 & 16 & 20 & 80 & 100 \\
Taxation & 13 & 16 & 60 & 75 & 7 & 9 & 80 & 100 \\
Advanced Accounting & 19 & 26 & 45 & 62 & 9 & 12 & 73 & 100 \\
Auditing & 10 & 12 & 59 & 74 & 11 & 14 & 80 & 100 \\
Accounting Information Systems & 11 & 16 & 49 & 72 & 8 & 12 & 68 & 100 \\
\hline
\end{tabular}

Note: I = Introduced; E= Emphasized; and NA = Not Addressed.

Respondents reported that information literacy was introduced in $16 \%$ of the AIS courses, emphasized in $72 \%$ of the courses, and not addressed at all in $12 \%$ of them.

Research Question 3c: Essential Skills Addressed in Required Accounting Courses: Oral Communication 
The responses indicated that oral communication was introduced in $31 \%$ of the Principles of Financial Accounting (I) courses, emphasized in 2\% of them, and not addressed at all in $67 \%$ of the courses (See Table 37). Respondents reported that oral communication was introduced in 35\% of the Principles of Managerial Accounting (II) courses, emphasized in $5 \%$ of them, and not addressed at all in $60 \%$ of them. Participants reported that oral communication was introduced in $29 \%$ of the Intermediate courses, emphasized in $14 \%$, and not addressed in $57 \%$ of them. They also indicated that oral communication was introduced in $32 \%$ of the Cost courses, emphasized in $23 \%$, but not addressed in $45 \%$ of them.

Respondents stated that oral communication was introduced in 32\% of the Taxation courses, emphasized in $24 \%$ of them, and not addressed in $44 \%$ of the courses.

\section{Table 37}

Oral Communication Addressed in Required Accounting Courses

\section{Oral Communication}

Course

\begin{tabular}{lrrrrrrrr} 
& \multicolumn{3}{c}{$\mathrm{I}$} & \multicolumn{2}{c}{$\mathrm{E}$} & \multicolumn{2}{c}{$\mathrm{NA}$} & \multicolumn{2}{c}{ Total } \\
& $\mathrm{N}$ & $\%$ & $\mathrm{~N}$ & $\%$ & $\mathrm{~N}$ & $\%$ & $\mathrm{~N}$ & $\%$ \\
\hline Principles of Financial Accounting (I) & 26 & 31 & 2 & 2 & 56 & 67 & 84 & 100 \\
Principles of Managerial Accounting (II) & 28 & 35 & 4 & 5 & 48 & 60 & 80 & 100 \\
Intermediate Accounting & 24 & 29 & 12 & 14 & 48 & 57 & 84 & 100 \\
Cost Accounting & 26 & 32 & 18 & 23 & 36 & 45 & 80 & 100 \\
Taxation & 26 & 32 & 20 & 24 & 36 & 44 & 82 & 100 \\
Advanced Accounting & 23 & 31 & 16 & 22 & 34 & 47 & 73 & 100 \\
Auditing & 18 & 22 & 38 & 47 & 25 & 31 & 81 & 100 \\
Accounting Information Systems & 18 & 26 & 19 & 28 & 31 & 46 & 68 & 100 \\
\hline
\end{tabular}

Note: I = Introduced; E= Emphasized; and NA = Not Addressed.

The study found that oral communication was introduced in 31\% in Advanced

Accounting courses, emphasized in $22 \%$ of them, and not addressed in $47 \%$ of the courses.

Participants indicated that oral communication was introduced in 22\% of the Auditing courses, emphasized in $47 \%$ of the courses, but not addressed in another $31 \%$. Oral 
communication was introduced in $26 \%$ of the AIS courses, emphasized in $28 \%$ of the courses, not addressed at all in $46 \%$ of them.

Research Question 3d: Essential Skills Addressed in Required Accounting Courses: Problem Solving

Respondents reported that problem solving was introduced in $38 \%$ of the Principles of Financial Accounting (I) courses, emphasized in 60\%, and not addressed at all in $2 \%$ of them (See Table 38). In the Principles of Managerial Accounting (II) courses, they indicated that problem solving was introduced in $30 \%$ of the courses, emphasized in $69 \%$ of them, and not addressed in $1 \%$ of the courses. For the Intermediate Accounting courses, the respondents reported that problem solving was introduced in $6 \%$ of the courses and emphasized in $94 \%$ of them.

Table 38

Problem Solving Addressed in Required Accounting Courses

$$
\text { Problem Solving }
$$

Course

\begin{tabular}{|c|c|c|c|c|c|c|c|c|}
\hline & \multicolumn{2}{|c|}{$\mathrm{I}$} & \multicolumn{2}{|c|}{$\mathrm{E}$} & \multicolumn{2}{|c|}{ NA } & \multicolumn{2}{|c|}{ Total } \\
\hline & $\mathrm{N}$ & $\%$ & $\mathrm{~N}$ & $\%$ & $\mathrm{~N}$ & $\%$ & $\mathrm{~N}$ & $\%$ \\
\hline Principles of Financial Accounting (I) & 32 & 38 & 50 & 60 & 2 & 2 & 84 & 100 \\
\hline Principles of Managerial Accounting (II) & 24 & 30 & 55 & 69 & 1 & 1 & 80 & 100 \\
\hline Intermediate Accounting & 5 & 6 & 79 & 94 & 0 & 0 & 84 & 100 \\
\hline Cost Accounting & 4 & 5 & 76 & 94 & 1 & 1 & 81 & 100 \\
\hline Taxation & 5 & 6 & 75 & 92 & 2 & 2 & 82 & 100 \\
\hline Advanced Accounting & 4 & 6 & 68 & 93 & 1 & 1 & 73 & 100 \\
\hline Auditing & 10 & 12 & 67 & 83 & 4 & 5 & 81 & 100 \\
\hline Accounting Information Systems & 18 & 26 & 46 & 67 & 5 & 7 & 69 & 100 \\
\hline
\end{tabular}

Note: I = Introduced; E= Emphasized; and NA = Not Addressed.

Participants reported that in 5\% of the Cost Accounting courses, problem solving was introduced; in $94 \%$ of them, the skill was emphasized; and in 1\% of the courses, problem solving was not addressed. The responses indicated that problem solving was introduced in $6 \%$ of the Taxation courses, emphasized in $92 \%$ of the courses, and not addressed at all in $2 \%$ of them. The respondents reported that problem solving was introduced in $6 \%$ of the 
Advanced Accounting courses, emphasized in $93 \%$ of them, and not addressed at all in $1 \%$ of the courses. They also indicated that problem solving was introduced in $12 \%$ of the Auditing courses, emphasized in $83 \%$, and not addressed in 5\% of the courses. The study found that problem solving was introduced in $26 \%$ of the AIS courses, emphasized in $67 \%$ of them, and not addressed in $7 \%$ of the courses.

Research Question 3e: Essential Skills Addressed in Required Accounting Courses: Written Communication

The responses indicated that written communication was introduced in $52 \%$ of the Principles of Financial Accounting (I) courses, emphasized in 6\%, and was not addressed in $42 \%$ of them (See Table 39). They also reported that written communication was introduced in $47 \%$ of the Principles of Managerial Accounting (II) courses, emphasized in 9\%, and not addressed at all in $44 \%$ of them.

For the Intermediate Courses, respondents reported that written communication was introduced in 39\% of them, emphasized in 38\%, and not addressed in $23 \%$ of the courses. The participants stated written communication was introduced in 39\% of the Cost Accounting courses, emphasized in $36 \%$ of them, and not addressed at all in $25 \%$ of the courses. The respondents indicated that written communication was introduced in $32 \%$ of the Taxation courses, emphasized in $43 \%$, and not addressed in $25 \%$ of the courses. The study found that written communication was introduced in 36\% of the Advanced Accounting courses, emphasized in $41 \%$ of them, and not addressed in $23 \%$ of the courses.

The participants indicated that written communication was introduced in $16 \%$ of the Auditing courses; emphasized in 74\%; and not addressed in 10\% of them. The respondents reported that written communication was introduced in $28 \%$ of the AIS courses; emphasized in $50 \%$ of them; and not addressed in $22 \%$ of them. 
Table 39

Written Communication Addressed in Required Accounting Courses

Written Communication

Course

\begin{tabular}{lrrrrrrrr}
\cline { 2 - 9 } & \multicolumn{3}{c}{$\mathrm{I}$} & \multicolumn{3}{c}{$\mathrm{E}$} & \multicolumn{3}{c}{$\mathrm{NA}$} & \multicolumn{3}{c}{ Total } \\
& $\mathrm{N}$ & $\%$ & $\mathrm{~N}$ & $\%$ & $\mathrm{~N}$ & $\%$ & $\mathrm{~N}$ & $\%$ \\
\hline Principles of Financial Accounting (I) & 44 & 52 & 5 & 6 & 35 & 42 & 84 & 100 \\
Principles of Managerial Accounting (II) & 36 & 47 & 7 & 9 & 34 & 44 & 77 & 100 \\
Intermediate Accounting & 33 & 39 & 32 & 38 & 19 & 23 & 84 & 100 \\
Cost Accounting & 31 & 39 & 29 & 36 & 20 & 25 & 80 & 100 \\
Taxation & 26 & 32 & 35 & 43 & 20 & 25 & 81 & 100 \\
Advanced Accounting & 26 & 36 & 30 & 41 & 17 & 23 & 73 & 100 \\
Auditing & 13 & 16 & 59 & 74 & 8 & 10 & 80 & 100 \\
Accounting Information Systems & 19 & 28 & 34 & 50 & 15 & 22 & 68 & 100 \\
\hline
\end{tabular}

Note: I = Introduced; E= Emphasized; and NA = Not Addressed.

Responses for other courses were insufficient to prepare comparable data. The titles and number of other accounting courses taught at various colleges and universities in which the identified five essential skills were introduced or emphasized include:

Governmental Accounting \& Not-for-profit (15), Corporate Tax (3), Partnership Accounting (1), Forensic Accounting (3), International Accounting (1), Accounting Seminar (11), Planning \& Control (1), Personal Financial Planning (2), Consolidations (1), Computerized Accounting (5), Internal Auditing (2), Research (1), and Ethics (1).

Research Question 4: Assessment Methods Used to Measure Skills and Competencies

Research question 4 asked if there was a significant difference in how extensively assessment methods are used to measure essential skills and competencies. The participants were asked to select methods used in their assessment programs from a list of commonly used direct and indirect methods.

Research Question 4a: Direct Assessment Methods

Direct assessment instruments provide evidence of student learning through observation and demonstration of skills and knowledge. Survey responses were analyzed in 
the three treatment groups to determine whether there were significant differences in the direct methods of assessment used when analyzed by the three treatment conditions.

\section{Direct assessment methods by Carnegie Classifications.}

The responses, when analyzed by Carnegie Classification, revealed that direct methods were used very little to often overall (See Table 40). The respondents were asked to write in other direct methods that were used as assessment methods but not listed. Three methods, commercial computerized math tests, commercial computerized accounting tests, and class projects were reported used often to extensively.

An Analysis of Variance (ANOVA) was computed for each of the eight dependent variables (portfolio, capstone, juried review, internships, case study, essays, locally designed tests, and standardized national licensure). The independent variable in each one-way, between subjects ANOVA was Carnegie Classification (doctoral versus master’s versus baccalaureate).

The ANOVA for portfolio yielded $\mathrm{F}(2,93)=.081, \mathrm{p}<.05$ and was not significant. The ANOVA for capstone yielded $\mathrm{F}(2,93)=.988, \mathrm{p}<.05$ and was not significant. The ANOVA for juried review yielded $\mathrm{F}(2,93)=1.148, \mathrm{p}<.05$ and was not significant. The ANOVA for internships yielded $\mathrm{F}(2,93)=.029, \mathrm{p}<.05$ and was not significant. The ANOVA for case study yielded $\mathrm{F}(2,93)=2.148, \mathrm{p}<.05$ and was not significant. The ANOVA for essays yielded $\mathrm{F}(2,91)=.411, \mathrm{p}<.05$ and was not significant. The ANOVA for locally designed tests yielded $\mathrm{F}(2,93)=.617, \mathrm{p}<.05$ and was not significant. The ANOVA for standardized national licensure yielded $F(2,93)=.008, p<.05$ and was not significant. 
Table 40

Direct Assessment Methods by Carnegie Classification

\begin{tabular}{|c|c|c|c|c|c|c|c|}
\hline \multirow{2}{*}{ Direct Assessment Methods } & \multicolumn{2}{|c|}{$\frac{\text { Group } 1}{\mathrm{D}}$} & \multicolumn{2}{|c|}{ Group 2} & \multicolumn{2}{|c|}{ Group 3} & \multirow[b]{2}{*}{ F } \\
\hline & $\mathrm{M}$ & $\mathrm{SD}$ & $\mathrm{M}$ & SD & $\mathrm{M}$ & $\mathrm{SD}$ & \\
\hline Portfolio $^{\mathrm{a}}$ & 4.25 & 1.39 & 4.30 & 1.15 & 4.17 & 1.40 & .081 \\
\hline Capstone Course $^{a}$ & 3.13 & 1.59 & 2.80 & 1.29 & 3.30 & 1.64 & .988 \\
\hline Juried Review $^{\mathrm{a}}$ & 4.31 & 1.25 & 4.59 & .93 & 4.78 & .74 & 1.148 \\
\hline Internships $^{\mathrm{a}}$ & 2.94 & 1.65 & 2.91 & 1.31 & 3.00 & 1.41 & .029 \\
\hline Case Study $^{\mathrm{a}}$ & 2.75 & 1.73 & 2.80 & 1.33 & 3.52 & 1.47 & 2.148 \\
\hline Essays $^{\mathrm{b}}$ & 3.47 & 1.46 & 3.20 & 1.39 & 3.48 & 1.38 & .411 \\
\hline Locally Designed Tests ${ }^{\mathrm{a}}$ & 2.75 & 1.95 & 3.22 & 1.72 & 2.83 & 1.70 & .617 \\
\hline Standard National Licensure $^{\underline{a}}$ & 3.13 & 1.67 & 3.17 & 1.60 & 3.13 & 1.71 & .008 \\
\hline
\end{tabular}

Note. $\mathrm{D}$ = Doctoral; $\mathrm{M}$ = Master’s; $\mathrm{B}$ = Baccalaureate.

${ }^{a} n=96,{ }^{b} n=94$.

When asked about the use of portfolios as an assessment tool, the respondents indicated that the method was used very little at the programs in all of the classifications. Capstone projects, internships, essays, locally designed tests and standardized national licensure tests were used somewhat as direct assessment methods as the results indicated. Juried review was reported used very little by the doctoral programs and not at all by the master's and baccalaureate as a direct assessment method. Case studies means indicated that this method was used somewhat at the doctoral and master's programs and very little at the baccalaureate ones as a direct assessment method.

Direct assessment method by region.

The responses for direct methods of assessment were analyzed again by region (See Table 41). An Analysis of Variance (ANOVA) was computed for each of the eight dependent variables (portfolio, capstone, juried review, internships, case study, essays, locally designed tests, and standardized national licensure). The independent variable in each 
one-way, between subjects ANOVA was region (middle states versus north central versus southern).

The ANOVA for portfolio yielded $\mathrm{F}(2,82)=.305, \mathrm{p}<.05$ and was not significant. The ANOVA for capstone yielded $\mathrm{F}(2,82)=1.884, \mathrm{p}<.05$ and was not significant. The ANOVA for juried review yielded $\mathrm{F}(2,82)=.282, \mathrm{p}<.05$ and was not significant. The ANOVA for internships yielded $\mathrm{F}(2,82)=2.315, \mathrm{p}<.05$ and was not significant. The ANOVA for case study yielded $\mathrm{F}(2,82)=1.392, \mathrm{p}<.05$ and was not significant. The ANOVA for essays yielded $\mathrm{F}(2,81)=.311, \mathrm{p}<.05$ and was not significant. The ANOVA for locally designed tests yielded $F(2,82)=5.204, \mathrm{p}<.05$ and was significant. The ANOVA for standardized national licensure yielded $F(2,82)=1.769, \mathrm{p}<.05$ and was not significant.

Table 41

Direct Assessment Methods by Region

\begin{tabular}{|c|c|c|c|c|c|c|c|}
\hline \multirow{3}{*}{ Direct Assessment Methods } & \multicolumn{2}{|c|}{ Group 1} & \multicolumn{2}{|c|}{ Group 2} & \multicolumn{2}{|c|}{ Group 3} & \multirow[b]{3}{*}{$\mathrm{F}$} \\
\hline & \multicolumn{2}{|c|}{ MS } & \multicolumn{2}{|c|}{$\mathrm{NC}$} & \multicolumn{2}{|c|}{$\mathrm{S}$} & \\
\hline & $\mathrm{M}$ & SD & $\mathrm{M}$ & $\mathrm{SD}$ & $\mathrm{M}$ & SD & \\
\hline Portfolio $^{a}$ & 4.06 & 1.39 & 4.27 & 1.20 & 4.39 & 1.33 & .305 \\
\hline Capstone Course $^{\mathrm{a}}$ & 2.59 & 1.33 & 3.28 & 1.54 & 2.67 & 1.33 & 1.884 \\
\hline Juried Review $^{\mathrm{a}}$ & 4.59 & .94 & 4.53 & .91 & 4.72 & .96 & .282 \\
\hline Internships $^{\mathrm{a}}$ & 2.29 & 1.10 & 3.00 & 1.48 & 3.28 & 1.49 & 2.315 \\
\hline Case Study & 2.65 & 1.10 & 3.25 & 1.60 & 2.72 & 1.27 & 1.392 \\
\hline Essays $^{\mathrm{b}}$ & 3.00 & 1.51 & 3.33 & 1.42 & 3.22 & 1.22 & .311 \\
\hline Locally Designed Tests ${ }^{\mathrm{a}}$ & 3.47 & 1.66 & 3.43 & 1.63 & 2.00 & 1.68 & $5.204^{*}$ \\
\hline Standard National Licensure ${ }^{\mathrm{a}}$ & 3.47 & 1.55 & 2.80 & 1.67 & 3.56 & 1.69 & 1.769 \\
\hline
\end{tabular}

Note. MS = Middle States; NC = North Central; $\mathrm{S}=$ Southern.

${ }^{\mathrm{a}} \mathrm{n}=85,{ }^{\mathrm{b}} \mathrm{n}=84$.

$* \mathrm{p}<.05$

The ANOVA determined a significant difference in the regions' means for the use of locally designed tests as an assessment method. A post-hoc test was used to determine which means differed. The LSD test revealed that there were significant differences in the use of 
locally designed tests as assessment measures of student learning between the Southern and North Central regions and the Southern and Middle States regions, $(\mathrm{F}(2,82)=5.204, \mathrm{p}<$ $.05)(\mathrm{MS}(\mathrm{M}=3.47, \mathrm{SD}=1.66), \mathrm{NC}(\mathrm{M}=3.43, \mathrm{SD}=1.63)$, and $\mathrm{S}(\mathrm{M}=2, \mathrm{SD}=1.68))$. The participants in the Southern region used locally designed tests often to measure student learning, but the respondents in the Middle States and North Central regions used them somewhat as assessment instruments.

Portfolios were used very little as assessment tools, and capstone courses were used somewhat as methods of assessment at all of the regions' programs. Juried review was not used at all as an assessment instrument in the regions' programs. Internships were used somewhat at North Central and Southern programs and often at Middle States programs as an assessment method. Case studies and essays were used somewhat as assessment methods at the programs in all of the regions. Standardized national licensure tests were used somewhat at Middle States and North Central programs and used very little at Southern ones.

Direct assessment methods by size.

The direct methods of assessment responses were analyzed again by enrollment categories to discover any significant differences due to enrollment (See Table 42). An Analysis of Variance (ANOVA) was computed for each of the eight dependent variables (portfolio, capstone, juried review, internships, case study, essays, locally designed tests, and standardized national licensure). The independent variable in each one-way, between subjects ANOVA was size (small versus mid-size versus large).

The ANOVA for portfolio yielded $\mathrm{F}(2,89)=.541, \mathrm{p}<.05$ and was not significant. The ANOVA for capstone yielded $\mathrm{F}(2,89)=.648, \mathrm{p}<.05$ and was not significant. The 
ANOVA for juried review yielded $F(2,89)=1.704, \mathrm{p}<.05$ and was not significant. The ANOVA for internships yielded $\mathrm{F}(2,89)=.907, \mathrm{p}<.05$ and was not significant.

Table 42

Direct Assessment Methods by Size

\begin{tabular}{|c|c|c|c|c|c|c|c|}
\hline \multirow[t]{2}{*}{ Direct Assessment Methods } & \multicolumn{2}{|c|}{$\frac{\text { Group } 1}{\mathrm{~S}}$} & \multicolumn{2}{|c|}{$\frac{\text { Group } 2}{M}$} & \multicolumn{2}{|c|}{$\frac{\text { Group } 3}{\mathrm{~L}}$} & \multirow[b]{2}{*}{$\mathrm{F}$} \\
\hline & M & SD & M & SD & M & $\mathrm{SD}$ & \\
\hline Portfolio $^{a}$ & 4.38 & 1.06 & 4.09 & 1.48 & 4.40 & 1.48 & .541 \\
\hline Capstone Course $^{\mathrm{a}}$ & 2.92 & 1.30 & 3.03 & 1.30 & 3.50 & 1.65 & .648 \\
\hline Juried Review $^{\mathrm{a}}$ & 4.78 & .67 & 4.38 & 1.10 & 4.40 & 1.35 & 1.704 \\
\hline Internships $^{\mathrm{a}}$ & 3.00 & 1.39 & 2.85 & 1.42 & 2.90 & 1.45 & .907 \\
\hline Case Study ${ }^{\mathrm{a}}$ & 2.78 & 1.42 & 2.85 & 1.44 & 3.70 & 1.49 & 1.680 \\
\hline Essays $^{\mathrm{a}}$ & 3.14 & 1.38 & 3.39 & 1.37 & 3.60 & 1.58 & .573 \\
\hline Locally Designed Tests ${ }^{\mathrm{a}}$ & 3.03 & 1.67 & 3.18 & 1.85 & 2.40 & 1.71 & .562 \\
\hline Standard National Licensure $^{\text {a }}$ & 3.70 & 1.53 & 2.71 & 1.64 & 2.90 & 1.45 & $3.771^{*}$ \\
\hline
\end{tabular}

The ANOVA for case study yielded $\mathrm{F}(2,89)=1.680, \mathrm{p}<.05$ and was not significant. The ANOVA for essays yielded $\mathrm{F}(2,89)=.573, \mathrm{p}<.05$ and was not significant. The ANOVA for locally designed tests yielded $\mathrm{F}(2,89)=.562, \mathrm{p}<.05$ and was not significant. The ANOVA for standardized national licensure yielded $F(2,89)=3.771, \mathrm{p}<$ .05 and was significant.

The ANOVA revealed a significant difference in the means of the size categories. The post-hoc LSD test discovered a significant difference for standardized licensure tests used as direct assessment measures between the small and mid-size programs by size, (F (2, $89)=3.771, \mathrm{p}<.05), \mathrm{S}(\mathrm{M}=3.7, \mathrm{SD}=1.53)$ and $\mathrm{M}(\mathrm{M}=2.71, \mathrm{SD}=1.64))$. The smallsized programs used the standardized national licensure tests very little, and the mid-size programs used the licensure tests somewhat.

Responses indicated that portfolios as direct measures of assessment were used very little, and capstone courses and internships were used somewhat as assessment measures at 
the programs in all of the size categories. Juried review was used very little at mid-size programs and large programs and not used at all at the small ones.

Case studies and essays were used somewhat at small and mid-size programs and very little at the large programs. Locally designed tests were used often at the large programs and somewhat at the small and mid-size ones.

Research Question 4b: Indirect Assessment Methods

Indirect assessment instruments collect students' opinions and perceptions that can corroborate evidence of student learning obtained through direct methods. The responses for indirect assessment methods were analyzed by the three treatment conditions to determine if significant differences existed. The participants did not report any additional indirect assessment methods used as other assessment instruments.

Indirect assessment methods by Carnegie Classification.

The responses were analyzed by Carnegie Classification to determine if significant differences existed between the groups (See Table 43). An Analysis of Variance (ANOVA) was computed for each of the eight dependent variables (alumni surveys, student surveys, employer surveys, focus groups, graduate follow-up studies, retention and transfer studies, exit interviews, and reflective papers). The independent variable in each one-way, between subjects ANOVA was Carnegie Classification (doctoral versus master’s versus baccalaureate).

The ANOVA for alumni surveys yielded $\mathrm{F}(2,93)=1.586, \mathrm{p}<.05$ and was not significant. The ANOVA for student surveys yielded $\mathrm{F}(2,93)=.979, \mathrm{p}<.05$ and was not significant. The ANOVA for employer surveys yielded $\mathrm{F}(2,93)=.625, \mathrm{p}<.05$ and was not 
significant. The ANOVA for focus groups yielded $F(2,93)=.363, p<.05$ and was not significant.

Table 43

Indirect Assessment Methods by Carnegie Classification

\begin{tabular}{|c|c|c|c|c|c|c|c|}
\hline \multirow{2}{*}{ Indirect Assessment Methods } & \multicolumn{2}{|c|}{ Group 1} & \multicolumn{2}{|c|}{ Group 2} & \multicolumn{3}{|c|}{ Group 3} \\
\hline & M & SD & $\mathrm{M}$ & SD & M & SD & $\mathrm{F}$ \\
\hline Alumni Surveys $^{\mathrm{a}}$ & 2.56 & 1.26 & 2.30 & 1.21 & 2.87 & 1.32 & 1.586 \\
\hline Student Surveys ${ }^{\mathrm{a}}$ & 2.00 & 1.37 & 2.24 & 2.24 & 2.57 & 1.47 & .979 \\
\hline Employer Surveys $^{\mathrm{a}}$ & 2.88 & 1.45 & 3.22 & 2.22 & 3.39 & 1.56 & .625 \\
\hline Focus Groups $^{\mathrm{a}}$ & 4.00 & 1.15 & 4.28 & 1.28 & 4.22 & 1.28 & .363 \\
\hline Graduate Follow-Up Studies $^{\mathrm{a}}$ & 1.75 & 1.34 & 3.78 & 1.41 & 4.57 & .73 & $3.354^{*}$ \\
\hline Retention And Transfer Studies & 4.21 & 1.01 & 3.46 & 1.76 & 4.39 & .78 & $3.494^{*}$ \\
\hline Exit Interviews $^{\mathrm{a}}$ & 3.44 & 1.75 & 4.39 & 1.61 & 3.35 & 1.53 & .237 \\
\hline Reflective Papers $^{\mathrm{a}}$ & 4.56 & 1.03 & 4.45 & 1.46 & 4.43 & .90 & .113 \\
\hline
\end{tabular}

Note. $\mathrm{D}$ = Doctoral; $\mathrm{M}$ = Master's; B = Baccalaureate.

${ }^{a} \mathrm{n}=96$.

${ }^{*} \mathrm{p}<.05$.

The ANOVA for graduate follow-up studies yielded $F(2,93)=3.354, p<.05$ and was significant. The ANOVA for retention and transfer studies yielded $F(2,93)=3.494, p<$ .05 and was significant. The ANOVA for exit interviews yielded $F(2,93)=.237, \mathrm{p}<.05$ and was not significant. The ANOVA for reflective papers yielded $F(2,93)=.113$, $\mathrm{p}<.05$ and was not significant.

The ANOVA discovered a significant difference among the means for graduate follow-up studies used as indirect assessment methods by the respondents. The LSD discovered a significant difference in the use of graduate follow-up studies between all three groups, the doctoral, master's, and baccalaureate institutions, $(\mathrm{F}(2,93)=3.354, \mathrm{D}(\mathrm{M}=$ $1.75, \mathrm{SD}=1.34), \mathrm{M}(\mathrm{M}=3.78, \mathrm{SD}=1.41)$, and $\mathrm{B}(\mathrm{M}=4.57, \mathrm{SD}=.73))$.

The doctoral institutions used graduate follow-up studies often as indirect methods of assessment, while the master's used them very little, and the baccalaureate did not use them 
at all. The ANOVA discovered a significant difference among the means for retention and transfer studies used as indirect assessment methods by the respondents. The LSD discovered a significant difference in their use between the master's and baccalaureate institutions, $(\mathrm{F}(2,93)=3.494, \mathrm{M}(\mathrm{M}=3.46, \mathrm{SD}=1.76)$, and $\mathrm{B}(\mathrm{M}=4.39, \mathrm{SD}=.78))$. The master's programs used the studies somewhat, and the baccalaureate programs used them very little.

Alumni surveys were used often at master's programs and used somewhat at doctoral and baccalaureate programs as indirect assessment methods. Student surveys were used often at doctoral and master's programs and used somewhat at baccalaureate ones to measure student learning. Employer surveys were used somewhat and focus groups were used very little at the programs in all of the classifications as indirect assessment tools. Exit interviews were used somewhat at doctoral and baccalaureate programs and very little at master’s programs to assess student learning. Reflective papers were used very little at baccalaureate institutions, somewhat at master's, and not used at all at doctoral programs as indirect assessment methods.

\section{Indirect assessment methods by region.}

The responses were analyzed again by region for indirect assessment methods used to assess student learning (See Table 44). An Analysis of Variance (ANOVA) was computed for each of the eight dependent variables (alumni surveys, student surveys, employer surveys, focus groups, graduate follow-up studies, retention and transfer studies, exit interviews, and reflective papers). The independent variable in each one-way, between subjects ANOVA was region (middle states versus north central versus southern). 
The ANOVA for alumni surveys yielded $\mathrm{F}(2,82)=.778, \mathrm{p}<.05$ and was not significant. The ANOVA for student surveys yielded $\mathrm{F}(2,82)=.918, \mathrm{p}<.05$ and was not significant. The ANOVA for employer surveys yielded $F(2,82)=2.033, \mathrm{p}<.05$ and was not significant.

Table 44

Indirect Assessment Methods by Region

\begin{tabular}{|c|c|c|c|c|c|c|c|}
\hline \multirow{3}{*}{ Indirect Assessment Methods } & \multirow{2}{*}{\multicolumn{2}{|c|}{$\frac{\text { Group } 1}{\mathrm{MS}}$}} & \multirow{2}{*}{\multicolumn{2}{|c|}{$\frac{\text { Group } 2}{\mathrm{NC}}$}} & \multirow{2}{*}{\multicolumn{2}{|c|}{$\frac{\text { Group } 3}{\mathrm{~S}}$}} & \multirow[b]{3}{*}{ F } \\
\hline & & & & & & & \\
\hline & M & SD & M & SD & M & SD & \\
\hline Alumni Surveys $^{\mathrm{a}}$ & 2.65 & 1.37 & 2.30 & 1.22 & 2.67 & 1.14 & .778 \\
\hline Student Surveys ${ }^{\mathrm{a}}$ & 2.59 & 1.18 & 2.25 & 1.39 & 2.00 & 1.14 & .91 \\
\hline Employer Surveys $^{\mathrm{a}}$ & 3.18 & 1.38 & 3.03 & 1.53 & 3.83 & 1.20 & 2.03 \\
\hline Focus Groups ${ }^{\mathrm{a}}$ & 3.94 & 1.20 & 4.30 & 1.14 & 4.11 & 1.23 & .59 \\
\hline Graduate Follow-Up Studies $^{\mathrm{a}}$ & 3.82 & 1.29 & 4.05 & 1.30 & 3.83 & 1.42 & .260 \\
\hline Retention And Transfer Studies ${ }^{\mathrm{a}}$ & 3.76 & 1.09 & 4.10 & 1.06 & 4.33 & .97 & 1.309 \\
\hline Exit Interviews $^{\mathrm{a}}$ & 3.35 & 1.27 & 3.38 & 1.66 & 3.28 & 1.60 & .024 \\
\hline Reflective Papers $^{\text {a }}$ & 4.41 & .94 & 4.45 & .88 & 4.56 & .86 & .130 \\
\hline
\end{tabular}

Note. MS = Middle States; NC = North Central; S = Southern.

${ }^{\mathrm{a}} \mathrm{n}=85$.

The ANOVA for focus groups yielded $\mathrm{F}(2,82)=.591, \mathrm{p}<.05$ and was not significant. The ANOVA for graduate follow-up studies yielded $F(2,82)=.260, \mathrm{p}<.05$ and was not significant. The ANOVA for retention and transfer studies yielded $F(2,82)=1.309$, $\mathrm{p}<.05$ and was not significant. The ANOVA for exit interviews yielded $\mathrm{F}(2,82)=.024, \mathrm{p}$ $<.05$ and was not significant. The ANOVA for reflective papers yielded $\mathrm{F}(2,82)=.130$, $\mathrm{p}$ $<.05$ and was not significant.

Alumni surveys were used somewhat as assessment measures in the Middle States and Southern regions and often in the North Central to assess student learning. Student surveys were used somewhat in the Middle States and often in the North Central and Southern regions as indirect assessment methods. Exit interviews were used somewhat in all the regions in the study as assessment tools. 
Focus groups, graduate follow-up studies, and retention and transfer studies were used very little in the all of the regions as indirect assessment instruments. Employer surveys were used somewhat in the Middle States and North Central regions and very little in the Southern region. Reflective papers were used very little in the Middle States and North Central regions, and they were not used at all in the Southern regions for assessment purposes.

Indirect assessment methods by size. Indirect assessment methods used to assess student learning were also analyzed to determine if there were significant differences by enrollment categories (See Table 45). An Analysis of Variance (ANOVA) was computed for each of the eight dependent variables (alumni surveys, student surveys, employer surveys, focus groups, graduate followup studies, retention and transfer studies, exit interviews, and reflective papers). The independent variable in each one-way, between subjects ANOVA was size (small versus mid-size versus large).

The ANOVA for alumni surveys yielded $\mathrm{F}(2,89)=5.349 \mathrm{p}<.05$ and was significant. The ANOVA for student surveys yielded $F(2,89)=.682, p<.05$ and was not significant. The ANOVA for employer surveys yielded $F(2,89)=6.373, \mathrm{p}<.05$ and was significant. The ANOVA for focus groups yielded $F(2,89)=.894, p<.05$ and was not significant. The ANOVA for graduate follow-up studies yielded $F(2,89)=.854, p<.05$ and was not significant. The ANOVA for retention and transfer studies yielded $\mathrm{F}(2,89)=.565$, $\mathrm{p}<.05$ and was not significant. The ANOVA for exit interviews yielded $\mathrm{F}(2,89)=1.474$, $\mathrm{p}$ $<.05$ and was not significant. The ANOVA for reflective papers yielded $F(2,89)=.316, \mathrm{p}$ $<.05$ and was not significant. 
Table 45

Indirect Assessment Methods by Size

\begin{tabular}{lccccccccc}
\hline \multirow{2}{*}{ Indirect Assessment Methods } & \multicolumn{2}{c}{ Group 1 } & & \multicolumn{2}{c}{ Group 2 } & \multicolumn{3}{c}{ Group 3 } \\
& \multicolumn{2}{c}{ S } & & \multicolumn{3}{c}{ M } & & L & \\
& M & SD & M & SD & M & SD & F \\
Alumni Surveys $^{\mathrm{a}}$ & 2.95 & 1.20 & 2.03 & 1.06 & 2.40 & 1.51 & $5.349^{*}$ \\
Student Surveys $^{\mathrm{a}}$ & 2.41 & 1.19 & 2.06 & 1.25 & 2.20 & 1.48 & .682 \\
Employer Surveys $^{\mathrm{a}}$ & 3.81 & 1.17 & 2.85 & 1.44 & 2.50 & 1.51 & $6.373^{*}$ \\
Focus Groups $^{\mathrm{a}}$ & 4.35 & 1.09 & 4.06 & 1.18 & 3.90 & 1.29 & .894 \\
Graduate Follow-Up Studies $^{\mathrm{a}}$ & 4.05 & 1.31 & 4.09 & 1.24 & 3.50 & 1.43 & .854 \\
Retention And Transfer Studies $^{\mathrm{a}}$ & 3.92 & 1.06 & 4.09 & 1.08 & 4.30 & 1.06 & .565 \\
Exit Interviews $^{\mathrm{a}}$ & 3.51 & 1.45 & 3.38 & 1.65 & 4.30 & 1.06 & 1.474 \\
Reflective Papers $^{\text {a }}$ & 4.51 & .80 & 4.38 & 1.02 & 4.60 & .70 & .316 \\
\hline
\end{tabular}

Note. $\mathrm{S}=$ Small $<200 ; \mathrm{M}=$ Mid-size $=200-400 ; \mathrm{L}=$ Large $>400$.

${ }^{a} n=92$

${ }^{*} \mathrm{p}<.05$

The LSD test determined that significant differences existed between the responses in the size categories in the use of alumni surveys, $(\mathrm{F}(2,89)=5.349, \mathrm{p}<.05), \mathrm{S}(\mathrm{M}=2.95$, SD $=1.2)$ and $\mathrm{M}(\mathrm{M}=2.03, \mathrm{SD}=1.06))$, and in the use of employer surveys, $(\mathrm{F}(2,89)=6.373$, $\mathrm{p}<.05), \mathrm{S}(\mathrm{M}=3.81, \mathrm{SD}=1.17), \mathrm{M}(\mathrm{M}=2.85, \mathrm{SD}=1.44)$, and $\mathrm{L}(\mathrm{M}=2.5, \mathrm{SD}=1.51))$ for assessment purposes. A significant difference was discovered for the use of alumni surveys between the small and mid-size programs. At small programs, alumni surveys were somewhat used, while at mid-size programs, the surveys were used often as indirect assessment methods. A significant difference was also found in the means for employer surveys used as an indirect method of assessment between the small programs and all other categories. Significant differences existed between the small and mid-size and between the small and large groups. Small institutions used employer surveys very little for assessment purposes as indirect assessment methods; however, mid-size used the surveys somewhat, and large institutions used them often to measure student learning. 
Student surveys were used often as indirect assessment methods at the programs in all of the sizes, while focus groups, graduate follow-up studies, and retention and transfer studies were used very little. Exit interviews were used very little at the small and large programs and somewhat at the mid-size ones for assessment. Reflective papers were used very little at mid-size programs and not at all at small and large programs as indirect assessment methods.

Research Question 5: Use of Assessment Results and Related Changes

Research question 5 addressed how extensively the assessment data were used to enhance programs and improve student learning. Responses were analyzed by the three treatment conditions to determine if significant differences existed in how assessment results were used and in reported assessment related changes and improvements due to assessment data.

Research Question 5a: Use of Assessment Results

Participants were asked how the assessment results were used at their institutions. They made their selections from a list of areas where assessment results could be used. No responses were recorded for other uses for assessment results that were not listed as requested.

Use of assessment results by Carnegie Classification.

The results were analyzed by Carnegie Classification to determine if significant differences existed in the responses (See Table 46). An Analysis of Variance (ANOVA) was computed for each of the seven dependent variables (planning and decision making, resource allocation, curricular changes, program review, student recruitment, improving learning, and evaluating the assessment process). The independent variable in each one-way, between 
subjects ANOVA was Carnegie Classification (doctoral versus master’s versus

baccalaureate).

Table 46

Use of Assessment Results by Carnegie Classification

\begin{tabular}{|c|c|c|c|c|c|c|c|}
\hline \multirow{2}{*}{ Use of Assessment Results } & \multicolumn{2}{|c|}{$\frac{\text { Group } 1}{\mathrm{D}}$} & \multicolumn{2}{|c|}{$\frac{\text { Group } 2}{\mathrm{M}}$} & \multicolumn{2}{|c|}{ Group 3} & \multirow[b]{2}{*}{ F } \\
\hline & $\mathrm{M}$ & SD & M & SD & $\mathrm{M}$ & SD & \\
\hline Planning \& decision making ${ }^{a}$ & 2.44 & 1.31 & 2.65 & 1.18 & 2.83 & 1.07 & .515 \\
\hline Resource allocation $^{\mathrm{a}}$ & 4.00 & .97 & 3.30 & 1.13 & 4.09 & 1.00 & $5.191 *$ \\
\hline Curricular changes $^{\mathrm{a}}$ & 2.13 & .89 & 2.04 & .82 & 2.39 & 1.20 & 1.024 \\
\hline Program review $^{\mathrm{a}}$ & 1.88 & .81 & 2.27 & 1.26 & 2.30 & 1.33 & .740 \\
\hline Student recruitment $^{\mathrm{a}}$ & 2.69 & 1.08 & 3.48 & 1.30 & 3.74 & .96 & .448 \\
\hline Improve learning $^{\mathrm{a}}$ & 1.88 & .89 & 2.04 & .82 & 2.48 & 1.27 & 2.211 \\
\hline Evaluate assessment process $^{\underline{\mathrm{a}}}$ & 2.50 & 1.15 & 2.76 & 1.25 & 2.30 & 1.15 & 2.430 \\
\hline \multicolumn{8}{|c|}{ Note. $\mathrm{D}=$ Doctoral; $\mathrm{M}=$ Master’s $; \mathrm{B}=$ Baccalaureate. } \\
\hline
\end{tabular}

The ANOVA for planning and decision making yielded $F(2,93)=.515, \mathrm{p}<.05$ and was not significant. The ANOVA for resource allocation yielded $F(2,93)=5.191, \mathrm{p}<.05$ and was significant. The ANOVA for curricular changes yielded $F(2,93)=1.024, p<.05$ and was not significant. The ANOVA for program review yielded $F(2,93)=.74, p<.05$ and was not significant.

The ANOVA for student recruitment yielded $\mathrm{F}(2,93)=.448, \mathrm{p}<.05$ and was not significant. The ANOVA for improving learning yielded $F(2,93)=2.211, \mathrm{p}<.05$ and was not significant. The ANOVA for evaluating the assessment process yielded $F(2,93)=2.43$, $\mathrm{p}<.05$ and was not significant. The LSD revealed a significant difference in the use of assessment data for resource allocation between the master's and the other two classifications, $(\mathrm{F}(2,93)=5.191, \mathrm{p}<.05, \mathrm{D}(\mathrm{M}=4, \mathrm{SD}=.97), \mathrm{M}(\mathrm{M}=3.3, \mathrm{SD}=1.13)$, and $\mathrm{B}(\mathrm{M}=4.09, \mathrm{SD}=1))$. 
The significant difference between the master's and doctoral institutions and the significant difference between the master's and baccalaureate groups disclosed that the master's institutions somewhat used assessment data for resource allocation, but the doctoral and baccalaureate groups used the data very little. Respondents indicated that doctoral institutions used assessment data often for planning and decision making, and the master's and baccalaureate programs used assessment data somewhat for that purpose.

The results were used often for curricular changes, for program review, and for improving learning at programs in all classifications. The data were used somewhat for student recruitment at doctoral and master's institutions and very little at baccalaureate programs. Assessment data were used often at doctoral and baccalaureate institutions and used somewhat at master's programs to evaluate the assessment process.

Use of assessment results by region.

The survey results were analyzed again by region (See Table 47). An Analysis of Variance (ANOVA) was computed for each of the seven dependent variables (planning and decision making, resource allocation, curricular changes, program review, student recruitment, improving learning, and evaluating the assessment process).

The independent variable in each one-way, between subjects ANOVA was region (middle states versus north central versus southern). The ANOVA for planning and decision making yielded $\mathrm{F}(2,82)=.262, \mathrm{p}<.05$ and was not significant. The ANOVA for resource allocation yielded $\mathrm{F}(2,82)=.558, \mathrm{p}<.05$ and was not significant. The ANOVA for curricular changes yielded $\mathrm{F}(2,81)=.08, \mathrm{p}<.05$ and was not significant. The ANOVA for program review yielded $\mathrm{F}(2,81)=2.38, \mathrm{p}<.05$ and was not significant. The ANOVA for student recruitment yielded $\mathrm{F}(2,82)=.024, \mathrm{p}<.05$ and was not significant. The ANOVA 
for improving learning yielded $\mathrm{F}(2,82)=.162, \mathrm{p}<.05$ and was not significant. The ANOVA for evaluating the assessment process yielded $\mathrm{F}(2,82)=1.03, \mathrm{p}<.05$ and was not significant.

Table 47

Use of Assessment Results by Region

\begin{tabular}{lcrccccrrr}
\hline \multirow{2}{*}{ Use of Assessment Results } & \multicolumn{2}{c}{ Group 1 } & & \multicolumn{3}{c}{ Group 2 } & & \multicolumn{3}{c}{ Group 3 } \\
& \multicolumn{2}{c}{ MS } & & \multicolumn{3}{c}{ NC } & & \\
& M & SD & M & SD & M & SD & F \\
\hline Planning \& decision making $^{\mathrm{a}}$ & 2.47 & .80 & 2.70 & 1.29 & 2.56 & 1.18 & .262 \\
Resource allocation $^{\mathrm{a}}$ & 3.47 & 1.12 & 3.80 & 1.11 & 3.67 & .97 & .558 \\
Curricular changes $^{\mathrm{b}}$ & 2.24 & .83 & 2.18 & 1.00 & 2.00 & .83 & .080 \\
Program review $^{\mathrm{b}}$ & 2.75 & 1.29 & 2.03 & 1.12 & 2.17 & .99 & 2.380 \\
Student recruitment $^{\mathrm{a}}$ & 3.53 & 1.12 & 3.55 & 1.18 & 3.61 & 1.24 & .024 \\
Improve learning $^{\mathrm{a}}$ & 2.24 & .97 & 2.20 & 1.11 & 2.06 & .87 & .162 \\
Evaluate assessment process $^{\mathrm{a}}$ & 3.24 & 1.30 & 2.78 & 1.14 & 2.72 & 1.27 & 1.030 \\
\hline
\end{tabular}

Note. $\mathrm{MS}=$ Middle States; NC = North Central; $\mathrm{S}=$ Southern.

${ }^{a} \mathrm{n}=85,{ }^{b} \mathrm{n}=84$.

Assessment data were used often for planning and decision-making at Middle States programs and somewhat at North Central and Southern ones. Assessment results were used somewhat for resource allocation in the Middle States and very little at North Central and Southern regions. Survey results showed that assessment data were used somewhat at Middle States programs for program review, and often at the North Central and Southern ones. At all of the programs in the study, assessment data were used very little in student recruitment, somewhat to evaluate the assessment process, and often for curricular changes and to improve student learning.

Use of assessment results by size.

The survey results were also analyzed by enrollment categories to determine whether significant differences existed in the use of assessment data by size (See Table 48). An Analysis of Variance (ANOVA) was computed for each of the seven dependent variables 
(planning and decision making, resource allocation, curricular changes, program review, student recruitment, improving learning, and evaluating the assessment process). The independent variable in each one-way, between subjects ANOVA was size (small versus mid-size versus large).

The ANOVA for planning and decision making yielded $\mathrm{F}(2,89)=.415, \mathrm{p}<.05$ and was not significant. The ANOVA for resource allocation yielded $F(2,89)=1.654, p<.05$ and was not significant. The ANOVA for curricular changes yielded $F(2,88)=1.541, \mathrm{p}<$ .05 and was not significant. The ANOVA for program review yielded $\mathrm{F}(2,87)=1.556, \mathrm{p}<$ .05 and was not significant. The ANOVA for student recruitment yielded $F(2,89)=2.061$, $\mathrm{p}<.05$ and was not significant. The ANOVA for improving learning yielded $\mathrm{F}(2,89)=$ $.578, \mathrm{p}<.05$ and was not significant. The ANOVA for evaluating the assessment process yielded $\mathrm{F}(2,89)=1.785, \mathrm{p}<.05$ and was not significant.

Table 48

Use of Assessment Results by Size

\begin{tabular}{|c|c|c|c|c|c|c|c|}
\hline \multirow{2}{*}{ Use of Assessment Results } & \multicolumn{2}{|c|}{$\frac{\text { Group } 1}{\mathrm{~S}}$} & \multicolumn{2}{|c|}{$\frac{\text { Group 2 }}{M}$} & \multicolumn{2}{|c|}{$\frac{\text { Group } 3}{\mathrm{~L}}$} & \multirow[b]{2}{*}{$\mathrm{F}$} \\
\hline & M & $\mathrm{SD}$ & M & $\mathrm{SD}$ & M & SD & \\
\hline Planning \& decision making ${ }^{\mathrm{a}}$ & 2.70 & 1.18 & 2.53 & 1.16 & 3.00 & 1.33 & .415 \\
\hline Resource allocation ${ }^{\mathrm{a}}$ & 3.76 & 1.14 & 3.35 & 1.12 & 4.00 & .94 & 1.654 \\
\hline Curricular changes $^{\mathrm{b}}$ & 2.39 & 1.13 & 1.91 & .75 & 2.20 & .92 & 1.541 \\
\hline Program review ${ }^{c}$ & 2.53 & 1.38 & 1.94 & .97 & 2.00 & 1.33 & 1.556 \\
\hline Student recruitment $\mathrm{t}^{\mathrm{a}}$ & 3.59 & 1.30 & 3.32 & 1.09 & 4.30 & .67 & 2.061 \\
\hline Improve learning $^{\mathrm{a}}$ & 2.27 & 1.10 & 1.97 & 1.00 & 2.20 & .63 & .578 \\
\hline Evaluate assessment process $^{\mathrm{a}}$ & 3.14 & 1.34 & 2.50 & 1.05 & 3.10 & 1.21 & 1.785 \\
\hline
\end{tabular}

Note. $\mathrm{S}=$ Small $<200 ; \mathrm{M}=$ Mid-size $=200-400 ; \mathrm{L}=$ Large $>400$.

${ }^{a} n=92,{ }^{b} n=91,{ }^{c} n=90$.

Assessment results were used somewhat for planning and decision making at the programs in all of the size categories. Assessment data were used very little at small and large programs and used somewhat at the mid-size programs for resource allocation. The data were used often for curricular changes at all of the programs in the three categories. 
Assessment data were used somewhat at small programs and often at the mid-size and large programs for program review.

The assessment results were used somewhat for student recruitment at the mid-size programs and very little at the small and large ones. The results were used often for improving learning. Assessment data were used somewhat at the small and large programs and often at the mid-size to evaluate the assessment process.

Research Question 5b: Assessment Related Changes and Improvements

The respondents were asked to record changes and improvements that had occurred in the accounting programs due to assessment data. No entries were recorded for other changes and improvements that had occurred but were not listed as requested.

Assessment related changes and improvements by Carnegie Classification.

The results were examined by Carnegie Classification to determine if significant differences existed in assessment related changes and improvements due to assessment data (See Table 49).

An Analysis of Variance (ANOVA) was computed for each of the eight dependent variables (planning and decision making, resource allocation, curricular changes, program review, student recruitment, improving learning, evaluating the assessment process, and faculty teaching). The independent variable in each one-way, between subjects ANOVA was Carnegie Classification (doctoral versus master’s versus baccalaureate).

The ANOVA for planning and decision making yielded $\mathrm{F}(2,93)=1.57, \mathrm{p}<.05$ and was not significant. The ANOVA for resource allocation yielded $F(2,93)=4.345, p<.05$ and was significant. The ANOVA for curricular changes yielded $F(2,93)=.586, p<.05$ and was not significant. 
Table 49

Assessment Related Changes and Improvements by Carnegie Classification

\begin{tabular}{|c|c|c|c|c|c|c|c|}
\hline \multirow[t]{2}{*}{ Assessment Related Changes } & \multicolumn{2}{|c|}{$\frac{\text { Group } 1}{\mathrm{D}}$} & \multicolumn{2}{|c|}{$\frac{\text { Group } 2}{\mathrm{M}}$} & \multicolumn{2}{|c|}{$\frac{\text { Group } 3}{\mathrm{~B}}$} & \multirow[b]{2}{*}{$\underline{F}$} \\
\hline & M & SD & $\mathrm{M}$ & SD & $\mathrm{M}$ & SD & \\
\hline lanning \& decision making ${ }^{a}$ & 3.94 & 1.06 & 3.34 & 1.24 & 3.39 & 1.16 & 1.570 \\
\hline ocation $^{\mathrm{a}}$ & 4.38 & .81 & 3.47 & .99 & 3.96 & 1.02 & $4.345^{\prime}$ \\
\hline langes ${ }^{\mathrm{a}}$ & 2.88 & 1.45 & 2.51 & 1.14 & 2.70 & 1.18 & .586 \\
\hline & 2.81 & 1.52 & 2.64 & 1.24 & 2.26 & 1.21 & 1.012 \\
\hline nent $^{\mathrm{a}}$ & 3.88 & 1.36 & 3.49 & 1.12 & 3.70 & .93 & .785 \\
\hline ing $^{\mathrm{a}}$ & 2.69 & 1.45 & 2.55 & 1.21 & 2.39 & 1.12 & .283 \\
\hline & 3.44 & 1.41 & 2.87 & 1.19 & 2.91 & 1.16 & 1.325 \\
\hline Faculty teaching ${ }^{\text {a }}$ & 2.94 & 1.39 & 2.66 & 1.05 & 2.91 & 1.31 & .526 \\
\hline
\end{tabular}

Note. $\mathrm{D}$ = Doctoral; $\mathrm{M}=$ Master's; $\mathrm{B}=$ Baccalaureate.

${ }^{a} \mathrm{n}=96$.

${ }^{*} \mathrm{p}<.05$.

The ANOVA for program review yielded $\mathrm{F}(2,93)=1.012, \mathrm{p}<.05$ and was not significant. The ANOVA for student recruitment yielded $F(2,93)=.785, \mathrm{p}<.05$ and was not significant. The ANOVA for improving learning yielded $F(2,93)=.283, p<.05$ and was not significant. The ANOVA for evaluating the assessment process yielded $\mathrm{F}(2,93)=$ 1.325, $\mathrm{p}<.05$ and was not significant. The ANOVA for faculty teaching yielded $\mathrm{F}(2,93)=$ $.526, \mathrm{p}<.05$ and was not significant. The ANOVA discovered a significant difference between the means of the Carnegie Classification responses for changes in resource allocation due to assessment.

The LSD test determined significant differences between the master's and doctoral institutions $(\mathrm{F}(2,93)=4.345, \mathrm{p}<.05), \mathrm{D}(\mathrm{M}=4.38, \mathrm{SD}=.81), \mathrm{M}(\mathrm{M}=3.47, \mathrm{SD}=.99))$. Changes had occurred somewhat in resource allocation due to assessment data at the master's institutions, but very little change had occurred at the doctoral institutions in resource allocation. 
Assessment results had been used somewhat to bring about changes or improvements in planning and decision making at master's and baccalaureate programs but very little at the doctoral ones. The assessment results were also used somewhat at doctoral and master's institutions for changes in program review and used often at baccalaureate programs.

Student recruitment was an area where changes had occurred somewhat in master's programs and very little at doctoral and baccalaureate institutions due to assessment results. Changes in student learning had occurred often at baccalaureate programs and somewhat at doctoral and master's programs due to assessment results. Changes were made somewhat in curriculum, the assessment process, and in faculty teaching due to assessment data at the programs in all of the classifications.

Assessment related changes and improvements by region.

The results were analyzed again to determine whether significant differences existed in the reported assessment related changes by region (See Table 50).

Table 50 Assessment Related Changes and Improvements by Region

\begin{tabular}{|c|c|c|c|c|c|c|c|}
\hline \multirow{2}{*}{ Assessment Related Changes } & \multicolumn{2}{|c|}{$\frac{\text { Group } 1}{\text { MS }}$} & \multicolumn{2}{|c|}{$\frac{\text { Group } 2}{\mathrm{NC}}$} & \multicolumn{2}{|c|}{$\frac{\text { Group } 3}{\mathrm{~S}}$} & \\
\hline & M & SD & M & SD & M & SD & \\
\hline Planning \& decision making ${ }^{a}$ & 3.71 & 1.16 & 3.46 & 1.16 & 3.28 & 1.32 & .617 \\
\hline Resource allocation $^{\mathrm{a}}$ & 3.65 & 1.11 & 3.93 & .93 & 3.78 & 1.11 & .995 \\
\hline Curricular changes $^{\mathrm{a}}$ & 3.00 & 1.17 & 2.49 & 1.16 & 2.44 & 1.20 & 1.690 \\
\hline Progra & 3.12 & 1.17 & 2.34 & 1.20 & 2.44 & 1.42 & 1.883 \\
\hline Studen & 4.00 & .87 & 3.45 & 1.14 & 3.44 & 1.34 & .982 \\
\hline Improve learning $^{\mathrm{a}}$ & 2.82 & 1.13 & 2.44 & 1.21 & 2.39 & 1.20 & 1.216 \\
\hline Evaluate assessment process ${ }^{a}$ & 3.29 & 1.16 & 2.90 & 1.16 & 2.80 & 1.30 & 1.388 \\
\hline Faculty Teaching & -3.00 & 1.17 & 2.61 & 1.12 & 2.61 & 1.29 & 1.433 \\
\hline
\end{tabular}

Note. $\mathrm{MS}=$ Middle States; NC = North Central; $\mathrm{S}=$ Southern.

${ }^{\mathrm{a}} \mathrm{n}=85$.

An Analysis of Variance (ANOVA) was computed for each of the eight dependent variables (planning and decision making, resource allocation, curricular changes, program 
review, student recruitment, improving learning, evaluating the assessment process, and faculty teaching). The independent variable in each one-way, between subjects ANOVA was region (middle states versus north central versus southern). The ANOVA for planning and decision making yielded $\mathrm{F}(2,82)=.617, \mathrm{p}<.05$ and was not significant. The ANOVA for resource allocation yielded $\mathrm{F}(2,82)=.995, \mathrm{p}<.05$ and was not significant. The ANOVA for curricular changes yielded $\mathrm{F}(2,82)=1.69, \mathrm{p}<.05$ and was not significant. The ANOVA for program review yielded $\mathrm{F}(2,82)=1.883, \mathrm{p}<.05$ and was not significant. The ANOVA for student recruitment yielded $\mathrm{F}(2,82)=.982, \mathrm{p}<.05$ and was not significant. The ANOVA for improving learning yielded $\mathrm{F}(2,82)=1.216, \mathrm{p}<.05$ and was not significant. The ANOVA for evaluating the assessment process yielded $\mathrm{F}(2,82)=1.388, \mathrm{p}<.05$ and was not significant. The ANOVA for faculty teaching yielded $F(2,82)=1.433, \mathrm{p}<.05$ and was not significant.

Changes and improvements had occurred somewhat at programs in the Southern and North Central regions and very little in the Middle States region in planning and decision making. Assessment related changes and improvements for resource allocation had occurred very little at the all the programs in all three regions. Changes and improvements in curriculum had occurred often in the North Central and Southern regions and somewhat in the Middle States region. Program review changes had occurred often in the North Central and Southern regions and somewhat in the Middle States region. Student recruitment changes had occurred somewhat in the North Central and Southern regions and very little in the Middle States region.

Changes and improvements due to assessment in student learning had occurred somewhat in the Middle States and often in the North Central and Southern regions. 
Changes in the assessment process and in faculty teaching due to assessment occurred somewhat as reported by the programs in all of the regions.

Assessment related changes and improvements by size.

The results were analyzed again to determine whether any significant differences existed in assessment related changes and improvements by size categories (See Table 51).

An Analysis of Variance (ANOVA) was computed for each of the eight dependent variables (planning and decision making, resource allocation, curricular changes, program review, student recruitment, improving learning, evaluating the assessment process, and faculty teaching). The independent variable in each one-way, between subjects ANOVA was size (small versus mid-size versus large).

Table 51

Assessment Related Changes and Improvements by Size

\begin{tabular}{|c|c|c|c|c|c|c|c|}
\hline \multirow{3}{*}{ Assessment Related Changes } & \multicolumn{2}{|c|}{ Group 1} & \multicolumn{2}{|c|}{ Group 2} & \multicolumn{2}{|c|}{ Group 3} & \multirow[b]{3}{*}{$\mathrm{F}$} \\
\hline & & $\bar{S}$ & & & & & \\
\hline & M & SD & M & SD & M & SD & \\
\hline Planning \& decision making ${ }^{\mathrm{a}}$ & 3.30 & 1.27 & 3.49 & 1.20 & 3.70 & .95 & .949 \\
\hline Resource allocation $^{\mathrm{a}}$ & 3.84 & .99 & 3.66 & 1.11 & 4.20 & .63 & 1.025 \\
\hline Curricular changes $^{\mathrm{a}}$ & 2.49 & 1.24 & 2.63 & 1.26 & 3.00 & 1.05 & .603 \\
\hline Program review ${ }^{\mathrm{a}}$ & 2.51 & 1.35 & 2.57 & 1.33 & 2.70 & 1.25 & .081 \\
\hline Student recruitment ${ }^{\mathrm{a}}$ & 3.62 & 1.11 & 3.34 & 1.19 & 4.40 & .52 & 2.635 \\
\hline Improve learning $^{\mathrm{a}}$ & 2.59 & 1.28 & 2.43 & 1.29 & 2.80 & 1.03 & .338 \\
\hline Evaluate assessment process ${ }^{a}$ & 2.97 & 1.26 & 2.86 & 1.31 & 3.50 & 1.08 & .702 \\
\hline Faculty Teaching ${ }^{\mathrm{a}}$ & 2.81 & 1.22 & 2.63 & 1.26 & 3.20 & .92 & .613 \\
\hline
\end{tabular}

Note. $\mathrm{S}=$ Small $<200 ; \mathrm{M}=$ Mid-size $=200-400 ; \mathrm{L}=$ Large $>400$.

${ }^{\mathrm{a}} \mathrm{n}=92$.

The ANOVA for planning and decision making yielded $F(2,89)=.949, \mathrm{p}<.05$ and was not significant. The ANOVA for resource allocation yielded $F(2,89)=1.025, p<.05$ and was not significant. The ANOVA for curricular changes yielded $F(2,89)=.603, p<.05$ and was not significant. The ANOVA for program review yielded $F(2,89)=.081, \mathrm{p}<.05$ and was not significant. The ANOVA for student recruitment yielded $\mathrm{F}(2,89)=2.635$, $\mathrm{p}<$ 
.05 and was not significant. The ANOVA for improving learning yielded $F(2,89)=.338$, p $<.05$ and was not significant. The ANOVA for evaluating assessment process yielded F (2, $89)=.702, \mathrm{p}<.05$ and was not significant. The ANOVA for faculty teaching yielded $\mathrm{F}$ (2, $89)=.613, p<.05$ and was not significant.

Changes and improvements in planning and decision making due to assessment results occurred somewhat in the programs in the small and mid-size groups but very little in the large category. Resource allocation was affected very little by assessment data at the programs in all of the size categories. Curricular changes due to assessment occurred often at the programs in the small group, but they occurred somewhat at the programs in the mid-size and large groups. Assessment related changes in program review occurred somewhat at the programs in all of the categories.

For student recruitment, changes and improvements occurred very little at programs in the small and large categories, and somewhat at the mid-size programs. Changes and improvements in student learning due to assessment occurred often at the mid-size programs and somewhat at the small and large ones. Changes and improvements in evaluation of the assessment process due to assessment results and in faculty teaching due to assessment occurred somewhat at the programs in all of the categories.

\section{Research Question 6: Sharing Assessment Results}

Research question 6 inquired about sharing assessment results. Survey results were examined to determine whether significant differences existed in assessment audiences and in how the assessment data were disseminated to the assessment audiences when analyzed by Carnegie Classification, region, and size.

Research Question 6a: Sharing Assessment Results: Assessment Audiences 
Participants were asked to indicate who received assessment data in their accounting programs from a list of individuals and groups. One participant stated that advisory boards received assessment reports or data in response to the request for other assessment audiences that are not listed.

Assessment audiences by Carnegie Classification.

The responses were analyzed by Carnegie Classification to determine if there was a significant difference in the audiences in this treatment group (See Table 52).

An Analysis of Variance (ANOVA) was computed for each of the nine dependent variables (students, parents, faculty, administrators, governance boards, accrediting organizations, general public, alumni, and business). The independent variable in each oneway, between subjects ANOVA was Carnegie Classification (doctoral versus master's versus baccalaureate).

The ANOVA for students yielded $\mathrm{F}(2,93)=.917, \mathrm{p}<.05$ and was not significant. The ANOVA for parents yielded $\mathrm{F}(2,93)=.548, \mathrm{p}<.05$ and was not significant. The ANOVA for faculty yielded $\mathrm{F}(2,92)=.177, \mathrm{p}<.05$ and was not significant.

Table 52 Assessment Audiences by Carnegie Classification

\begin{tabular}{|c|c|c|c|c|c|c|c|}
\hline \multirow{3}{*}{ Assessment Audiences } & \multicolumn{2}{|c|}{ Group 1} & \multicolumn{2}{|c|}{ Group 2} & \multicolumn{2}{|c|}{ Group 3} & \\
\hline & & 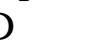 & & & & & \\
\hline & $\mathrm{M}$ & SD & M & SD & M & SD & \\
\hline Students $^{\mathrm{a}}$ & 4.00 & 1.41 & 4.32 & .91 & 4.00 & 1.17 & .917 \\
\hline Parents ${ }^{\mathrm{a}}$ & 4.75 & .68 & 4.57 & .71 & 4.70 & .47 & .548 \\
\hline Faculty $^{\mathrm{b}}$ & 2.19 & 1.42 & 2.00 & 1.10 & 2.13 & 1.32 & .177 \\
\hline Administrators $^{\mathrm{c}}$ & 1.81 & .91 & 2.37 & 3.25 & 2.35 & 1.40 & .310 \\
\hline Governance Board $^{\mathrm{b}}$ & 4.00 & 1.10 & 3.63 & 1.40 & 3.83 & 1.23 & .524 \\
\hline Accrediting Organizations & 2.25 & 1.57 & 2.50 & 1.46 & 2.96 & 1.49 & 1.197 \\
\hline General Public $^{\mathrm{a}}$ & 4.63 & 1.02 & 4.68 & .56 & 4.65 & .65 & .043 \\
\hline Alumni $^{\mathrm{a}}$ & 4.25 & 1.13 & 4.34 & .87 & 4.52 & .99 & .441 \\
\hline Business $^{\underline{\mathrm{a}}}$ & 4.25 & 1.24 & 4.09 & 1.10 & 4.39 & 1.08 & .598 \\
\hline
\end{tabular}

Note. $\mathrm{D}=$ Doctoral; $\mathrm{M}=$ Master's; $\mathrm{B}=$ Baccalaureate.

${ }^{a} n=96,{ }^{b} n=95,{ }^{c} n=92$. 
The ANOVA for administrators yielded $\mathrm{F}(2,89)=.31, \mathrm{p}<.05$ and was not significant. The ANOVA for governance boards yielded $\mathrm{F}(2,92)=.524, \mathrm{p}<.05$ and was not significant. The ANOVA for accrediting organizations yielded $F(2,92)=1.197, \mathrm{p}<.05$ and was not significant. The ANOVA for general public yielded F $(2,93)=.043, \mathrm{p}<.05$ and was not significant. The ANOVA for alumni yielded $\mathrm{F}(6,93)=.441, \mathrm{p}<.05$ and was not significant. The ANOVA for business was $\mathrm{F}(2,93)=.598, \mathrm{p}<.05$ and was not significant.

Students, governance boards, and business received very little assessment information from the programs in all of the classifications, and parents and the general public received none at all. Faculty and administrators received assessment data often at the programs in all classifications. Assessment reports were often given to accrediting organizations in the doctoral and master's programs, and somewhat given to the organizations in the baccalaureate programs. Alumni organizations at the doctoral and master's programs received very little assessment data, and the alumni at baccalaureate programs received none at all.

Assessment audiences by region.

The same responses were analyzed by region to determine if significant differences in assessment audiences existed among the regions (See Table 53). An Analysis of Variance (ANOVA) was computed for each of the nine dependent variables (students, parents, faculty, administrators, governance boards, accrediting organizations, general public, alumni, and business). The independent variable in each one-way, between subjects ANOVA was region (middle states versus north central versus southern). 
Table 53

Assessment Audiences Region

\begin{tabular}{|c|c|c|c|c|c|c|c|}
\hline \multirow{2}{*}{ Assessment Audiences } & Group 1 & $\frac{\text { up } 1}{\text { uS }}$ & Group 2 & $\frac{\text { up } 2}{\mathrm{C}}$ & & Group 3 & \\
\hline & M & SD & M & SD & M & SD & $\mathrm{F}$ \\
\hline Students $^{\mathrm{a}}$ & 4.35 & .86 & 3.93 & 1.08 & 4.22 & 1.35 & 1.050 \\
\hline Parents ${ }^{\mathrm{a}}$ & 4.53 & .62 & 4.51 & .75 & 4.83 & .51 & 1.523 \\
\hline Faculty $^{\mathrm{b}}$ & 2.29 & 1.26 & 1.88 & 1.19 & 2.12 & 1.22 & .771 \\
\hline Administrators $^{\mathrm{b}}$ & 2.12 & 1.17 & 2.46 & 3.42 & 1.88 & 1.15 & .305 \\
\hline Governance Board $^{\mathrm{c}}$ & 3.65 & 1.41 & 3.68 & 1.37 & 3.89 & 1.13 & .195 \\
\hline Accrediting Organizations ${ }^{c}$ & 2.76 & 1.79 & 2.68 & 1.42 & 2.06 & 1.26 & 1.334 \\
\hline General Public $^{\mathrm{a}}$ & 4.65 & .49 & 4.68 & .61 & 4.56 & 1.04 & .199 \\
\hline Alumni $^{\mathrm{a}}$ & 4.18 & 1.07 & 4.32 & 1.04 & 4.56 & .70 & .686 \\
\hline Business $^{\underline{\text { a }}}$ & 4.12 & 1.11 & 4.41 & 1.07 & 4.06 & 1.11 & .875 \\
\hline
\end{tabular}

Note. MS $=$ Middle States; $\mathrm{NC}=$ North Central; $\mathrm{S}=$ Southern .

${ }^{a} \mathrm{n}=85,{ }^{\mathrm{b}} \mathrm{n}=84,{ }^{\mathrm{c}} \mathrm{n}=82$.

The ANOVA for students yielded $\mathrm{F}(2,82)=1.05, \mathrm{p}<.05$ and was not significant.

The ANOVA for parents yielded $F(2,82)=1.523, \mathrm{p}<.05$ and was not significant. The ANOVA for faculty yielded $\mathrm{F}(2,81)=.771, \mathrm{p}<.05$ and was not significant. The ANOVA for administrators yielded $\mathrm{F}(2,81)=.305, \mathrm{p}<.05$ and was not significant. The ANOVA for governance boards yielded $\mathrm{F}(2,79)=.195, \mathrm{p}<.05$ and was not significant. The ANOVA for accrediting organizations yielded $\mathrm{F}(2,79)=1.334, \mathrm{p}<.05$ and was not significant. The ANOVA for general public yielded $\mathrm{F}(2,82)=.199, \mathrm{p}<.05$ and was not significant. The ANOVA for alumni yielded $\mathrm{F}(2,82)=.686, \mathrm{p}<.05$ and was not significant. The ANOVA for business was $F(2,82)=.875, \mathrm{p}<.05$ and was not significant.

Assessment results were shared very little with students, governance boards, and business at the programs in all of the regions, and parents and the general public received no assessment information at all. Faculty and administrators received assessment data often at these programs. Very little assessment data were shared with alumni in the Middle States and North Central regions, and none at all was shared in the Southern region. Accrediting 
organizations somewhat receive assessment data in the Middle States and North Central regions, and they often receive assessment results in the Southern region.

Assessment audiences by size.

The responses were analyzed again by size to determine if significant differences existed in the assessment audiences between the categories (See Table 54). An Analysis of Variance (ANOVA) was computed for each of the nine dependent variables (students, parents, faculty, administrators, governance boards, accrediting organizations, general public, alumni, and business).

The independent variable in each one-way, between subjects ANOVA was size (small versus mid-size versus large). The ANOVA for students yielded $F(2,89)=1.731, \mathrm{p}<.05$ and was not significant. The ANOVA for parents yielded $F(2,89)=1.856, p<.05$ and was not significant. The ANOVA for faculty yielded $\mathrm{F}(2,87)=.884, \mathrm{p}<.05$ and was not significant.

Table 54 Assessment Audiences by Size

\begin{tabular}{|c|c|c|c|c|c|c|c|}
\hline \multirow[t]{2}{*}{ Assessment Audiences } & \multicolumn{2}{|c|}{$\frac{\text { Group } 1}{\mathrm{~S}}$} & \multicolumn{2}{|c|}{$\frac{\text { Group } 2}{M}$} & \multicolumn{2}{|c|}{$\frac{\text { Group } 3}{\mathrm{~L}}$} & \multirow[b]{2}{*}{$F$} \\
\hline & M & $\mathrm{SD}$ & M & SD & M & SD & \\
\hline Students $^{\mathrm{a}}$ & 4.14 & 1.11 & 4.11 & 1.13 & 4.80 & .63 & 1.731 \\
\hline Parents ${ }^{\mathrm{a}}$ & 4.62 & .64 & 4.57 & .70 & 5.00 & .00 & 1.856 \\
\hline Faculty ${ }^{b}$ & 2.19 & 1.39 & 1.83 & 1.12 & 2.20 & .92 & .884 \\
\hline Administrators $^{\mathrm{c}}$ & 2.26 & 1.42 & 2.26 & 3.59 & 2.00 & .94 & .046 \\
\hline Governance Board $^{\mathrm{b}}$ & 4.00 & 1.31 & 3.31 & 1.28 & 4.30 & 1.06 & $3.698 *$ \\
\hline Accrediting Organizations ${ }^{\mathrm{b}}$ & 3.08 & 1.59 & 2.11 & 1.23 & 2.30 & 1.49 & $4.251^{*}$ \\
\hline General Public $^{\mathrm{a}}$ & 4.76 & .49 & 4.49 & .89 & 4.80 & .42 & 1.691 \\
\hline Alumni $^{\mathrm{a}}$ & 4.65 & .68 & 4.09 & 1.15 & 4.30 & .95 & $3.278 *$ \\
\hline$\underline{B u s i n e s s}^{\mathrm{a}}$ & 4.35 & 1.14 & 4.03 & 1.12 & 4.10 & 1.10 & .769 \\
\hline
\end{tabular}


The ANOVA for administrators yielded $\mathrm{F}(2,86)=.046, \mathrm{p}<.05$ and was not significant. The ANOVA for governance boards yielded $\mathrm{F}(2,87)=3.698, \mathrm{p}<.05$ and was significant. The ANOVA for accrediting organizations yielded $F(2,87)=4.251, \mathrm{p}<.05$ and was significant. The ANOVA for general public yielded $\mathrm{F}(2,89)=1.691, \mathrm{p}<.05$ and was not significant. The ANOVA for alumni yielded $\mathrm{F}(2,89)=3.278, \mathrm{p}<.05$ and was significant. The ANOVA for business was $\mathrm{F}(2,89)=.769, \mathrm{p}<.05$ and was not significant.

The ANOVA discovered significant differences in the means of governance boards, accrediting organizations, and alumni as assessment audiences by size categories. The LSD found significant differences between the small and mid-size programs for governance boards, $(\mathrm{F}(2,87)=3.698, \mathrm{p}<.05), \mathrm{S}(\mathrm{M}=4, \mathrm{SD}=1.31)$ and $\mathrm{M}(\mathrm{M}=3.31, \mathrm{SD}=1.28)$, accrediting organizations, $(\mathrm{F}(2,87)=4.251, \mathrm{p}<.05), \mathrm{S}(\mathrm{M}=3.08, \mathrm{SD}=1.59)$ and $\mathrm{M}(\mathrm{M}=$ $2.11, \mathrm{SD}=1.23))$, and alumni, $(\mathrm{F}(2,89)=3.278, \mathrm{p}<.05), \mathrm{S}(\mathrm{M}=4.65, \mathrm{SD}=.68)$ and $\mathrm{M}(\mathrm{M}$ $=4.09, \mathrm{SD}=1.15)$ ).

Governance boards received very little assessment information at the small programs, but they received assessment information somewhat as assessment audiences at the mid-size programs. The small programs shared assessment data only somewhat with accrediting organizations, but the mid-size programs shared assessment data often with them. Alumni received very little assessment information from the mid-size, but they received none at all from the small programs.

Business received very little assessment data from the programs in the size categories. Parents received no assessment data at all. Faculty and administrators received assessment reports often from the programs in the three groups. The general public received very little assessment information in the mid-size group, and none at all from the small and large 
programs. Students at the small and mid-size programs received very little assessment information, and they received none at all at the large ones.

Research Question 6b: Sharing Assessment Results: Dissemination of Assessment Results

Survey responses were also analyzed to determine whether significant differences existed in how extensively specified methods were used to disseminate assessment data across treatment conditions. No responses were recorded for requested other methods of dissemination used but not listed.

\section{Dissemination of assessment results by Carnegie Classification.}

The responses were analyzed first by Carnegie Classification (See Table 55).

An Analysis of Variance (ANOVA) was computed for each of the seven dependent variables (school newspapers, accrediting organizations reports, governance board reports, marketing campaign, school website, school catalog or brochure, and conferences or workshops). The independent variable in each one-way, between subjects ANOVA was Carnegie Classification (doctoral versus master's versus baccalaureate).

Table 55

Dissemination of Assessment Results by Carnegie Classification

\begin{tabular}{lrrrrrrrrr}
\hline & \multicolumn{2}{c}{ Group 1 } & & \multicolumn{2}{c}{ Group 2 } & \multicolumn{3}{c}{ Group 3 } \\
Dissemination of Results & \multicolumn{2}{c}{ D } & & \multicolumn{3}{c}{ M } & & \multicolumn{1}{c}{ B } & \\
& SD & M & SD & M & SD & M & F \\
\hline School Newspapers $^{\mathrm{a}}$ & 4.81 & .54 & 4.23 & 1.16 & 4.65 & .78 & 2.712 \\
Accrediting Organization Reports $^{\mathrm{a}}$ & 2.38 & 1.54 & 2.51 & 1.43 & 3.22 & 1.44 & 2.242 \\
Governance Board Reports $^{\mathrm{a}}$ & 4.06 & 1.29 & 3.70 & 1.20 & 3.91 & 1.28 & .587 \\
Marketing Campaigns $^{\mathrm{a}}$ & 4.75 & .68 & 4.19 & .97 & 4.39 & .89 & 2.315 \\
School Website $^{\mathrm{a}}$ & 4.38 & 1.20 & 3.87 & 1.23 & 4.04 & 1.25 & 1.004 \\
School Catalog or Brochures $^{\mathrm{a}}$ & 4.63 & .72 & 3.85 & 1.20 & 4.00 & 1.31 & 2.670 \\
Conferences or Workshops $^{\mathrm{a}}$ & 4.13 & 1.36 & 3.94 & 1.07 & 4.26 & 1.05 & .678 \\
\hline
\end{tabular}

Note. $\mathrm{D}=$ Doctoral; $\mathrm{M}$ = Master's; $\mathrm{B}=$ Baccalaureate.

${ }^{\mathrm{a}} \mathrm{n}=96$.

The ANOVA for school newspapers yielded $\mathrm{F}(2,93)=2.712, \mathrm{p}<.05$ and was not significant. The ANOVA for accrediting organization reports yielded $F(2,93)=2.242, \mathrm{p}<$ 
.05 and was not significant. The ANOVA for governance board reports yielded $\mathrm{F}(2,93)=$ .587, $\mathrm{p}<.05$ and was not significant. The ANOVA for marketing campaigns yielded $\mathrm{F}$ (2, $93)=2.315, \mathrm{p}<.05$ and was not significant.

The ANOVA for school websites yielded $\mathrm{F}(2,93)=1.004, \mathrm{p}<.05$ and was not significant. The ANOVA for school catalogs or brochures yielded $\mathrm{F}(2,93)=2.67, \mathrm{p}<.05$ and was not significant. The ANOVA for conferences or workshops yielded $\mathrm{F}(2,93)=.678$, $\mathrm{p}<.05$ and was not significant.

The school newspaper was used very little to report assessment information in the master's programs, and it was not used at all in the doctoral and baccalaureate programs. Accrediting organization often received assessment reports from the doctoral programs and somewhat received them at master's and baccalaureate programs.

Very little assessment data were disseminated in governance board reports, at school websites, and at conferences and workshops by these programs. Marketing campaigns were also used very little as a method of disseminating assessment data at the master's and baccalaureate institutions and not at all at the doctoral ones. School catalogs or brochures were used very little at master's and baccalaureate institutions to disseminate assessment data and not at all used at the doctoral programs.

Dissemination of assessment results by region.

The responses were analyzed again to determine any significant differences that might exist in the dissemination methods by region (See Table 56). An Analysis of Variance (ANOVA) was computed for each of the seven dependent variables (school newspapers, accrediting organizations reports, governance board reports, marketing campaign, school website, school catalog or brochure, and conferences or workshops). The 
independent variable in each one-way, between subjects ANOVA was region (middle states versus north central versus southern).

The ANOVA for school newspapers yielded $\mathrm{F}(2,82)=.104, \mathrm{p}<.05$ and was not significant. The ANOVA for accrediting organization reports yielded $F(2,82)=2.83$, $\mathrm{p}<$ .05 and was not significant. The ANOVA for governance board reports yielded $\mathrm{F}(2,82)=$ $.159, \mathrm{p}<.05$ and was not significant. The ANOVA for marketing campaigns yielded $\mathrm{F}$ (2, $82)=.132, \mathrm{p}<.05$ and was not significant. The ANOVA for school websites yielded $\mathrm{F}(2$, $82)=.543, \mathrm{p}<.05$ and was not significant. The ANOVA for school catalogs or brochures yielded $\mathrm{F}(2,82)=.374, \mathrm{p}<.05$ and was not significant. The ANOVA for conferences or workshops yielded $\mathrm{F}(2,82)=.923, \mathrm{p}<.05$ and was not significant.

Table 56

Dissemination of Assessment Results by Region

\begin{tabular}{|c|c|c|c|c|c|c|c|}
\hline \multirow{2}{*}{ Dissemination of Results } & \multicolumn{2}{|c|}{ Group 1} & \multicolumn{2}{|c|}{ Group 2} & \multicolumn{2}{|c|}{ Group 3} & \\
\hline & M & $\mathrm{SD}$ & $\mathrm{M}$ & $\mathrm{SD}$ & $M$ & SD & \\
\hline School Newspapers $^{\mathrm{a}}$ & 4.29 & 1.10 & 4.41 & 1.02 & 4.44 & 1.10 & .10 \\
\hline Accrediting Organization Reports & 2.47 & 1.66 & 2.95 & 1.50 & 2.00 & 1.03 & 2.830 \\
\hline Governance Board Reports ${ }^{\mathrm{a}}$ & 3.71 & 1.26 & 3.90 & 1.20 & 3.89 & 1.32 & .15 \\
\hline Marketing Campaigns $^{\mathrm{a}}$ & 4.24 & 1.09 & 4.37 & .83 & 4.28 & 1.07 & .132 \\
\hline School Website ${ }^{\mathrm{a}}$ & 4.24 & 1.15 & 3.90 & 1.22 & 3.83 & 1.42 & .54 \\
\hline School Catalog or Brochures ${ }^{a}$ & 4.18 & 1.13 & 3.95 & 1.14 & 3.83 & 1.38 & .374 \\
\hline Conferences or Workshops ${ }^{\underline{a}}$ & 3.76 & 1.20 & 4.20 & 1.17 & 3.94 & 1.06 & .923 \\
\hline
\end{tabular}

Note. MS = Middle States; $\mathrm{NC}=$ North Central; $\mathrm{S}=$ Southern.

${ }^{\mathrm{a}} \mathrm{n}=85$

School newspapers, governance boards, marketing campaigns, school websites, school catalogs or brochures, and conferences and workshops were used very little to report assessment data at the programs in all of the regions. Assessment data were disseminated often in the Middle States and Southern regions and somewhat at the North Central regions through accrediting organization reports. 


\section{Dissemination of assessment results by size.}

The survey results were analyzed again by size categories to determine whether any significant differences existed in dissemination methods used to report assessment data (See Table 57). An Analysis of Variance (ANOVA) was computed for each of the seven dependent variables (school newspapers, accrediting organizations reports, governance board reports, marketing campaign, school website, school catalog or brochure, and conferences or workshops). The independent variable in each one-way, between subjects ANOVA was size (small versus mid-size versus large).

The ANOVA for school newspapers yielded $\mathrm{F}(2,89)=2.339, \mathrm{p}<.05$ and was not significant. The ANOVA for accrediting organization reports yielded $\mathrm{F}(2,89)=2.319, \mathrm{p}<$ .05 and was significant. The ANOVA for governance board reports yielded $\mathrm{F}(2,89)=$ 2.553, $\mathrm{p}<.05$ and was not significant.

Table 57

Dissemination of Assessment Results by Size

\begin{tabular}{|c|c|c|c|c|c|c|c|}
\hline \multirow[t]{2}{*}{ Dissemination of Results } & \multicolumn{2}{|c|}{$\frac{\text { Group } 1}{\mathrm{~S}}$} & \multicolumn{2}{|c|}{$\frac{\text { Group 2 }}{M}$} & \multicolumn{2}{|c|}{$\frac{\text { Group } 3}{L}$} & \multirow[b]{2}{*}{$\mathrm{F}$} \\
\hline & $\mathrm{M}$ & $\mathrm{SD}$ & M & SD & $\mathrm{M}$ & SD & \\
\hline School Newspapers $^{\mathrm{a}}$ & 4.46 & .99 & 4.23 & 1.14 & 5.00 & .00 & 2.339 \\
\hline Accrediting Organization Reports ${ }^{\mathrm{a}}$ & 3.11 & 1.56 & 2.14 & 1.17 & 2.90 & 1.66 & 2.319 \\
\hline Governance Board Reports $^{\mathrm{a}}$ & 4.14 & 1.16 & 3.57 & 1.20 & 3.40 & 1.51 & 2.553 \\
\hline Marketing Campaigns $^{\mathrm{a}}$ & 3.49 & .80 & 4.00 & 1.06 & 3.80 & .42 & 4.345* \\
\hline School Website $^{\mathrm{a}}$ & 4.30 & 1.00 & 3.63 & 1.40 & 4.30 & 1.16 & 3.114 \\
\hline School Catalog or Brochures ${ }^{a}$ & 4.00 & 1.27 & 3.97 & 1.12 & 4.40 & 1.07 & .539 \\
\hline Conferences or Workshops ${ }^{\underline{\text { a }}}$ & 4.41 & .90 & 3.50 & 1.25 & 4.40 & .84 & $4.127 *$ \\
\hline
\end{tabular}

The ANOVA for marketing campaigns yielded $\mathrm{F}(2,89)=4.345, \mathrm{p}<.05$ and was significant. The ANOVA for school websites yielded $\mathrm{F}(2,89)=3.114, \mathrm{p}<.05$ and was not significant. The ANOVA for school catalogs or brochures yielded $\mathrm{F}(2,89)=.539, \mathrm{p}<.05$ 
and was not significant. The ANOVA for conferences or workshops yielded F $(2,89)=$ 4.127, $\mathrm{p}<.05$ and was significant.

The ANOVA discovered significant differences between the means for the use of marketing campaigns, $(\mathrm{F}(2,89)=4.345, \mathrm{p}<.05), \mathrm{S}(\mathrm{M}=3.49, \mathrm{SD}=.8)$, and $\mathrm{M}(\mathrm{M}=4$, SD $=1.06)$ ) as methods used to disseminate assessment data. Marketing campaigns were used somewhat to disseminate assessment data at the programs in the small category, but they were used very little at the mid-size group.

Significant differences were also found for disseminating assessment information through conferences and workshops between the mid-size and small categories and between the mid-size and large programs, $(\mathrm{F}(2,89)=4.127, \mathrm{p}<.05), \mathrm{S}(\mathrm{M}=4.41, \mathrm{SD}=.9), \mathrm{M}(\mathrm{M}=$ 3.50, $\mathrm{SD}=1.25)$, and $\mathrm{L}(\mathrm{M}=4.4, \mathrm{SD}=.84))$.

Assessment results were shared somewhat at conferences and workshops at programs in the mid-size category, but the results were shared very little at conferences and workshops at programs in the small and large categories. School newspapers were used very little at small and mid-size programs and not at all at the large programs to disseminate assessment data. Governance board reports were used somewhat at the large programs and very little at the small and mid-size ones to disseminate assessment information. School websites, and school catalogs or brochures were used very little to disseminate assessment information.

\section{Summary}

No significant differences were found in the responses of the accounting chairs when asked how extensively the five essential skills (critical thinking, information literacy, oral communication, problem solving, and written communication) were addressed and identified in the accounting programs. The respondents reported that the essential skills were addressed 
often to extensively, and the skills were also identified as learning outcomes often and extensively in the accounting programs.

When participants reported (Table 35 - 39) how extensively the essential skills were addressed in individual required courses; however, the responses were inconsistent with the previous results. The responses to how extensively the essential skills were addressed in individual required courses were: not addressed, introduced, and emphasized. It is important to note that theses responses were not analyzed for significant differences by ANOVA due to the scope of the analysis.

Significant differences were reported by the accounting chairs in the use of direct and indirect assessment instruments to measure student learning. Differences were also discovered in the use of assessment data and the assessment related changes and improvements. Assessment audiences and methods used for dissemination of assessment results were also significantly different. The participants reported great variability in direct and indirect assessment methods used by the programs:

1. A significant difference was found in the use of locally designed tests as direct assessment instruments between the Middle States and Southern regions and between the Southern and North Central regions (See Table 41). The study revealed that locally designed tests were used significantly more often in the Southern region than in the Middle States and North Central regions.

2. A significant difference was also found between the programs in the small and mid-size categories in the use of standardized national tests as direct assessment instruments. The mid-size programs sometimes used the standardized national 
licensure tests, which was significantly different from small schools that used them very little (See Table 42).

3. A significant difference existed in the use of graduate follow-up studies as an indirect method of assessment between all three Carnegie Classifications, the doctoral, master's, and baccalaureate institutions (See Table 43). The doctoral institutions used graduate follow-up studies significantly more often as indirect methods of assessment than the master's institutions that used them very little, and the baccalaureate colleges that did not use them at all.

4. A significant difference was also found in the use of retention and transfer studies as indirect assessment methods between the master's and the baccalaureate institutions (See Table 43). Master’s institutions sometimes used retention and transfer studies and this was significantly different from baccalaureate institutions that used these studies very little.

5. Additionally, a significant difference was discovered for the use of alumni surveys as an indirect method between the small and mid-size programs (See Table 45). At mid-size program alumni surveys were used significantly more often than small programs that only sometimes used these surveys.

6. Significant differences also existed between the small and mid-size and between the small and large groups for employer surveys. Mid-size programs sometimes used employer surveys and large institutions often used them, and this was significantly different from small institutions that seldom used these surveys. Significant differences were discovered in the use of assessment data and in the assessment related changes and improvements reported by the participants: 
7. Significant differences were found between the master's and doctoral institutions and between the master's and baccalaureate in the use of assessment data for resource allocation (See Table 46). The master's institutions sometimes used assessment data for resource allocation, but this was significantly different from the doctoral and baccalaureate groups that reported seldom using the data.

8. Significant differences were also found between the master's and doctoral institutions in resource allocation changes due to assessment data (See Table 49). Sometimes changes were made to resource allocations in the master's institutions and this was significantly different from the very few changes in resources that occurred at doctoral institutions.

Significant differences were also found in the assessment audiences who received assessment data:

9. Significant differences were found between the small and mid-size programs for governance boards as audiences of assessment results (See Table 54). Mid-size institutions sometimes shared assessment results with governance boards and this was significantly different from small program that seldom shared this information with their boards.

10. Significant differences were found between the small and mid-size programs for accrediting organizations as recipients of assessment data. The mid-size programs significantly more often shared their assessment data with accrediting organizations than did small programs.

11. Significant differences were also found between the small and mid-size programs for alumni as assessment audiences. Mid-size programs seldom shared 
assessment results with alumni and this was significantly different from small programs that reported sharing no information with alumni.

Significant differences also existed in the responses by the participants in the accounting programs regarding the use of marketing campaigns as methods to disseminate assessment data (See Table 57):

12. Significant differences were found between the small and mid-size programs for marketing campaigns. Marketing campaigns were sometimes used to disseminate assessment data for the programs in the small category and this was significantly different from the mid-size group that seldom used these campaigns.

13. Significant differences were found between the small and mid-size programs for the presentation of assessment results at conferences and workshops. Mid-size institutions significantly more often shared their assessment results at conferences and workshops than did accounting programs in small and large universities. 


\section{Chapter 5: Conclusion and Recommendations}

This study gathered assessment information from accounting educators throughout the United States to determine the frequency of various assessment activities occurring in accounting programs. Overall, the research offers evidence of the development, refinement, and understanding of the assessment process at the majority of the reporting accounting programs. Although this study indicates much progress has been made in assessment of accounting education, it also shows that more work is needed to prepare students for success in the ever changing, dynamic accounting profession.

\section{Assessment Process}

Of the 96 institutions (six did not have separate accounting programs) represented in this study 90\% $(n=86)$ reported that they had either implemented assessment plans, or they were somewhere in the process of creating plans. By classification, $100 \%(n=17)$ of the doctorate-granting institutions, 88\% (n = 46) of the master's-granting institutions, and 85\% $(n=23)$ of the baccalaureate-granting institutions reported some commitment to assessment of student learning (See Table 15). By region, 88\% $(n=15)$ of the Middle States accounting programs, 93\% $(n=42)$ of the North Central, $78 \%(n=18)$ of the Southern programs, and all of the North West $(n=5)$, West $(n=5)$, and New England $(n=1)$ accounting programs were involved in assessment to some degree (See Table 16).

By size, $84 \%(n=36)$ of the programs in the small category, $92 \%(n=35)$ of those in the mid-size group, and $100 \%(n=11)$ of the programs in the large category (four did not respond to accounting enrollment numbers) had become engaged in the assessment process (See Table 17). The results indicated that mostly large doctorate-granting institutions in the 
North Central region are taking the lead in developing assessment plans for their accounting programs.

Of the 86 accounting programs that conducted assessments, $55 \%(n=47)$ of them reported that assessment was an ongoing, routine activity. By classification, that is $65 \%$ ( $\mathrm{n}=$ 11) of the doctoral, $46 \%(n=22)$ of the master's, and $58 \%(n=14)$ of the baccalaureate institutions engaged in assessment activity (See Table 18). By region, 35\% $(n=6)$ of the Middle States, 58\% $(n=25)$ of the North Central, $44 \%(n=8)$ of the Southern, and all of the North West $(n=5)$, and Western region $(n=3)$ reported on-going assessment (See Table 19). By size, $47 \%(n=18)$ of the small, $61 \%(n=22)$ of the mid-size, and $45 \%(n=5)$ of the large accounting programs had made assessment a routine activity (See Table 20). The findings indicated that mostly mid-size doctorate-granting institutions in the North Central region have made assessment an on-going routine activity.

Eighty percent of the accounting chairs in this study reported that assessment occurred more than once during a student's academic career. Huba \& Freed (1999) state that assessment is learner-centered and faculty should collect and discuss data to develop a greater understanding of what our students know and what they can do with that knowledge.

The results showed that students were involved in assessment at any one or perhaps all academic levels including freshman, sophomore, junior, senior, and even post-graduate. Some accounting programs reported assessment activity occurred only once, while others reported students were assessed from the freshman year to post-graduate status. However, all of the respondents indicated that students were assessed in the senior year. 


\section{Essential Skills and Competencies Addressed in Accounting Programs}

Impressively, all of the accounting program chairs reported that all of the essential skills identified in this study (critical thinking, information literacy, oral communication, problem solving, and written communication) were addressed often or extensively in the accounting programs across the three treatment groups (Carnegie Classification, region, and size).

The findings from this study are not consistent with calls for reform to integrate these skills across the curriculum particularly in the major. For example, the AICPA Core Competency Framework (See Appendix A) calls on accounting educators to integrate the identified core competencies into the coursework and evaluate the program's success through assessment of graduating seniors (AICPA, 1999).

In the Albrecht \& Sack (2000) study commissioned by accounting organizations and professional groups, faculty and practitioners were asked to "prioritize skills in terms of how much class time should be spent in developing each [skill]” (p 56). In the 2000 study, analytical/critical thinking was ranked as the top priority. Written communication ranked second, oral communication was in third position, and computer technology ranked fourth.

These skills were also the focus of this research noting that the number one ranked skill in the Albrecht \& Sack study, analytical/critical thinking is consistent with two of the skills addressed in this study, problem solving and critical thinking. Additionally, computer technology is a subset of information literacy. Furthermore, the AICPA's Core Competency Framework (1999) and its Vision Statement (1998) emphasized the same skills identified in the 2000 study. 
Education organizations and governmental officials alike call for more emphasis on oral and written communication skills, qualitative and quantitative reasoning capabilities, critical thinking abilities, and information literacy as outlined in the 2001 Association of American Colleges and Universities (AAC\&U) report and the 1994 U. S. Department of Education study.

\section{Essential Skills and Competencies Identified as Learning Outcomes}

This study revealed that the specified essential skills in this study were identified as learning outcomes often or extensively in the accounting programs across all treatment conditions. Hutchings \& Marchese (1990) define student learning outcomes by the questions posed by assessment: What do faculty intend for students to learn in their programs of study? What should our graduates know? What should they able to do? Have our graduates acquired what faculty intended them to learn?

Learning outcomes should measure discipline-specific knowledge and transferable skills such as critical thinking and problem solving (Palomba and Banta, 1999). Many professional accrediting organizations as early as 1989 required the linking of technical knowledge and appropriate abilities such as critical thinking and interpersonal skills (Hagerty \& Stark, 1996). Competency based learning and assessment aids in the development of workplace skills and traits that permit graduates to meet the challenges of life and become successful business leaders (Russell, 2005).

A well-documented example of competency-based assessment can be found at Alverno College. The faculty describe assessment as "a multidimensional process of judging the individual in action ... in both course-based assessments and integrative assessments which focus on student learning from several courses” (2006). The faculty began with a 
conceptual framework based upon "an ability based approach to learning." They identified specific abilities that students are expected to develop in their selected disciplines, and those competencies are assessed at the individual and program level. Chief among the abilities identified in the Alverno framework are communication, analysis, and problem solving (2006).

\section{Essential Skills and Competencies Addressed in Required Accounting Courses}

The results showed that most of the essential skills identified in this study often were introduced, sometimes emphasized, or not addressed at all in traditionally required accounting courses. These findings are inconsistent with previous responses that reported all of the essential skills were addressed often or extensively in accounting courses. When reporting on individual courses with few exceptions, the program chairs reported that critical thinking, information literacy, and written communication were mostly introduced in the beginning principles courses. Problem solving was predominantly emphasized, and oral communication was mainly not addressed.

In the intermediate level courses, the chairs indicated that critical thinking, problem solving, and information literacy were primarily emphasized, and written communication was either introduced or emphasized. Oral communication was mostly not addressed. In the upper level courses, the program leaders reported that critical thinking, information literacy, and problem solving for the most part were emphasized. Oral communication, by and large, was not addressed, and written communication generally was introduced.

Critical thinking and problem solving skills were the most often emphasized skills. Information literacy was introduced in the lower level accounting courses and emphasized in the upper level courses. This study found that students were not given as much opportunity 
to develop good oral and written communication skills in accounting courses. Oral communication was mostly not addressed or just introduced in the majority of the courses, while written communication was mostly not addressed or just introduced in the first few courses in the students' program of study, but it was somewhat emphasized in the upper level courses.

Constituents of higher education advocate integration of these essential skills into all majors, including accounting. Addressing these essential skills in business education programs of study is imperative to properly prepare students for successful careers; the integration of these essential skills improves a student's ability to process financial information and to make sensible business decisions (Jones 1995).

“The new accounting professional needs a value added focus from the time of entry into the profession until retirement” (Bolt-Lee \& Foster, 2002, p. 34). These professionals must possess keen critical thinking, communication, and problem solving skills as well as an exceptional understanding of information technology (Gary Siegel Organization, 1994).

Starting with the 1986 Bedford Report, accounting professionals have urged educators to restructure accounting programs and revise traditional accounting education to include what is often referred to as 'soft' skills such as critical thinking, oral and written communication, and other essential core competencies (Bolt-Lee \& Foster, 2002). So strong is the belief in the accounting profession that accounting education must include workplace essential skills that Phase Two of the AICPA's Core Competency Framework addresses strategies for developing curriculum and enhancing instruction to incorporate the competencies into the classroom. In addition, the organization is developing assessment software that will assess the level of integration of these essential skills into upper-level 
accounting courses. Future phases will go so far as to link the core competencies to accounting research and textbooks (Bolt-Lee \& Foster, 2002).

\section{Assessment Methods}

The American Accounting Association (AAA) published A Guide for Professional Accounting Programs (1995) that emphasized the use of outcomes-based assessment to measure the development of students' skills and their mastery of knowledge obtained in their major. The Guide compiled a list of the most frequently used assessment methods that included objective examinations, measurements of performance, surveys, and proxy indicators (Gainen \& Locatelli).

Measurements of performance and objective examinations are the most commonly used direct methods of assessment to measure students' general knowledge upon completion of undergraduate programs. Performances are measured through essay and oral exams, presentations, group projects, case studies, and proxy indicators, such as GRE and GMAT tests. The most commonly used indirect methods of assessments discussed in the assessment guide are surveys of current students, graduates, and employers that focus on satisfaction and attitudes about the educational programs (Gainen \& Locatelli, 1995). These assessment instruments provide evidence of the integration of skills and measure students' ability to apply knowledge learned in other courses and programs (AICPA, 2002).

Assessment methods used by survey participants were consistent with those identified in the AAA Guide, but very few of the methods were used extensively. The study indicated that capstone courses, internships, case studies, essays, locally designed tests, and standardized or national licensure tests were used mostly somewhat as direct methods of assessment of student learning. Other direct methods such as portfolios and juried review 
were seldom used or not used at all for assessment by most of the accounting programs.

Responses were similar across treatment conditions except for significant differences that were discovered in the use of locally designed tests among the programs in the size categories and in the use of standardized national or licensure tests among the programs in the regions.

The indirect methods of assessment used by participants in the study also mirrored the methods identified in the AAA Guide (Gainen \& Locatelli, 1995). Student surveys generally were used often for assessment by all of the programs. Alumni surveys, employer surveys, and exit interviews were used somewhat. Graduate follow-up studies were used often to very little. The programs reported that focus groups, retention and transfer studies, and reflective papers were used mostly very little for assessment.

The survey responses revealed great variability in the use of assessment instruments across the treatment conditions. More significant differences were found in the indirect assessment instruments used than in any other dependent variable in the analysis. Significant differences existed in the use of four indirect methods. The survey responses showed that significant differences were found in the Carnegie Classifications for the use of graduate follow-up studies and for the use of retention and transfer studies. Significant differences were also found in the use of alumni surveys and employer surveys in the programs in the size categories.

\section{Uses of Assessment Data}

Generally, the respondents across treatment conditions indicated that assessment data were used often for curricular changes and program review as well as to improve student learning. The results also revealed that the data were used for resource allocation somewhat 
to very little. The participants also indicated that assessment results were used somewhat for planning and decision-making, very little for student recruitment, and somewhat for evaluation of the assessment process. Responses were similar across the treatment groups except for a significant difference that existed between the Carnegie Classifications programs for the use of assessment data for resource allocation.

A great deal of time has been devoted to creating assessment instruments, developing methods of analysis, and storing of assessment data, but little attention has been given to the use of assessment data to revise programs and improve learning (Soundarajan, 2004). The Transformative Assessment Project (TAP) was designed to help bridge the gap between collecting and analyzing assessment data and using the assessment data to improve learning through curricular changes, program review, planning, and decision making (WSU, NLII, Educause, CNI, \& TLT Group, 2003). The TAP collects and analyzes data about student learning, the learning process, and its purpose from multiple and diverse sources. The findings of a TAP are used continuously to redesign learning and teaching models, to inform stakeholders of changes and accomplishments, and to invite discussion that can lead to further improvement and revision (2003).

\section{Assessment Related Changes and Improvements}

When asked what assessment related changes or improvements had occurred in their programs, the chairs revealed that assessment data had been used somewhat in planning and decision making and to improve student learning. The data were also used somewhat for program review, curricular changes, faculty teaching, and changes in the assessment process. Assessment results have also been used mostly very little for student recruitment and resource allocation. The programs were in agreement with these responses in all of the 
groups with one exception in the Carnegie Classification for changes in resource allocation due to assessment results.

Although this study's respondents indicated that assessment results were used often for program changes, curricular changes, and improvements in student learning, little change was reported in these areas due to the assessment data. Too often, assessment information is collected, tabulated, and reported to the constituents who request it, but little resulting change occurs (Maki, 2002; Lorenzetti, 2004). Maki (2002) maintains that to achieve institutional effectiveness, decisions should be made based upon interpretation of the assessment data and results and changes should be communicated to those audiences who need to respond.

\section{Assessment Audiences}

The respondents indicated that students, parents, alumni, governance boards, business, and the general public received very little assessment data. However, faculty, administrators, and accrediting organizations often received assessment results. Responses were similar across treatment conditions except for significant differences that existed in governance boards, accrediting organizations, and alumni as audiences of assessment data in the size categories.

\section{Dissemination of Assessment Results}

The assessment data were often disseminated in accrediting organization reports, and very little assessment data were included in governance board reports. However, assessment results were seldom disseminated by school newspapers, in marketing campaigns, at school websites, in school catalogs or brochures, or at conferences or workshops. Significant differences existed in the size categories for the use of marketing campaigns and conferences and workshops as methods of dissemination of assessment data. 
The survey results supported the prevailing literature that contends assessment data are not often shared with constituents. Few reports were disseminated except to those agencies or stakeholders who required assessment data. However, all constituents of higher education should be informed of assessment results. Huba \& Freed (2000) declare that one of the primary audiences for assessment data is the student being assessed. The authors maintain that students should be informed of the skills and competencies assessed, and assessment results should be shared with students to permit them to improve their skills and expand their knowledge.

Faculty must receive assessment results to enable them to evaluate the findings and make changes in curriculum and programs to meet the needs of students if change is needed. Assessment data should be made available to administrators so they can use it in strategic planning, resource allocation, and program changes (Maki, 2002). In addition, accrediting organizations, legislative bodies, governance boards, business leaders, and other external constituents should receive pertinent assessment data as determined by the needs of the constituents (Palomba \& Banta, 1999).

A greater number of significant differences were found between the size categories (small, mid-size, and large) than between the Carnegie Classifications (doctoral, masters', and baccalaureate) or region categories (middle states, north central, and southern). Significant differences existed in eight of the dependent variables that were analyzed by size, mostly between the small and mid-size categories; whereas, significant differences were found in four dependent variables primarily between the doctoral and masters' Carnegie Classifications, and only one significant difference was discovered for the dependent variables between all three region categories. 


\section{Implications for Practice}

This section offers recommendations to faculty and administrators of accounting programs to encourage them to build stronger, more successful accounting programs and assessment plans based upon the findings of this study and the expertise of leading authorities in the field. This study revealed that some of the essential skills were introduced in most of the accounting courses. However, the data also showed that sometimes the skills were not emphasized, especially written and oral communication skills.

If introductory courses integrated these skills early into the programs of study, students would be given greater opportunity to develop stronger skills and competencies before entering the job market. Intermediate and upper-level courses could reinforce the essential skills to strengthen learning and enhance the development of the skills and competencies. Redesigning accounting programs as recommended in the Albrecht \& Sachs (2000) study to integrate the strategic/critical thinking, communication, analytical, and decision-making skills into the coursework in the early courses would provide a stronger program and enhance student learning.

Documentation of students' entering abilities is needed to determine improvement in student learning. Such information would permit faculty to establish baseline evidence of students' skill development as beginning undergraduates. The educational achievements of students during previous formal education years must be known to determine which skills and knowledge were acquired in the current curriculum (Maki, 2002).

Collecting sufficient and representative data using a greater variety of methods to document the integration of essential skills into students’ programs of study, skill development, and resulting curricular and program changes will lead to improved student 
learning (Huba \& Freed, 2000; Palomba \& Banta, 1999; Maki, 2002; \& Martinson \& Dole, 2002).

This study found that many accounting program assessment plans had provisions for collecting and analyzing assessment data, but the majority of the faculty and assessment administrators are not "closing the loop"; that is, they are not acting on the assessment results and making the needed changes and improvements in student learning to complete the process. Therefore, seven major recommendations are suggested. 


\section{Recommendations}

1. Redesign accounting courses and restructure programs to integrate essential skills into the coursework. Such modifications would promote the development of the workplace skills and competencies students need to be successful in their careers.

2. Accounting program faculty should receive assessment training to enable them to better understand the assessment process and to prepare them to competently assess student learning.

3. Accounting program faculty should create and implement assessment plans to measure the development of skills and knowledge attained by their graduates and to enhance the learning process.

4. Assessment programs should be designed to establish baseline evidence of students' skills as beginning undergraduates, and additional assessment activities implemented to measure students' skill development as they progress through the programs. Relevant and timely assessment data that focus on student learning should be continually collected.

5. An assessment plan that consists of a combination of direct and indirect methods of assessment to observe student performance and to gather their opinions of the program and their level of satisfaction should be implemented. Using both methods will assure that valid assessment data is compiled.

6. Faculty should use assessment data to track results over time to discover patterns and trends that identify areas in the curriculum or program that need attention and make changes and improvements when necessary to enhance student learning. 
7. Faculty should use an assortment of means to disseminate assessment data. The vehicle for sharing assessment methods could include school websites, marketing campaigns, and conferences and workshops. Also, assessment results should be shared on a regular basis with appropriate constituents. Sharing assessment data with multiple audiences will lead to a greater understanding of the education process and generate relevant feedback that can result in further refinement of the process.

8. An internship should be required for all accounting seniors to provide the opportunity to apply the skills and knowledge they have acquired and to strengthen those competencies in a learning/training setting to prepare them for successful accounting careers.

\section{Implications for Future Studies}

As stated throughout this study, governmental officials, professional organizations, business leaders, and the public began to question whether colleges and universities were adequately preparing graduates for the workplace and graduate education in the early 1980's. Reports from these constituents indicated that institutions of higher education were failing to meet these objectives and posed the following questions about college graduates. "Were they learning what they should be learning? Were they able to apply specialized knowledge and skills in the workplace or as they sought further education? Were they able to communicate well and solve problems?” (Palomba \& Banta, 1999, p. 1).

Hindi et al (2002) reported that higher education constituents’ demands have contributed to increased research efforts that examine educational programs and document changes and improvements in student learning in higher education resulting from continuous 
self-examination studies and the development of formal assessment plans (2000). Martinson and Cole contend that both external and internal pressures have caused greater recognition of the need to develop formal assessment programs (2002).

\section{Recommendations}

This section offers suggestions for future research studies that could benefit accounting educators in their quest to provide students with the necessary skills and knowledge to become successful accounting professionals.

1. Future studies should examine accounting curriculum and programs to determine how well essential skills are integrated and emphasized in the coursework. The study would determine whether essential skills are introduced early in students’ programs of study and reinforced as students progress toward graduation.

2. Future studies should be conducted to discover how faculty integrate essential skills into accounting programs. The study would ascertain what methods of instruction and assignments are used to provide students the opportunity to develop essential skills and competencies.

3. A study should be conducted to compare the student learning outcomes of accounting programs to the AICPA Core Competencies. The study could detect correlations between the skills and knowledge assessed in the accounting programs and the AICPA's Core Competency Framework that consists of functional competencies, personal competencies, and the seven business perspectives. 
4. More research needs to be done to determine the assessment instruments used in accounting education assessment and how effectively the assessment methods measure the essential skills and competencies.

5. More research is needed to discover evidence that assessment results are used to improve student learning. Little documentation is available that indicates changes and improvements in the learning process have occurred due to assessment data.

6. A study should be conducted to discover how accounting faculty and administrators share assessment data and what group(s) receives the accounting programs' assessment information. A future study could determine to what degree faculty and administrators share and publish assessment results to make the results available to constituents. It could also explore how useful this information is from the perspectives of the constituencies who receive assessment results.

7. A future study should be conducted to determine if the necessary practical and cognitive/conceptual skills and knowledge required of the accounting field can be addressed adequately in the last two years of a student's program of study to prepare them for successful accounting careers.

8. A future study could determine whether accounting faculty are adequately trained and prepared to teach the technical and cognitive/conceptual skills that accounting students need in their careers. The study could address issues such as creating agreements with public accounting firms and private companies to permit accounting faculty to periodically practice accounting and develop or reinforce the technical and cognitive/conceptual skills required in the workplace. The 
extent to which administrative support and funding opportunities are available for accounting faculty to participate in such arrangements or to receive additional training through other avenues should also be determined.

As the assessment process evolves at these institutions of higher education, this researcher expects future studies will find faculty and administrators have successfully integrated essential skills into the coursework. Assessment results will document the effectiveness of the restructured curriculum and the assessment-related changes and improvements in the learning process. 


\section{References}

Accounting Education Change Commission. (1996). Position and issues statements of the accounting education change commission. Accounting Education Series, 13, Sarasota, FL: American Accounting Association.

Albrecht, S. W., \& Sack, R. J. (2000). Accounting education: Charting the course through a perilous future. Accounting Education Series, 16, Sarasota, FL: American Accounting Association.

Alreck, P. L., \& Settle, R. B. (1995). The survey research handbook, (2 ${ }^{\text {nd }}$ ed.). New York, NY: McGraw-Hill.

Alverno College. (2006). Student assessment-as-learning. Retrieved July 01, 2006, from http://www.alverno.edu/for_educators/student_as_learn.html

American Accounting Association Committee on the Future Structure, Content, and Scope of Accounting Education Report. (1986). Future accounting education: Preparing for the expanding profession. Issues in Accounting Education, 1(1), 169-175. Sarasota, FL: American Accounting Association.

American Accounting Association. (1993). Report of the outcomes assessment committee. Sarasota, FL: Author.

American Institute of Certified Public Accountants. (1998). CPA vision project: Focus on the horizon. New York, NY: Author.

American Institute of Certified Public Accountants. (2004). Accounting graduates and the demands for public accounting recruits. New York, NY: Author.

American Institute of Certified Public Accountants Academic and Career Development Team. (2001). Taking care of business. New York, NY: Author. 
American Institute of Certified Public Accountants. (1999). What is the framework? Retrieved June 22, 2002, from http://www.aicpa.org/edu/overview/htm American Institute of Certified Public Accountants. (2003). AICPA core competency framework for entry into the accounting profession (the framework). Retrieved February 18,2005, from http://www.aicpa-.org/pubs/cpaltr/may2000

Association of American Colleges. (1985). Integrity in the college curriculum. Washington, DC: Author.

Association of American Colleges. (1991). Liberal learning and the arts and science major: The challenge of connecting learning, (1). Washington, DC: Author. Association of American Colleges. (1992). Liberal learning and the arts and science major: Program review and educational quality in the major, (3). Washington, DC: Author.

Association of American Colleges. (1994). Strong foundations: Twelve principles for effective general education programs. Washington, DC. Author.

Association of American Colleges and Universities. (2002). Greater expectations: A new vision for learning as a nation goes to college: National panel report. Washington, DC: Author.

Association of American Colleges. (1992). Program review and educational quality in the major: A faculty handbook. Washington, DC: Author.

Banta, T. W., \& Associates. (1993). Making a difference: Outcomes of a decade of assessment in higher education. San Francisco, CA: Jossey-Bass.

Banta, T. W., \& Associates. (2002). Building a scholarship of assessment. San Francisco, CA: Jossey-Bass. 
Big Eight Accounting Firms. (1989). Perspectives on education: Capabilities for success in the accounting profession. New York: Author.

Black, T. H., \& Duhon, D. L. (2003). Evaluating and improving student achievement in business programs: The effective use of standardized assessment tests. Journal of Education for Business, 79(2), 90-99.

Bloom, B. S. (1956). Taxonomy of education objectives: Handbook 1: The cognitive domain. White Plains, NY: McKay.

Bolt-Lee, C., \& Foster, S. D. (2003). The core competency framework: A new element in the continuing call for accounting education change in the United States. Accounting Education, 12(1), 33-47.

Brantley, C. P., \& Davis, B. J., Eds. (1997). The changing dimensions of business Education. National Business Education Yearbook, No. 35. Reston, VA: National Business Education Association.

Brown, G., Ehrmann, S. C., Lippincott, J. K., \& Suter, V. (2004). Accountability as opportunity: Tapping the transformative power of accreditation. Boulder, $\mathrm{CO}$ : Educause.

Bryman, A., \& Cramer, D. (2001). Quantitative data analysis with SPSS release 10 for windows. Philadelphia, PA: Routledge, Taylor \& Francis Group.

Burke, J. C. (2002). Accountability for results: Ready or not. Trusteeship, 10(1), 8-13. Carey, J. O., \& Gregory, V. L. (2003). Toward improving student learning: Policy issues and design structures in course-level outcomes assessment. Assessment \& Evaluation in Higher Education, 28(3), 215-228. 
Carnegie Foundation for the Advancement of Teaching. (2000). Carnegie Classification of Institutions of Higher Education. Retrieved, June 22, 2002, from http://www.aicpa.org/edu/overview/htm

Carnevale, A. P., Gainer, L. J., \& Meltzer, A. S. (1990). Workplace basics training manual. San Francisco, CA: Jossey-Bass.

Carnevale, A. P., \& Porro, J. D. (1994). Quality education: School reform for the new American economy. Washington, D. C.: U. S. Department of Education.

Chickering, A. W., \& Gamson, Z. F. (1987). Seven principles for good practice in undergraduate education. AAHE Bulletin, 39(7), 3-7.

Christensen, D., \& Rees, D. (2002). Communication skills needed by entry-level accountants. Retrieved May 13, 2004, from http://www.aicpa.org/edu Wingspread Group on Higher Education. (1994). An American imperative: Higher expectations for higher education. New York, NY: The Johnson Foundation.

Cottell, Jr., P. G. \& Harwood, E. M. (1998). Using classroom assessment techniques to improve student learning in accounting classes. Issues in Accounting Education, 13(3), 551-564.

Curry, L., Wergin, F., \& Associates. (1993). Educating professionals: Responding to new expectations for competence and accountability. San Francisco, CA: JosseyBass.

Davis, G. B., \& Parker, C. A. (1997). Writing the doctoral dissertation: A systematic approach, ( $2^{\text {nd }}$ ed.). Hauppauge, NY: Barron’s Educational Services, Inc.

Denzin, N. K. (1978). The research act: A theoretical introduction to sociological methods. ( $2^{\text {nd }}$ ed.) New York: McGraw-Hill. 
Dey, I. (1993). Qualitative data analysis. London: Rutledge. Doney, L. D., \& Lephardt, N. E. (1993). Developing critical thinking skills in accounting students. Journal of Education for Business, 68(5), 297-300.

Education Commission of the States. (1996). What research says about improving undergraduate education. Denver, CO: Author.

Erwin, T. D. (2000). The NPEC sourcebook on assessment, volume 1: Definitions and assessment methods for critical thinking, problem solving, and writing. Washington, D.C.: National Postsecondary Education Cooperative and the National Center for Education Statistics.

Erwin, T. D. (2000). The NPEC sourcebook on assessment, volume 2: Selected institutions utilizing assessment results. Washington, D.C.: National Postsecondary Education Cooperative and the National Center for Education Statistics.

Ewell, P. (1991). Back to the future. Change, 23(6), 12-17.

Ewell, P. (1997). Organizing for learning. AAHE Bulletin, 50 (1), 3-6.

Ewell, P. (2003). The learning curve. Biz Ed, 68(5), 28-33.

Ewell, P., Lutz, D. A., \& Ratcliff, J. L. (1997). Assessment, management, and institutional effectiveness. University Park, PA: National Center on Postsecondary Teaching, Learning, and Assessment.

Farmer, D. W. (1999). Course embedded assessment: A catalyst for realizing the paradigm shift from teaching to learning. Journal of Staff, Program, and organizational Development, 16 (4), 199-211.

Farmer, D. W. (1988). Enhancing student learning: Emphasizing essential competencies in academic programs. Wilkes-Barre, PA: King’s College. 
Farmer, D. A., Romero, J., Jones, E. A., Ratcliff, J. L., \& Upcraft, M. L. (1995). Atlanta assessment institute: Turning results into improvement strategies. University Park, PA: National Center on Postsecondary Teaching, Learning, and Assessment.

Fraenkel, J. R., \& Wallen, N. E. (2003). How to design and evaluate research in education, ( $5^{\text {th }}$ ed.). New York, NY: McGraw-Hill.

Francis, P. L., \& Steven, D. A. (2003). The SUNY assessment initiative initial campus and system perspectives. Assessment \& Evaluation in Higher Education, 28(3), 333-350.

Gainen, J., \& Locatelli, P. (1995). Assessment for the new curriculum: A guide for professional accounting programs. Accounting Education Series, 11. Sarasota, FL: American Accounting Association.

Gardner, J. N., \& Van der Veer, G. (1998). The senior year experience. San Francisco, CA: Jossey-Bass.

Gardiner, L. F. (1989). Planning for assessment: Mission statements, goals, and objectives. Trenton, NJ: New Jersey Department of Higher Education.

Gary Siegel Organization. (1994). What corporate America wants in entry-level accountants. Mountvale, NJ: Institute of Management Accountants.

Goldberg, M., \& Traiman, S. L. (2001). Why business backs education standards. Brookings Papers on Education Policy. Retrieved November 17, 2003, from: file://E:\\\%20Business\%20Backs\%20Education\%20Standards.htm

Gravetter, F. J., \& Wallnau, L. B. (2000). Statistics for the behavioral sciences, ( $5^{\text {th }}$ ed.). Stamford, CT: Wadsworth/Thomas Learning. 
Greenberg, M. (2002). It’s time to require liberal arts accreditation: Why we can no longer ignore general education. AAHE Bulletin. Retrieved November 6, 2003, from http://aahebulletin.com/public/archive/liberalarts.asp

Hagerty, B. M. K., \& Stark, J. S. (1989). Comparing educational Accreditation standards in selected professional fields. Journal of Higher Education, 60(1), 1-20.

Hasselback, J. R. (2004). Prentice hall accounting faculty directory 2004 - 2005. Upper Saddle River, NJ: Prentice Hall.

Hindi, N., \& Miller, D. (2000). A survey of assessment practices in accounting departments of colleges and universities. Journal of Education for Business, 75(5) 286-290.

Howell, D. C. (2002). Statistical methods for psychology, ( $5^{\text {th }}$ ed.). Pacific Grove, CA: Duxbury-Thomson Learning.

Huba, M. E., \& Freed, J. E. (2000). Learner-centered assessment on college campuses: Shifting the focus from teaching to learning. Needham Heights, MA: Allyn \& Bacon.

Hutchings, P., \& T. Marchese. (1990). Watching assessment: Questions, stories, prospects. Change, 22(5), 12-38.

Institute of Internal Auditors. (1999). A vision for the future: Professional practice framework for internal auditors. Altamonte Springs, FL. Author.

Institute of Management Accountants. (1996). The practice analysis of management: Results of research. Montvale, NJ. Author.

Jones, E. A. (1994). Goals inventories. University Park, PA: National Center on Postsecondary Teaching, Learning, and Assessment.

Jones, E. A. (1996). National and state policies affecting learning expectations. New Directions for Higher Education, 96, 7-15. 
Jones, E. A., Hoffman, S., Moore, L. M., Ratcliff, G., Tibbetts, S., \& Click, III, B. A. (1994). Essential skills in writing, speech and listening, critical thinking for college graduates: Perspectives of faculty, employers, and policymakers. University Park, PA: National Center on Postsecondary Teaching, Learning, and Assessment.

Jones, E. A. (2002). Transforming the curriculum: Preparing students for a changing world. ASHE-ERIC Higher Education Report, 29(3). Hoboken, NJ: Wiley Periodicals, Inc.

Langenberg, D. N. (1997, September 12). Diplomas and degrees are obsolescent. Chronicle of Higher Education, 44 (3), A64.

Lorenzetti, J. P. (2004). Transformative assessment in higher education. Distance Education Report, 8(6), 3-7.

Maki, P. L. (2001). From standardized tests to alternative methods: Some current resources on methods to assess learning in general education. Change, 33 (2), 8-31.

Maki, P. L. (2002a). Developing an assessment plan to learn about student learning. Retrieved November 6, 2003, from www.aahe.org/iniatives/assessment/planning Maki, P. (2002b). Using multiple assessment methods to explore student learning and development inside and outside of the classroom. Retrieved June 16, 2002, from http://naspa.org/NetResults/PrinterFriendly.cfm

Marchese, T. (1991). Standards and us. Change 23 (6), 4.

Martinson, O. B., \& Cole, E. T. (2002). Improving accounting education through outcomes assessment. Management Accounting Quarterly, 3(2), 1-6.

Merriam, S. B. (1998). Qualitative research and case study application in education. San Francisco, CA: Jossey-Bass. 
Michlitsch, J. F. (2002). Assessing student learning outcomes: A comparative study of techniques used in business school disciplines. Journal of Education for Business, 77(3), 125-130.

Middle States Commission on Higher Education. (2002). Developing research \& communication skills: Guidelines for information literacy in the curriculum. Retrieved April 10, 2004, from //www.msache.org

Nardi, P. M. (2003). Doing survey research: A guide to quantitative methods. Boston, MA: Pearson Education, Inc.

National Commission on Excellence in Education. (1983). A nation at risk: The imperative for educational reform. Washington, DC: Government Printing Office. National Institute for Higher Education. (1984). Involvement in learning: Realizing the potential of American higher education. Washington, D.C.: Author.

Oblinger, D. G., \& Verville, A. L. (1998). What business wants from higher education. Phoenix, AZ: Oryx Press.

Palomba, C. A., \& Banta, T. W. (1999). Assessment essentials: Planning, implementing, and improving assessment in higher education. San Francisco, CA: Jossey-Bass.

Patton, M. Q. (2002). Qualitative research \& evaluation methods, (3 ${ }^{\text {rd }}$ ed.). Sage Publications: Thousand Oaks: CA.

Paulson, K. (2001). Using competencies to connect the workplace and postsecondary education. In Voorhees, R. (Ed.), Measuring what matters: Competency-based learning models in higher education. New Directions for Institutional Research, (110), 41-54. 
Peterson, M. W., \& Augustine, C. H. (2000a). Organizational practices and influence of student assessment information in academic decisions. Research in Higher Education, 41(1), 21-53.

Peterson, M. W., \& Augustine, C. H. (2000b). External and internal influences on institutional approaches to student assessment: Accountability or improvement? Research in Higher Education, 41(4), 443-480.

Rao, M., \& Sylvester, S. (2000, April). Business and education in transition: Why new partnerships are essential to student success in the new economy. AAHE Bulletin, 52(8), 11-13.

Ratcliff, J. L. (1995). Realizing the potential: Improving postsecondary teaching, learning, and assessment. University Park: PA: National Center on Postsecondary Teaching, Learning, and Assessment.

Ratcliff, J. L., Jones, E. A., \& Hoffman, S. (1993). Linking assessment and general education. University Park: PA: National Center on Postsecondary Teaching, Learning, and Assessment.

Raymond, M.A., \& McNabb, D. E. (1993). Preparing graduates for the workforce: The role of business education. Journal of Education for Business, 68(4), 202-206.

Russell, L. (2005). The education jigsaw. New Zealand Management, 52(9), 16-17.

Schwartz, R. B., \& Robinson, M. A. (2000). Goals 2000 and the standards movement. The Brookings Papers on Education Policy 2000. Washington, D.C.: The Brookings Institution. 
Scriven, M., \& Paul, R. (1996). Defining critical thinking: A draft statement for the National Council for Excellence in Critical Thinking. Retrieved April 5, 2004, from http://www.criticalthinking.org/University/univclass/Defining.html

Soundarajan, N. (2004). Program assessment and program improvement: Closing the loop. Assessment \& Evaluation in Higher Education, 29(5), 597-610.

Sternberg, R. J. (1996). Successful intelligence. New York: Simon and Schuster.

Stone, J., \& Friedman, S. (2002). A case study in the integration of assessment and general education: Lessons learned from a complex process. Assessment \& Evaluation in Higher Education, 27(2), 199-211.

Suskie, L. A. (1996). Questionnaire survey research: What works (2 ${ }^{\text {nd }}$ ed.). Tallahassee, FL: Association for Institutional Research.

Taylor Research \& Consulting Group. (2000). Student and academic research study. Jersey City, NJ: American Institute of Certified Public Accountants.

Terenzini, P. T. (1997). Student outcomes information for policy-making. Final report of the national postsecondary education cooperative working group on student outcomes from a policy perspective. Washington, D.C.: National Postsecondary Education Cooperative and the National Center for Education Statistics.

Tschopp, D. J. (2004). The Seneca Babcock business plan: A case study in using service learning to meet the AICPA core competencies. Journal of Education for Business, 79(5), 261-266.

U. S. Department of Labor, Employment, and Training Administration \& U. S. Department of Education. (2000). Workplace essential skills: Resources related to the SCANS competencies and foundation skills. Washington, D.C.: Author. 
Van Horn, C. E. (1995). Enhancing the connection between higher education and the workplace: A survey of employers. Denver, CO: State Higher Education Executive Officers and the Education Commission of the States.

Walvoord, B. E., Bardes, B. \&Denton, J. (1998). Closing the feedback loop in classroombased assessment. Assessment Update, 10(5), 1-2, 10-11.

Weeks, R. (1996). The academic major as a model for general education. Liberal Education, 82(1), 50-53.

Whetzel, D. (2000, March). The secretary of labor's commission on achieving necessary skills. ERIC Digests. Washington, DC: ERIC Clearinghouse on Tests Measurement and Evaluation. 
Identifying Assessment Practices 173

Appendix A

AICPA Core Competency Framework 


\section{AICPA Core Competency Framework}

The Core Competency Framework (CCF) defines a set of skills-based competencies needed by all students entering the accounting profession, regardless of the career path they choose (public/industry/government/nonprofit) or the specific accounting services they will perform.

The CCF focuses on skills and is not structured around traditional subject/content areas or accounting services. A skills-based curriculum is advocated, because the body of knowledge and the accounting profession are changing so rapidly. Although knowledge requirements will change with time, the core set of competencies identified by the Framework will have long-term value and will support a variety of career opportunities for the future CPA.

In addition, by basing entry-level competency requirements on professional models, the Framework supports the concept of learning as a continuum that begins in an academic setting and continues with life-long professional education and experience. Further, by basing curriculum guidance on professional expectations, the Framework aims to ease transition from student to professional.

\section{Category: Functional Competencies}

1. Competency: Leveraged Technology

Description: Technology is pervasive in the accounting profession. Individuals entering the Accounting profession must acquire the necessary skills to use technology tools effectively and efficiently.

$>$ Identifies risks associated with technology and automated business processes

> Accesses appropriate electronic databases to obtain decision-supporting information

> Appropriately uses electronic spreadsheets and other software to build models and simulations

> Uses technology assisted tools to assess and control risk and document work performed

$>$ Assesses the degree of risk of technology and automated business processes

> Develops strategic uses of technology for enhancing work performance

$>$ Adopts new technology over time

\section{Competency: Decision Modeling}

Description: Individuals preparing to enter the accounting profession must be able to use strategic and critical approaches to decision-making. They must objectively consider issues, identify alternatives, and choose and implement solution approaches in order to deliver services and provide value.

> Identifies problems, potential solution approaches, and related uncertainties

> Organizes and evaluates information, alternatives, cost/benefits, risks and rewards of alternative scenarios

> Employs model-building techniques to quantify problems or test solutions

> Uses quantitative techniques to explore the likelihood of alternative scenarios

> Objectively identifies strengths, weaknesses, opportunities, and threats associated with a specific scenario, case, or business activity 
> Links data, knowledge, and insights together for decision-making purposes

$>$ Engages in continuous improvement and constructs new models over time

> Makes decisions over time as a result of engaging in continuous improvement and constructing new models

\section{Competency: Reporting}

Description: Communicating the scope of work and findings or recommendations is an integral part of a professional service. An accounting professional in public practice might issue an audit or attestation report, recommendations for improved services, or tax or financial planning advice. An accounting professional in business, industry, or government might analyze operations or provide communications to the board of directors.

Communicating clearly and objectively the work done and the resulting findings is critical to the value of the professional service. Some forms of communication are governed by professional standards (such as the form and content of the standard auditor's report or the required communications to the audit committees) or law. Others are based on the service applied and the needs of those to whom the accounting professional reports.

> Lists types of information relevant to a given report

> Considers the pros and cons of alternative contents and formats in preparing written and oral presentations

> Describes work performed and conclusions reached in a manner that enhances the reports' usefulness

> Using appropriate media, prepares reports with objectivity, conciseness and clarity

$>$ Continuously monitors and updates reports, as needed

> Serves as spokesperson for an organization

\section{Competency: Research}

Description: Although accounting professionals need a foundation in standards and other relevant rules, such guidance is constantly evolving. Many accounting profession functions depend on obtaining information from within and outside of an entity. Accordingly, the individual preparing to enter the accounting profession needs to have strong research skills to access relevant guidance or other information, understand it, and apply it.

$>$ Accesses relevant standards, rules, and other information

> Identifies relevant information such as industry trends, internal performance history, benchmarks, and best practices

> Explains why there are uncertainties about the interpretation of information, including existing rules

> Employs relevant research skills for locating data

> Articulates assumptions and reasoning associated with application of existing rules to a given problem

> Qualitatively interprets research findings from a variety of viewpoints

> Articulates general concepts from existing rules and explains how those concepts apply across a range of problems, including problems not explicitly described

> Develops and uses reasonable guidelines for drawing conclusions in light of conflicting or ambiguous data

> Employs relevant research skills over time to generate new information 
5. Competency: Measurement

Description: Measures used should be both relevant (that is, bear on the decision to be made) and reliable (consistently measure what they purport to measure). Various measurement and disclosure criteria used by accounting professionals—-such as GAAP, OCBOA (Other Comprehensive Basis of Accounting) and tax reporting — have been codified to some degree. Other performance measures (such as Economic Value Added) or stated criteria (for example, investment performance) are used for special purposes. Some measurement criteria (such as effectiveness of internal control) are measured qualitatively, rather than quantitatively.

$>$ Appropriately applies a given measurement method

$>$ Identifies what needs to be measured

> Describes uncertainties about data and how items should be measured

$>$ Describes the pros and cons of alternative methods of measurement

$>$ Describes the implications of ambiguities when estimates are required

> Presents the measurement results objectively using applicable standards of disclosure or reporting

> Determines an appropriate, relevant and reliable measure for the intended use

> Recognizes changing circumstances and reconsiders measurement methods and estimates as appropriate

\section{Competency: Risk Analysis}

Description: Risk analysis and control is fundamental to professional service delivery. The identification and management of audit risk (that is, the risk that the auditor will fail to detect a misstatement, caused by inadvertent error or fraud, that is material to financial statements) is the basis for the conduct of a GAAS audit. The understanding of business risk (that is, the risk that an entity—either a client or the prospective accounting professional's employerwill fail to achieve its objectives) affects how business strategy is created and implemented.

> Explains why controls cannot completely eliminate risk of negative outcomes

$>$ Describes the pros and cons of controls that mitigate risk of negative outcomes through prevention or detection and correction

> Identifies risks of negative outcomes (including fraud) for particular scenarios

> Communicates the impact of identified risks and recommends corrective action

> Assesses and controls unmitigated risks through, for example, designing, applying, and drawing conclusions from tests

> Develops and monitors strategies for managing risk over time

> Implements appropriate corrective action over time 


\section{Category: Personal Competencies}

1. Competency: Communication

Description: Accounting professionals are called upon to communicate financial and nonfinancial information so that it is understood by individuals with diverse capabilities and interests. Individuals entering the accounting profession should have the skills necessary to give and exchange information within a meaningful context and with appropriate delivery. They should have the ability to listen, deliver powerful presentations and produce examples of effective business writing.

$>$ Identifies uncertainties about the best way to communicate

$>$ Expresses information and concepts with conciseness and clarity when writing and speaking

$>$ Selects appropriate media for dissemination or accumulation of information

> Places information in appropriate context when listening, reading, writing and speaking

> Organizes and effectively displays information so that it is meaningful to the receiving party

$>$ Receives and originates direct and indirect messages as appropriate when listening, reading, writing and speaking

> Uses interpersonal skills to facilitate effective interaction over time

> Communicates decisions appropriately over time

\section{Competency: Interaction}

Description: Accounting professionals must be able to work with others to accomplish objectives. This requires them to act as valuable business partners within organizations and markets and work in teams to provide business solutions. Thus, individuals entering the accounting profession should demonstrate an ability to work productively with individuals in a diversity of roles and with varying interests in the outcome.

$>$ Identifies uncertainties about interactions with others

$>$ Accepts suggestions and guidance of team leaders and other members

$>$ Commits to achievement of common goals when working on a team

$>$ Interacts and cooperates productively and maturely with others

$>$ Recognizes the value of working within diverse, cross-functional teams

$>$ Recognizes and accommodates the protocols and expectations of teams

$>$ Facilitates free expression and constructive activities of others

$>$ Coaches or mentors in appropriate circumstances

3. Competency: Leadership

Description: Individuals entering the accounting profession should be able to effectively lead in appropriate circumstances. This involves acquiring the skills needed to influence, inspire, and motivate individuals and groups to achieve results.

$>$ Describes why there is no single, "correct" way to perform as a leader

$>$ Identifies the various leadership styles

> Analyzes potential ways to reach a consensus or compromise from alternative points of view

> Recognizes and controls for own biases when receiving input from others

> Relates leadership styles to different situations 
$>$ Facilitates decisions that involve consensus or compromise as appropriate

$>$ Motivates others to achieve excellence

$>$ Persuades and rallies the support of others to a course of action by reasoning or incentive

$>$ Practices principles of effective governance over time

$>$ Effectively chairs teams or volunteers for projects

4. Competency: Leverage Technology

Description: Technological adaptability is a requirement for today's accounting professional. As technology advances, the accounting professional must acquire new skills and determine how new technologies should be best incorporated into their practices. This commitment to continual technological learning will enhance the development and application of other personal competencies.

$>$ Recognizes commonly used information architectures

> Recognizes business opportunities and risks associated with electronic commerce

$>$ Mines electronic data sources for business and industry information

$>$ Develops and communicates reasonable recommendations for technology use in an organization

> Uses technology to develop and present strategic information

$>$ Adopts new technology over time

\section{Competency: Problem Solving/Decision Making}

Description: Accounting professionals are often asked to discern the true nature of a situation and then determine the principles and techniques needed to solve problems or make judgments. Thus, individuals entering the accounting profession should display effective problem solving and decision-making skills, good insight and judgment, as well as innovative and creative thinking.

$>$ Lists information and evidence that is relevant for a problem

$>$ Identifies uncertainties about the interpretation or significance of information and evidence

> Considers unconventional approaches and solutions to problems

> Makes valid and reliable evaluations of information, including the significance of evidence or facts for problem definition and solution

> Analyzes the impact, pros, and cons of potential solutions or actions

$>$ Analyzes the quality of information and evidence, including validity, reliability, and significance

> Reasons carefully and thinks effectively in abstract terms or generalizations

$>$ Seeks consensus where appropriate

$>$ Knows when to follow directions, question plans or seek help

$>$ Uses experience and comparison in forming opinions

$>$ Synthesizes novel or original definitions of problems and solutions as circumstances dictate

> Adapts to new contexts and promotes constructive change

> Strategically considers contingencies and future developments 


\section{Competency: Professional Demeanor}

Description: The accounting profession is committed to maintaining a public reputation for excellence in the performance of important roles in business and society. Individuals entering the accounting profession should behave in a manner that is consistent with the character and standards of the discipline of accounting, as well as the norms of the environment in which they interact. This competency involves demonstrating objectivity, integrity, and ethical behavior. It also includes a commitment to stable work performance, as well as a commitment to continuously acquire new skills and knowledge.

$>$ Identifies career and personal goals

$>$ Accepts professional development as an uncertain and life-long process

$>$ Commits to confidentiality, quality, efficiency, growth in personal conduct and capabilities, and ethical behavior

$>$ Identifies ethical dilemmas

$>$ Considers the impact of alternative solutions on various stakeholders in an ethical dilemma

> Evaluates information, including others' professional criticism and evaluation, in a manner free of distortions, personal bias or conflicts of interest

$>$ Relates lessons learned from prior mistakes to new situations

$>$ Conducts oneself with honesty

> Objectively considers others' professional criticism or evaluation when making decisions

$>$ Adheres to a level of personal appearance appropriate to the environment

> Recognizes situations where professional ethical standards apply and behaves accordingly

$>$ Prioritizes career and personal goals

> Uses appropriate ethical values in making decisions

$>$ Takes appropriate action to gain competencies

> Manages stress and performs reliably under changing or unusual demands

> Measures oneself against evolving standards and meets or exceeds those standards

\section{Competency: Project Management}

Description: Accounting professionals must successfully manage a diversity of projects throughout their career. Individuals entering the accounting profession should demonstrate the ability to effectively control the course of a multi-dimensional, multi-step undertaking. This includes managing project assets, including human, financial, property, and technical resources.

$>$ Identifies uncertainties related to time and resource requirements for a project

$>$ Identifies project goals

$>$ Lists information relevant to managing a project

$>$ Organizes the various aspects of a project in order to allocate resources for optimum results

> Utilizes methods to measure project progress

> Develops alternative estimates of time and resource requirements for a project

> Recognizes situations where prompt and determined actions are needed and responds accordingly

> Sees projects through to completion or orderly transition 
$>$ Prioritizes and delegates as needed

$>$ Effectively facilitates and controls the project process and takes corrective action as needed

> Effectively manages human resources that are committed to the project

\section{Category: Broad Business Perspective}

1. Competency: Industry/Sector Perspective

Description: Individuals entering the accounting profession should be able to identify (through research and analysis) the economics and broad business financial risks and opportunities of the industry and economic sector in which a given organization operates. Identification of these risks and opportunities should include both issues specific to the enterprise, as well as those pervasive throughout the industry/sector.

$>$ Identifies the economic, broad business, and financial risks of the industry/sector

$>$ Identifies and describes competitive advantages and disadvantages

> Describes market forces that make a given organization a candidate for merger, acquisition, and/or strategic alliance

> Communicates the financial and nonfinancial performance of an organization's operational processes

$>$ Recommends courses of action that take advantage of an organization's key competitive advantages and disadvantages

> Effectively addresses changes in the economic, broad business, and financial risks of the industry/sector over time

2. Competency: International/Global Perspective

Description: Individuals entering the accounting profession should be able to identify and communicate the variety of threats and opportunities of doing business in a borderless world. The accounting professional of the future must provide services to support and facilitate commerce in the global marketplace.

> Identifies global issues relevant to a business decision

> Describes uncertainties about the cultural and financial impacts of moving into new markets, and expanding existing markets

$>$ Analyzes global customer and supplier demographics

$>$ Identifies and analyzes the social costs and benefits of relevant decisions, including human and financial resource management, in the global marketplace/ environment

> Analyzes the cultural and financial impacts of moving into new markets, and expanding existing markets

> Modifies communications as appropriate for global settings

$>$ Objectively considers and prioritizes global issues in reaching business decisions

> Develops, implements, and monitors global business strategies

3. Competency: Legal/Regulatory Perspective

Description: Regulatory forces are being shaped by collaboration, migration, and reform as the various stakeholders globalize, share information, and force their particular needs and viewpoints onto political agendas. Individuals preparing to enter the accounting profession 
need to be capable of describing the legal and regulatory environment and analyzing the impact of changes in relevant requirements, constraints, and competitive practices.

> Identifies uncertainties about how an organization should respond to a legal/regulatory issue

> Identifies reasons why the legal/regulatory environment might change

$>$ Identifies and explains the political and environmental forces impacting both the accounting standard setting process and the regulation of the profession; articulates the dynamic nature of these processes and recognizes their implications for organizations and the ways in which they operate

> Describes the legal and governmental/regulatory environment in which entities operate and the significant costs and benefits of regulation

$>$ Develops reasonable policies and responses for legal/regulatory matters

> Develops, monitors, and implements strategies for addressing potential threats and opportunities for the organization from changing legal requirements

4. Competency: Leverage Technology

Description: Technology alters how organizations operate. To provide the greatest value, today's accounting professional must understand and appreciate the effects of technology on the broader business environment.

$>$ Recognizes commonly used information architectures

> Recognizes business opportunities and risks associated with electronic commerce

$>$ Mines electronic data sources for business and industry information

> Develops and communicates reasonable recommendations for technology use in an organization

> Uses technology to develop and present strategic information

$>$ Adopts new technology over time

\section{Competency: Marketing/Client Focus}

Description: Individuals who are marketing- and client- focused are better able to anticipate and meet the changing needs of clients, employers, customers, and markets. This involves both the ability to recognize market needs and the ability to develop new markets.

$>$ Identifies factors that motivate internal and external customers to enter into relationships or continue doing business with an organization

> Articulates uncertainties about relationships with internal and external customers

$>$ Recognizes and understands employer/client protocol and expectations

$>$ Develops an effective plan for addressing a particular employer/client need

$>$ Generates new engagements for services over time

$>$ Builds good working relationships over time

6. Competency: Resource Management

Description: The ability to appreciate the importance of all resources (human, financial, physical, environmental, etc.) is critical for success. Individuals entering the accounting profession should be able to apply management and human resources development theories to human resource issues and organizational problems. Individuals preparing to enter the accounting profession should be able to identify sources of capital, and analyze the impact of participation in the global capital markets. 
$>$ Explains why there are uncertainties about the availability and alternatives uses of resources

$>$ Identifies resources available to an organization

> Identifies the effects of market forces on organizations' costs of capital, labor, commodities, etc.

> Analyzes the implications of an organization's lack of access to supply sources, financial markets, and intellectual capital (barriers to entry, expansion, or survival)

$>$ Articulates how organizations make decisions to allocate scarce resources, including recognition of both quantitative and qualitative constraints on these decisions (Specific examples include decisions regarding capacity and resource utilization.)

$>$ Identifies both traditional and non-traditional performance criteria and measurement methods by selecting appropriate success factors and measures of their achievement (See functional competencies)

> Identifies and addresses the social costs and benefits of business decisions and evaluates the fiduciary performance of public sector and not-for-profit management

> Articulates how resource availability affects the organization's business functions, processes and administrative procedures

> Facilitates analysis of the organization and applies continuous improvement principles to the organization

7. Competency: Strategic/Critical Thinking

Description: Critical thinking encompasses the ability to link data, knowledge, and insight together from various disciplines to provide information for decision-making. Being in tune with the "big picture" perspective is a necessary component for success. Individuals entering the accounting profession should be able to communicate to others the vision, strategy, goals, and culture of organizations.

> Identifies uncertainties about an organization's strengths, weaknesses, opportunities, and threats

$>$ Articulates the principles of the strategic planning process

$>$ Identifies and gathers data from a wide variety of sources for decision-making

$>$ Transfers knowledge from one situation to another

> Analyzes strategic information (e.g., market share, customer satisfaction, competitor actions, product innovation, etc.)

$>$ Considers strengths, weaknesses, opportunities, and threats in reaching conclusions

> Develops, monitors, implements, and transforms business strategies over time 
Identifying Assessment Practices 183

\section{Appendix B}

Accrediting Organization Regions 
Accrediting Organizations

Middle States Commission on Higher Education, Middle States Association of Colleges and Schools

Accredits institutions of higher education in: Delaware, Maryland, New York, New Jersey, Pennsylvania, the District of Columbia, Puerto Rico, the U.S. Virgin Islands, and locations overseas.

New England Association of Schools and Colleges, Commission on Institutions of Higher Education

Accredits institutions of higher education in: Connecticut, Maine, Massachusetts, New Hampshire, Rhode Island, Vermont, and abroad.

The Higher Learning Commission, North Central Association of Colleges and Schools Accredits institutions of higher education in: Arizona, Arkansas, Colorado, Illinois, Indiana, Iowa, Kansas, Michigan, Minnesota, Missouri, Nebraska, New Mexico, North Dakota, Ohio, Oklahoma, South Dakota, West Virginia, Wisconsin, and Wyoming.

Commission on Colleges, Northwest Association of Schools and Colleges

Accredits institutions of higher education in: Alaska, Idaho, Montana, Nevada, Oregon, Utah, and Washington.

Commission on Colleges, Southern Association of Colleges and Schools

Accredits institutions of higher education in: Alabama, Florida, Georgia, Kentucky, Louisiana, Mississippi, North Carolina, South Carolina, Tennessee, Texas, Virginia, and Mexico.

Western Association of Schools and Colleges

Accredits institutions of higher education in: California, Hawaii, the Pacific Basin, and East Asia. 
Identifying Assessment Practices 185

Appendix C1

Dissertation Study

Research Questions 


\section{Research Questions}

1. Is there a significant difference in how extensively these essential skills and competencies (critical thinking, information literacy, oral communication, problem solving, and written communication) are addressed in accounting programs by:
a. Carnegie classification?
b. Geographic region?
c. Enrollment numbers?

2. Is there a significant difference in how extensively these skills and competencies are articulated as student learning outcomes by:
a. Carnegie classification?
b. Geographic region?
c. Enrollment numbers?

3. Is there a significant difference in how extensively these skills and competencies are aligned at the course and program levels by:
a. Carnegie classification?
b. Geographic region?
c. Enrollment numbers?

4. Is there a significant difference in how extensively assessment methods are used to measure these skills and competencies by:
a. Carnegie classification?
b. Geographic region?
c. Enrollment numbers? 
5. Is there a significant difference in how extensively the assessment data are used to enhance the program and improve student learning by:
a. Carnegie classification?
b. Geographic region?
c. Enrollment numbers?

6. Is there a significant difference in how extensively faculty share the assessment results with multiple audiences by:
a. Carnegie classification?
b. Geographic region?
c. Enrollment numbers? 
Identifying Assessment Practices 188

Appendix C2

Dissertation Study

Research Questions

(Question 3Revised) 


\section{Research Questions}

1. Is there a significant difference in how extensively these essential skills and competencies (critical thinking, information literacy, oral communication, problem solving, and written communication) are addressed in accounting programs by:
a. Carnegie classification?
b. Geographic region?
c. Student enrollment numbers?

2. Is there a significant difference in how extensively these skills and competencies are articulated as student learning outcomes by:
a. Carnegie classification?
b. Geographic region?
c. Student enrollment numbers?

3. How extensively are certain skills and competencies addressed within the individual required accounting courses?

4. Is there a significant difference in how extensively assessment methods are used to measure these skills and competencies by:
a. Carnegie classification?
b. Geographic region?
c. Student enrollment numbers?

5. Is there a significant difference in how extensively the assessment data are used to enhance the program and improve student learning by:
a. Carnegie classification?
b. Geographic region? 
c. Student enrollment numbers?

6. Is there a significant difference in how extensively faculty share the assessment results with multiple audiences by:
a. Carnegie classification?
b. Geographic region?
c. Student enrollment numbers? 
Appendix D1

Survey Instrument 


\section{Accounting Program Assessment Questionnaire}

This survey seeks information about the content and structure of your accounting program's assessment process, the student skills assessed, the assessment methods used, and how the results are used to make changes in the program and improve student learning. Please review the following statements and record the appropriate response as indicated.

\section{Accounting Program Information}

For the individual completing this survey, please indicate your formal title:

Please indicate your formal faculty rank (Assistant, Associate, or Full Professor):

Please indicate the appropriate response for each statement.

1. Total number of hours required for the entire undergraduate accounting degree:

2. Number of accounting hours required:

3. Number of students currently enrolled in program: FTE

4. Number of Accounting program graduates 2003 - 2004:

5. Number of Accounting Faculty: Full-time Adjunct Head Count

Please select the statement that best describes the level of development of the assessment plan for your program.

6. The accounting program faculty

[ ] has not created an assessment plan.

[ ] is in the beginning stages of developing an assessment plan.

[ ] has developed an assessment plan.

[ ] has implemented an assessment plan.

Please return this questionnaire regardless of your answer to this question.

7. The assessment process at this institution is

[ ] episodic; it occurs during program review, for accreditation purposes, or as needed.

[ ] on-going; it is a routine activity in the program.

Please review the following statements and indicate your response by checking the appropriate box.

8. The accounting program has a clear explicitly stated purpose that guides assessment in the program.

Extensively Somewhat Little

Not

9. Assessment data are collected and analyzed.

10. The assessment process focuses on improving student learning.

11. The assessment process focuses on accountability.

12. The student learning outcomes reflect the accounting program's goals and objectives for learning.

The program's student learning outcomes reflect the institution's mission and its values.

]$\quad\left[\begin{array}{lll}] & {[}\end{array}\right]$


Essential Skills

Please review the following statements and indicate your response by checking the appropriate box.

These essential skills are addressed in the accounting program:

\section{Critical Thinking:}

14. The ability to critically analyze, synthesize, and evaluate information as a guide to action.

Information Literacy:

15. The ability to identify, find, understand, evaluate and use information appropriately.

\section{Oral Communication:}

16. The ability to organize ideas and communicate messages appropriate to listeners and situations.

\section{Problem Solving:}

17. The ability to recognize, define, and analyze problems and to identify key causes and solutions.

Written Communication:

18. The ability to communicate thoughts and ideas in writing, completely and accurately, in the appropriate format, using proper grammar, spelling, and punctuation.
Extensively Somewhat Little

Not

At All

$\left[\begin{array}{llll}] & {[}\end{array}\right]$

[ ]

]

$\left[\begin{array}{llll}] & {[}\end{array}\right]\left[\begin{array}{l}1 \\ {[}\end{array}\right.$

$\left[\begin{array}{llll}] & {[}\end{array}\right]\left[\begin{array}{l}1 \\ {[}\end{array}\right.$

\section{Student Learning Outcomes}

Please review the following statements and indicate your response by checking the appropriate box.

These essential skills are identified as student learning outcomes in the accounting program's assessment plan:

Critical Thinking:

19. The ability to critically analyze, synthesize, and evaluate information as a guide to action.

Information Literacy:

20. The ability to identify, find, understand, evaluate and use information appropriately.

\section{Oral Communication:}

21. The ability to organize ideas and communicate messages appropriate to listeners and situations.

Problem Solving:

22. The ability to recognize, define, and analyze problems and to identify key causes and solutions.

Written Communication:

23. The ability to communicate thoughts and ideas in writing, completely and accurately, in the appropriate format, using proper grammar, spelling, and punctuation.

$\begin{array}{lllc} & & \text { Very } & \text { Not } \\ \text { Extensively } & \text { Somewhat } & \text { Little } & \text { At All }\end{array}$

$\left[\begin{array}{llll}] & {[}\end{array}\right]$

$\left[\begin{array}{llll}] & {[}\end{array}\right]$

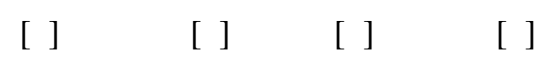


24. For each accounting course offered in your program, please indicate the extent to which these essential skills are addressed. Please circle I if the skill is introduced into the course, circle $E$ if the skill is emphasized in the course, and circle NA if the skill is not addressed in the course.

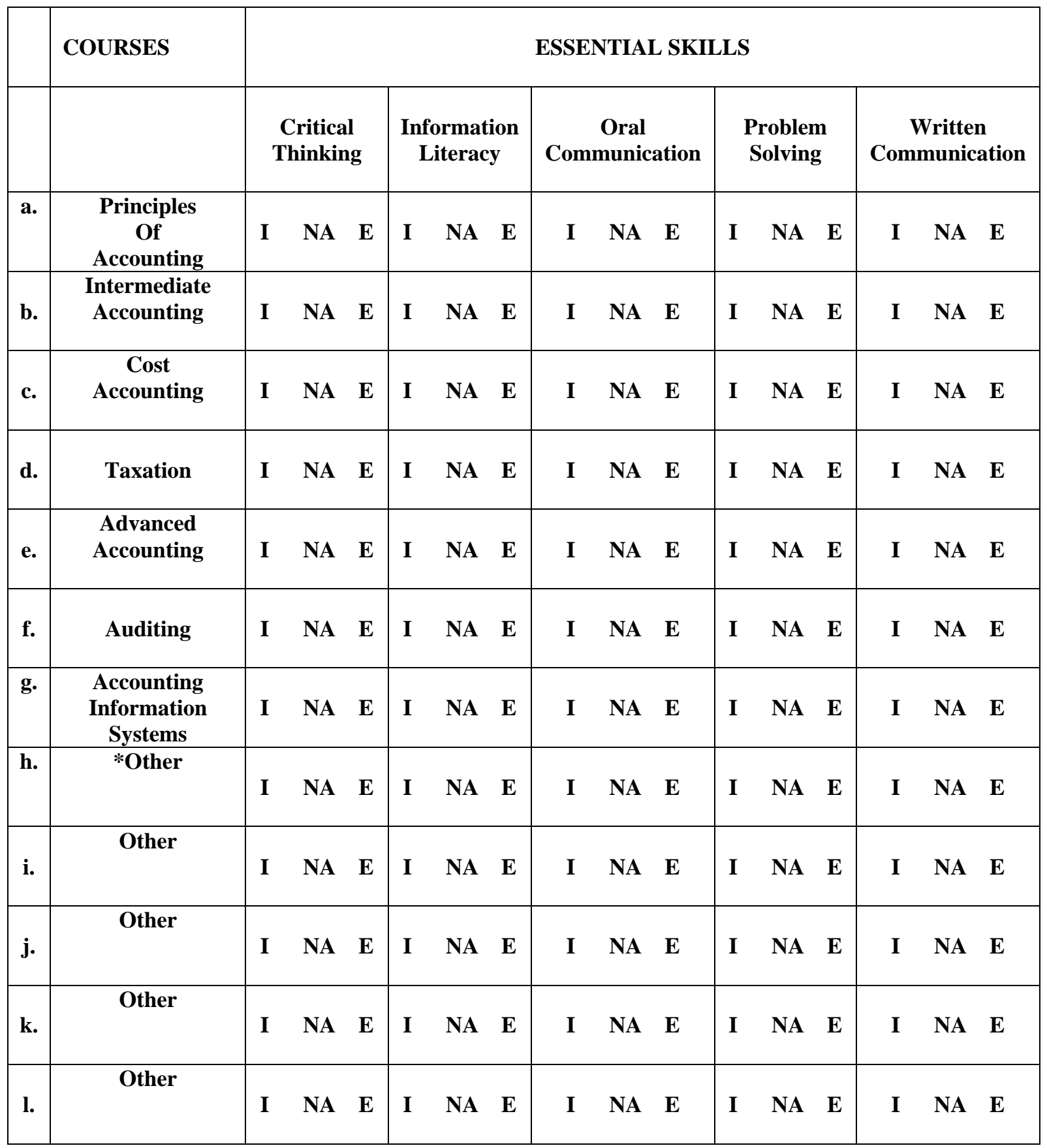

*Other courses include accounting electives or specialty courses. Please identify course titles. 
Please indicate each year students are engaged in assessment activities.

25. Assessment activities are conducted at these points in the students' program of study:
[ ] Freshman year.
[ ] Sophomore year.
[ ] Junior year.
[ ] Senior year.
[ ] Post-graduate.

Please indicate the methods used to assess student learning.

$$
\begin{array}{lll} 
& \text { Very } & \text { Not } \\
\text { Extensively Somewhat } & \text { Little } & \text { At All }
\end{array}
$$

\section{Direct Methods}

26. Student Portfolios

27. Course-Embedded Assignments

28. Capstone Projects

29. Juried Reviews Of Student Projects Or Performances

30. Internships

31. Case Study

32. Essays

33. Locally Designed Tests

34. Standardized Or National Licensure Tests

35. Other

(Please describe)

\begin{tabular}{|c|c|c|}
\hline [ ] & [ ] & [ ] \\
\hline [ ] & [ ] & [ ] \\
\hline [ ] & [ ] & [ ] \\
\hline [ ] & [ ] & [ ] \\
\hline [ ] & [ ] & [ ] \\
\hline [ & [ ] & [ ] \\
\hline [ ] & [ ] & [ ] \\
\hline [ ] & [ ] & [ ] \\
\hline [ ] & [ ] & [ ] \\
\hline [ ] & [ ] & [ ] \\
\hline
\end{tabular}

Indirect Methods

36. Alumni Surveys

37. Student Surveys

38. Employer Surveys

39. Focus Groups

40. Graduate Follow-Up Studies

41. Retention And Transfer Studies

42. Exit Interviews

43. Reflective Papers

44. Other

(Please describe)

$\begin{array}{cccc} & & \text { Very } & \text { Not } \\ \text { Extensively } & \text { Somewhat } & \text { Little } & \text { At All } \\ {[\text { ] }} & {[\text { ] }} & {[\text { [ ] }} & {[\text { [ ] }} \\ {[\text { ] }} & {[]} & {[]} & {[]} \\ {[\text { ] }} & {[]} & {[]} & {[]} \\ {[]} & {[]} & {[]} & {[]} \\ {[]} & {[]} & {[]} & {[]} \\ {[\text { ] } ~} & {[]} & {[]} & {[]} \\ {[]} & {[]} & {[]} & {[]} \\ {[]} & {[]} & {[]} & {[]} \\ {[]} & {[]} & {[]} & {[]}\end{array}$

Assessment Results

Please indicate how assessment results are used.

Assessment results are used for:

45. Institutional planning and decision-making.

46. Resource allocation.

47. Curricular changes.

48. Program review.

49. Student Recruitment.

50. Improving student learning.

51. Evaluation of the assessment process.

52. Other

\begin{tabular}{lllc}
\multirow{2}{*}{ Extensively } & Somewhat & Very & Not \\
& Little & At All
\end{tabular}

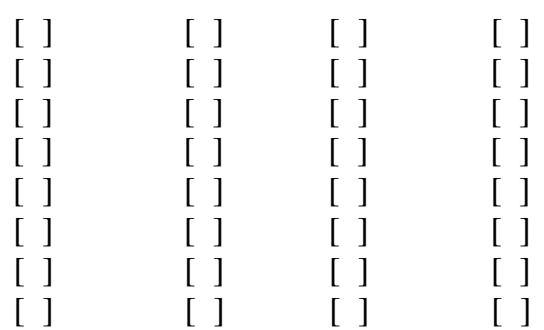


Assessment Related Changes and Improvements

Please check the areas in which changes have occurred due to assessment.

Assessment data has led to improvements in these areas:

53. Institutional planning and decision-making.

54. Resource allocation.

55. Curricular changes.

56. Program review.

57. Student recruitment.

58. Student learning.

59. The assessment process.

60. Faculty teaching techniques.

61. Other

(Please describe)

$\begin{array}{cccc} & & \text { Very } & \text { Not } \\ \text { Extensively } & \text { Somewhat } & \text { Little } & \text { At All } \\ {[\text { ] }} & {[\text { [ ] }} & {[\text { ] }} & {[]} \\ {[]} & {[]} & {[]} & {[]} \\ {[]} & {[]} & {[]} & {[]} \\ {[]} & {[]} & {[]} & {[]} \\ {[]} & {[]} & {[]} & {[]} \\ {[]} & {[]} & {[]} & {[]} \\ {[]} & {[]} & {[]} & {[]} \\ {[]} & {[]} & {[]} & {[]} \\ {[]} & {[]} & {[]} & {[]}\end{array}$

Assessment Audiences

Please indicate the groups or individuals that receive assessment reports.

Assessment data is reported to:

\begin{tabular}{|c|c|c|c|}
\hline & & Very & Not \\
\hline Extensively & Somewhat & Little & At All \\
\hline [ ] & [ ] & [ ] & [ ] \\
\hline [ ] & [ ] & [ ] & [ ] \\
\hline [ ] & [ ] & [ ] & [ ] \\
\hline [ ] & [ ] & [ ] & [ ] \\
\hline [ ] & [ ] & [ ] & [ ] \\
\hline [ ] & [ ] & [ ] & [ ] \\
\hline [ ] & [ ] & [ ] & [ ] \\
\hline [ ] ] & [ ] ] & [ ] & [ ] ] \\
\hline [ ] & [ ] & [ ] & [ ] \\
\hline [ ] & [ ] & [ ] & [ ] \\
\hline
\end{tabular}

Methods of Dissemination of Assessment Results

Please indicate the methods used to disseminate assessment results.

The institution disseminates assessment data via:

62. Students.

63. Parents.

64. Faculty.

65. Administrators.

66. Governance Board.

67. Accrediting Organizations.

68. General Public.

69. Alumni Organizations.

70. Business Leaders.

(Please describe)

71. Other

(Please describe)

72. School newspaper.

73. Accrediting organization reports.

74. Governance board reports.

75. Marketing campaigns.

76. Institution's website postings.

77. Institution's catalog and brochures.

78. Conference presentations and workshops.

79. Other

(Please describe)

\begin{tabular}{|c|c|c|c|}
\hline Extensively & Somewhat & $\begin{array}{l}\text { Very } \\
\text { Little }\end{array}$ & $\begin{array}{l}\text { Not } \\
\text { At All }\end{array}$ \\
\hline [ ] & [ ] & [ ] & [ ] \\
\hline [ ] & [ ] & [ ] & [ ] \\
\hline [ ] & [ ] & [ ] & [ ] \\
\hline [ ] & [ ] & [ ] & [ ] \\
\hline [ ] & [ ] & [ ] & [ ] \\
\hline [ ] & [ ] & [ ] & [ ] \\
\hline [ ] & [ ] & [ ] & [ ] \\
\hline [ ] & [ ] & [ ] & [ ] \\
\hline
\end{tabular}


A copy of the survey results will be made available to participants upon request. If you would like a copy, indicate whether you prefer to receive it as:

an E-mail attachment or by U. S. Postal Service mail

Please return the completed survey by ___ (date)____ in the enclosed stamped envelope.

If you have any questions or comments, you can contact me by Phone: 304.234.7162

Email: alusher1211@yahoo.com or write to:

Anna L. Lusher 268 GC\&P Road

Wheeling, WV 26003

This survey is confidential. You name and institution will not be revealed. Your participation is greatly appreciated.

Thank You, 
Identifying Assessment Practices 198

Appendix D2

Survey Instrument

(Revised) 
Undergraduate Accounting Program Assessment Questionnaire

This survey seeks information about the content and structure of your undergraduate accounting program's assessment process, the student skills assessed, the assessment methods used, and how results are used to make changes in the program and improve student learning. Please review the following statements and record the appropriate response as indicated.

\section{Undergraduate Accounting Program Information}

Please indicate the appropriate response for each statement.

1. For the individual completing this survey, please indicate your formal title:

2. Please indicate your formal faculty rank (Assistant, Associate, or Full Professor):

3. Total number of hours required for the entire undergraduate accounting degree:

4. Number of accounting hours required:

5. Number of students currently enrolled in program:

6. Number of Accounting program graduates $2004-2005$ :

7. Number of Accounting Faculty: Full-time Part-time

8. The Baccalaureate Accounting Program is accredited is not accredited

9. Accrediting Organization

\section{Assessment Process}

Please select the statement that best describes the level of development of the assessment plan for your program.

10. The baccalaureate accounting program faculty

[ ] has not created an assessment plan.

[ ] will develop an assessment plan in the near future.

[ ] is developing an assessment plan.

[ ] has developed an assessment plan.

[ ] has implemented an assessment plan.

Please return this questionnaire if you do or you do not have an assessment plan.

11. The assessment process at this institution is

[ ] episodic; assessment occurs during program review, for accreditation purposes, or as needed.

[ ] periodic; assessment occurs periodically, but it is not an integral part of the accounting program.

[ ] on-going; assessment is a routine activity in the program.

Please review the following statements and indicate your response by checking the appropriate box.

12. The accounting program has a clear explicitly stated purpose that guides assessment in the program.

Extensively Often Somewhat Little At All

. Assessment data are collected and analyzed.

14. Assessment focuses on improving student learning.

15. Assessment focuses on accountability.

16. Student learning outcomes reflect the accounting program's goals and objectives for learning.

17. Student learning outcomes reflect the institution's mission and its values. 
Please review the following statements and indicate your response by checking the appropriate box.

These essential skills are addressed in the accounting program:

\section{Critical Thinking:}

18. The ability to critically analyze, synthesize, and evaluate information as a guide to action.

\section{Information Literacy:}

19. The ability to identify, find, understand, evaluate and use information appropriately.

\section{Oral Communication:}

20. The ability to organize ideas and communicate messages appropriate to listeners and situations.

\section{Problem Solving:}

The ability to recognize, define, and analyze problems and to identify key causes and solutions.

\section{Written Communication:}

22. The ability to communicate thoughts and ideas in writing, completely and accurately, in the appropriate format, using proper grammar, spelling, and punctuation. $\begin{array}{lll} & \text { Very Not } \\ \text { Extensively Often Somewhat } & \text { Little At All }\end{array}$ $\left[\begin{array}{llll}1 & {[}\end{array}\right]$

[ ] $\quad\left[\begin{array}{llll} & {[} & {[} & {[}\end{array}\right]$

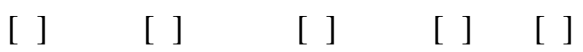

\section{Student Learning Outcomes}

Please review the following statements and indicate your response by checking the appropriate box.

These essential skills are identified as student learning outcomes in the accounting program's assessment plan:

\section{Critical Thinking:}

23. The ability to critically analyze, synthesize, and evaluate information as a guide to action.

\section{Information Literacy:}

24. The ability to identify, find, understand, evaluate and use information appropriately.

\section{Oral Communication:}

25. The ability to organize ideas and communicate messages appropriate to listeners and situations.

\section{Problem Solving:}

26. The ability to recognize, define, and analyze problems and to identify key causes and solutions.

\section{Written Communication:}

27. The ability to communicate thoughts and ideas in writing, completely and accurately, in the appropriate format, using proper grammar, spelling, and punctuation.
Very Not

Extensively Often Somewhat Little At All

\begin{tabular}{|c|}
\hline [ ] \\
\hline
\end{tabular}


28. For each accounting course offered in your program, please indicate the extent to which these essential skills are addressed by writing in each cell in the matrix below the specific abbreviation:

I - if the skill is introduced into the course,

$\mathrm{E}$ - if the skill is emphasized in the course, or

NA - if the skill is not addressed in the course.

\begin{tabular}{|c|c|c|c|c|c|c|}
\hline & \multicolumn{5}{|c|}{ COURSES } & \multicolumn{3}{|c|}{ ESSENTIAL SKILLS } \\
\hline & $\begin{array}{c}\text { Critical } \\
\text { Thinking }\end{array}$ & $\begin{array}{c}\text { Information } \\
\text { Literacy }\end{array}$ & $\begin{array}{c}\text { Oral } \\
\text { Communication }\end{array}$ & $\begin{array}{c}\text { Problem } \\
\text { Solving }\end{array}$ & $\begin{array}{c}\text { Written } \\
\text { Communication }\end{array}$ \\
\hline a. & $\begin{array}{c}\text { Principles Of } \\
\text { Financial } \\
\text { Accounting (I) }\end{array}$ & & & & & \\
\hline b. & $\begin{array}{c}\text { Principles of } \\
\text { Managerial } \\
\text { Accounting (II) }\end{array}$ & & & & & \\
\hline c. & $\begin{array}{c}\text { Intermediate } \\
\text { Accounting }\end{array}$ & & & & \\
\hline d. & $\begin{array}{c}\text { Cost } \\
\text { Accounting }\end{array}$ & & & & & \\
\hline e. & Taxation & & & & & \\
\hline f. & $\begin{array}{c}\text { Advanced } \\
\text { Accounting }\end{array}$ & & & & & \\
\hline g. & Auditing & & & & & \\
\hline h. & $\begin{array}{c}\text { Accounting } \\
\text { Information } \\
\text { Systems }\end{array}$ & & & & & \\
\hline i. & $*$ Other & & & & & \\
\hline j. & Other & & & & & \\
\hline k. & Other & & & & & \\
\hline & Other & & & & \\
\hline
\end{tabular}

*Other courses include accounting electives or specialty courses. Please identify course titles. 
Please indicate each year students are engaged in assessment activities.

29. Assessment activities are conducted at these points in the students' program of study:
[ ] Freshman year.
[ ] Sophomore year.
[ ] Junior year.
[ ] Senior year.
[ ] Post-graduate.

Please indicate the methods used to assess student learning.

\section{Direct Methods}

30. Student Portfolios

31. Capstone Projects

32. Juried Reviews Of Student Projects Or Performances

33. Internships

34. Case Study

35. Essays

36. Locally Designed Tests

37. Standardized Or National Licensure Tests

38. Other

(Please describe)

Indirect Methods

39. Alumni Surveys

40. Student Surveys

41. Employer Surveys

42. Focus Groups

43. Graduate Follow-Up Studies

44. Retention And Transfer Studies

45. Exit Interviews

46. Reflective Papers

47. Other (Please describe)
Very Not Extensively Often Somewhat Little At All

$\begin{array}{ll}{[]} & {[]} \\ {[]} & {[]} \\ {[]} & {[]} \\ {[]} & {[]} \\ {[]} & {[]} \\ {[]} & {[]} \\ {[]} & {[]} \\ {[]} & {[]} \\ {[]} & {[]}\end{array}$

Extensively Often Somewhat Little At All

$\begin{array}{lllll}{[]} & {[]} & {[]} & {[]} & {[]} \\ {[]} & {[]} & {[]} & {[]} & {[]} \\ {[]} & {[]} & {[]} & {[]} & {[]} \\ {[]} & {[]} & {[]} & {[]} & {[]} \\ {[]} & {[]} & {[]} & {[]} & {[]} \\ {[]} & {[]} & {[]} & {[]} & {[]} \\ {[]} & {[]} & {[]} & {[]} & {[]} \\ {[]} & {[]} & {[]} & {[]} & {[]} \\ {[]} & {[]} & {[]} & {[]} & {[]}\end{array}$

Assessment Results

Please indicate how assessment results are used.

Assessment results are used for:

48. Institutional planning and decision-making.

49. Resource allocation.

50. Curricular changes.

51. Program review.

52. Student Recruitment.

53. Improving student learning.

54. Evaluation of the assessment process.

55. Other (Please describe)
Very Not

Extensively Often Somewhat Little At All

$\begin{array}{lllll}{[]} & {[]} & {[]} & {[]} & {[]} \\ {[]} & {[]} & {[]} & {[]} & {[]} \\ {[]} & {[]} & {[]} & {[]} & {[]} \\ {[]} & {[]} & {[]} & {[]} & {[]} \\ {[]} & {[]} & {[]} & {[]} & {[]} \\ {[]} & {[]} & {[]} & {[]} & {[]} \\ {[]} & {[]} & {[]} & {[]} & {[]} \\ {[]} & {[]} & {[]} & {[]} & {[]}\end{array}$


Assessment Related Changes and Improvements

Please check the areas in which changes have occurred due to assessment.

Assessment data has led to improvements in these areas:

56. Institutional planning and decision-making.

57. Resource allocation.

58. Curricular changes.

59. Program review.

60. Student recruitment.

61. Student learning.

62. The assessment process.

63. Faculty teaching techniques.

64. Other (Please describe)

Very Not

Extensively Often Somewhat Little At All

$\begin{array}{lllll}{[]} & {[]} & {[]} & {[]} & {[]} \\ {[]} & {[]} & {[]} & {[]} & {[]} \\ {[]} & {[]} & {[]} & {[]} & {[]} \\ {[]} & {[]} & {[]} & {[]} & {[]} \\ {[]} & {[]} & {[]} & {[]} & {[]} \\ {[]} & {[]} & {[]} & {[]} & {[]} \\ {[]} & {[]} & {[]} & {[]} & {[]} \\ {[]} & {[]} & {[]} & {[]} & {[]} \\ {[]} & {[]} & {[]} & {[]} & {[]}\end{array}$

Assessment Audiences

Please indicate the groups or individuals that receive assessment reports.

Assessment data is reported to:

Extensively Often Somewhat Little At All

65. Students.

66. Parents.

67. Faculty.

68. Administrators.

69. Governance Board.

70. Accrediting Organizations.

71. General Public.

72. Alumni Organizations.

73. Business Leaders.

74. Other

(Please describe)

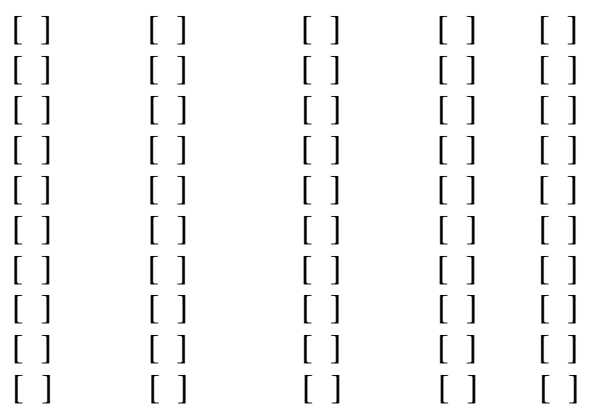

Methods of Dissemination of Assessment Results

Please indicate the methods used to disseminate assessment results.

The institution disseminates assessment data via:

75. School newspapers.

76. Accrediting organization reports.

77. Governance board reports.

78. Marketing campaigns.

79. Institution's website postings.

80. Institution's catalog and brochures.

81. Conference presentations and workshops.

82. Other

(Please describe)

\begin{tabular}{|c|c|c|c|c|}
\hline & & & Very & Not \\
\hline Extensively & Often & Somewhat & Little & At All \\
\hline [ ] & [ ] & [ ] & [ ] & [ ] \\
\hline [ ] & [ ] & [ ] & [ ] & [ ] \\
\hline [ ] & [ ] & [ ] & [ ] & [ ] \\
\hline [ ] & [ ] & [ ] & [ ] & [ ] \\
\hline [ ] & [ ] & [ ] & [ ] & [ ] \\
\hline [ ] & [ ] & [ ] & [ ] & [ ] \\
\hline [ ] & [ ] & [ ] & [ ] & [ ] \\
\hline [ ] & [ ] & [ ] & [ ] & [ ] \\
\hline [ ] & [ ] & [ ] & [ ] & [ ] \\
\hline
\end{tabular}


A copy of the survey results will be made available to participants upon request. Because this is an anonymous survey, you must enter your name and address to receive a copy of the study. If you would like a copy, indicate whether you prefer to receive it as:

an E-mail attachment address:

or by U. S. Postal Service mail address:

Please return the completed survey by October 14, 2005 in the enclosed stamped envelope. If you have any questions or comments, you can contact me:

Anna L. Lusher

Phone: 304.234.7162

Email: alusher1211@yahoo.com or write to me at:

268 GC\&P Road

Wheeling, WV 26003

Again, this survey is confidential. Your name and institution will not be revealed. Your participation is greatly appreciated.

Thank You! 
Identifying Assessment Practices 205

Appendix E

Survey Cover Letter:

Pilot Study 


\title{
Survey Cover Letter: Pilot Study
}

\author{
Current date \\ Department /Dean/Chair/Director \\ Any College \\ Anywhere, USA
}

\section{Dear Department /Dean/Chair/Director:}

I am a doctoral student at West Virginia University in the College of Human Resources and Education conducting my dissertation study of undergraduate accounting education. This research is a partial fulfillment of the requirements for the dissertation. The purpose of the study is to examine baccalaureate accounting programs to determine the content and structure of their assessment plans. This study also evaluates how faculty assess students' skills and how they use the results to make changes in their programs and improve student learning.

The intent of the enclosed questionnaire is to identify baccalaureate accounting programs that integrate essential workplace skills into the curriculum and identify those skills as student learning outcomes in the assessment process. This survey focuses on five essential skills: critical thinking, information literacy, oral communication, problem solving, and written communication. In addition, the enclosed questionnaire inquires about your accounting program's assessment process and any improvements in student learning or changes in your accounting program due to assessment.

I am asking you to participate in this pilot study. The purpose of this pilot study is to pretest the enclosed questionnaire for clarity, readability, and relevancy. As you complete the survey, please keep track of the number of minutes it takes you to complete the entire instrument. Your feedback will be beneficial in designing the final version for the actual study. I would appreciate the opportunity to discuss the questionnaire and your responses on the Pilot Study Evaluation form by telephone. I will contact you within two weeks to make an appointment for the discussion. Comments and suggestions that you feel will strengthen the cover letter or the questionnaire are welcome. Please return the survey and evaluation form in the enclosed stamped envelope by ___date)_. Thank you in advance for participating in this pilot study.

It is important to stress that your participation in the study is voluntary and your responses will be kept confidential. You do not have to answer every question. Names and other information that may identify participants will not be released. Your job status will not be affected by refusal to participate or by withdrawal from the study. 
This study can establish a database for accounting educators involved in accounting program assessment. It will provide useful information about the development and implementation of assessment plans and will offer ideas for analyzing and reporting assessment data. Educators already engaged in assessment of accounting programs will find the study useful when enhancing or modifying current assessment plans based on the practices identified in this study. If you have any questions, feel free to contact me.

Sincerely,

Anna L. Lusher, CPA

Doctoral Student

West Virginia University

alusher1211@yahoo.com

304.234.7162 
Identifying Assessment Practices 208

Appendix F1

Pilot Study Survey

Evaluation Form 


\section{Survey Pilot Study Evaluation}

Thanks again for your participation in this pilot study. Your comments and suggestions are greatly appreciated and will be considered in the revision of the questionnaire for the actual study.

\section{Cover Letter}

1. Is the intent and content of the survey clearly stated? Yes _ No

2. Does the letter adequately describe the purpose of the study? Yes _ No

3. Is the letter easy to understand? Yes No

4. Are the instructions for completing and returning the survey and evaluation form clear? Yes

5. Does the letter convey the benefits of this study to accounting educators?

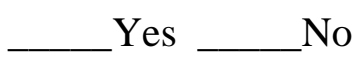

6. Does the letter encourage you to participate in the study?

Yes No

Questionnaire

1. Is the format of the questionnaire easy to follow?

Yes No

2. Are the questions easy to read and answer?

Yes _ No

3. Is there any question you did not understand?

Yes No

4. How long did it take to complete the questionnaire? Minutes

5. Are there any questions that you believe should be added? Yes No

6. Please feel free to make any comments or suggestions for improvement. 
Appendix F2

Pilot Study Survey

Evaluation Form

(Revised) 


\section{Survey Pilot Study Evaluation}

Thanks again for your participation in this pilot study. Your comments and suggestions are greatly appreciated and will be considered in the revision of the questionnaire for the formal study.

\section{Cover Letter}

1. Is the intent and content of the survey clearly stated?

Yes No

2. Does the letter adequately describe the purpose of the study? Yes __ No

3. Is the letter easy to understand?

Yes No

4. Are the instructions for completing and returning the survey and evaluation form clear?

Yes No

5. Does the letter convey the benefits of this study to accounting educators?

Yes No

6. Does the letter encourage you to participate in the study? Yes _ No

\section{Questionnaire}

1. Is the format of the questionnaire easy to follow?

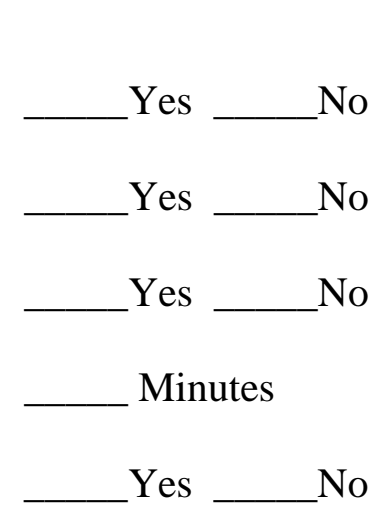

5. Are there any questions that you believe should be added?

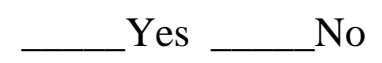

2. Are the questions easy to read and answer?

3. Is there any question you did not understand?

4. How long did it take to complete the questionnaire?

6. For the convenience of participants, please indicate the most suitable time and month during the fall semester for mailing the formal study by entering an $\mathrm{E}$ (early), $\mathrm{M}$ (mid), or L (late) in the space preceding the month listed below.
August
September
October
November
December

Please feel free to make any comments or suggestions for improvement. 
Identifying Assessment Practices 212

Appendix G

Survey Cover Letter:

Participant 


\section{Survey Cover Letter: Participant}

\section{Current date}

Participant's Address

Dear Participant:

I am a doctoral student at West Virginia University in the College of Human Resources and Education conducting my dissertation study of undergraduate accounting education. This research is a partial fulfillment of the requirements for the dissertation. The purpose of the study is to examine baccalaureate accounting programs to determine the content and structure of their assessment plans. This study also evaluates how faculty assess students' skills and how they use the results to make changes in their programs and improve student learning.

The intent of the enclosed questionnaire is to identify baccalaureate accounting programs that integrate essential workplace skills into the curriculum and identify those skills as student learning outcomes in the assessment process. This survey focuses on five essential skills: critical thinking, information literacy, oral communication, problem solving, and written communication. In addition, the enclosed questionnaire inquires about your accounting program's assessment process and any improvements in student learning or changes in your accounting program due to assessment. The research will also indicate how long the institutions have collected assessment data, reveal whether curriculum and/or program changes have been made as a result of the assessment data, and divulge the uses of the assessment data by constituents.

I am requesting your participation in this study because of your current position at the college. Your experience and current role can provide insight concerning assessment issues. It is important to stress that your participation in the study is voluntary and your responses will be kept confidential. You do not have to answer every question. Names and other information that may identify participants will not be released. Your job status will not be affected by refusal to participate or by withdrawal from the study. 
This study can establish a database for accounting educators involved in accounting program assessment. It will provide useful information about the development and implementation of assessment plans and offers ideas for analyzing and reporting assessment data. For educators already engaged in assessment of accounting programs, the study can be useful in enhancing or modifying current assessment plans based on the practices identified in this study.

Thank you in advance for completing the survey and returning it in the postage paid envelope by ___ _ (date) ___. If you have any questions, feel free to contact me.

Sincerely,

Anna L. Lusher, CPA

Doctoral Student

West Virginia University alusher1211@yahoo.com 304.234.7162 
Identifying Assessment Practices 215

Appendix H

Institutional Review Board:

Approval Letter 


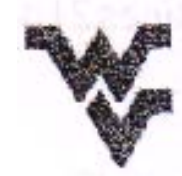

\section{West Virginia University}

College of Human Resources and Education

September 2, 2005

MEMORANDUM
TO:
Anna Lusher

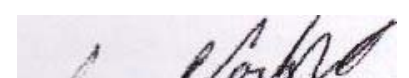
FROM: Lynn Cartwright
Interim Associate Dean
RE: $\quad$ Human Resources \& Education H.S. \#2005-068

\section{Title: "Identifying Assessment Practices in Undergraduate Accounting Education"}

Your Application for Exemption for the above-captioned research project has been reviewed under the Human Subjects Policies and has been approved Attached is the original of your cover letter with the signed stamp of approval. This must accompany your survey or questionnaire.

This exemption will remain in effect on the condition that the research is carried out exactly as described in the application.

Best wishes for the success of your research.

\section{cc: Deans Office \\ Student Advising and Records \\ Elizabeth Jones, Advisor}


Identifying Assessment Practices 217

Appendix I

WVU HIPPA Certification 


\section{WVU HIPPA Certification}

http://webct.hsc.wvu.edu:8900/HIPAA/Privacy_Confidentiality/HIPAA_registration.h tm

Your training information has been added to the Research Compliance Database. No certificates are offered for this course.

You may also be required to complete Human Participant Protections

Training; see notice at http://www.wvu.edu/ rc/irb/notc_hpp.htm

alusher@mix.wvu.edu 06/04/03 07:45PM

First_Name: Anna

Preferred_name:

Middle_Name: L

Last_Name: Lusher

WebCT_ID: alusher

Job_Title: Doctoral Student

Position_not_listed:

Primary_Department: Advanced Educational Studies

Department_not_listed:

Institution: College of Human Resources and Education

Institution_not_listed:

Regional_Location: Morgantown

Submitted: June 4, 2003

Comments:

Submitted: 6/4/2003 at 7:45:51 PM

HTTP_REFERER:

http://webct.hsc.wvu.edu:8900/HIPAA/Privacy_Confidentiality/HIPAA_registration.h tm

HTTP_USER_AGENT: Mozilla/4.0 (compatible; MSIE 5.5; MSN 2.5; Windows 98; AT\&T ELC5.5; AT\&T ELC5.5 IE5.0.01)

REMOTE_ADDR: 65.238.53.134 